Wayne E. Ferson Boston College NBER

Meijun Qian Boston College

\title{
Conditional Performance Evaluation, Revisited
}

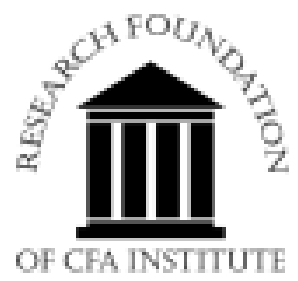




\section{Research Foundation Publications}

Anomalies and Efficient Portfolio Formation by S.P. Kothari and Jay Shanken

Benchmarks and Investment Management by Laurence B. Siegel

The Closed-End Fund Discount

by Elroy Dimson and Carolina Minio-Paluello

Common Determinants of Liquidity and Trading by Tarun Chordia, Richard Roll, and Avanidhar Subrahmanyam

Company Performance and Measures of Value Added

by Pamela P. Peterson, CFA, and

David R. Peterson

Controlling Misfit Risk in Multiple-Manager

Investment Programs

by Jeffery V. Bailey, CFA, and David E. Tierney

Country Risk in Global Financial Management

by Claude B. Erb, CFA, Campbell R. Harvey, and

Tadas E. Viskanta

Country, Sector, and Company Factors in

Global Equity Portfolios

by Peter J.B. Hopkins and C. Hayes Miller, CFA

Currency Management: Concepts and Practices

by Roger G. Clarke and Mark P. Kritzman, CFA

Earnings: Measurement, Disclosure, and the

Impact on Equity Valuation

by D. Eric Hirst and Patrick E. Hopkins

Earnings Quality

by Patricia M. Dechow and Catherine M. Schrand

Economic Foundations of Capital Market Returns by Brian D. Singer, CFA, and

Kevin Terhaar, CFA

Emerging Stock Markets: Risk, Return, and

Performance

by Christopher B. Barry, John W. Peavy III,

CFA, and Mauricio Rodriguez

Employee Stock Options and Equity Valuation by Mark Lang

The Franchise Value Approach to the Leveraged Company

by Martin L. Leibowitz

Interest Rate and Currency Swaps: A Tutorial by Keith C. Brown, CFA, and Donald J. Smith
Interest Rate Modeling and the Risk Premiums in Interest Rate Swaps

by Robert Brooks, CFA

The International Equity Commitment

by Stephen A. Gorman, CFA

International Financial Contagion: Theory and Evidence in Evolution

by Roberto Rigobon

Investing in Emerging Markets

by Robert F. Bruner, Robert M. Conroy, CFA, Wei Li, Elizabeth F. O'Halloran, and Miguel Palacios Lleras

Investment Styles, Market Anomalies, and Global Stock Selection

by Richard O. Michaud

Long-Range Forecasting

by William S. Gray, CFA

Option-Implied Risk-Neutral Distributions and Risk Aversion

by Jens Carsten Jackwerth

Real Options and Investment Valuation

by Don M. Chance, CFA, and

Pamela P. Peterson, CFA

Risk Management, Derivatives, and Financial Analysis under SFAS No. 133

by Gary L. Gastineau, Donald J. Smith, and Rebecca Todd, CFA

The Role of Monetary Policy in Investment Management

by Gerald R. Jensen, Robert R. Johnson, CFA, and Jeffrey M. Mercer

Sales-Driven Franchise Value

by Martin L. Leibowitz

The Stochastic Programming Approach to Asset, Liability, and Wealth Management

by William T. Ziemba

Term-Structure Models Using Binomial Trees

by Gerald W. Buetow, Jr., CFA, and James Sochacki

The Welfare Effects of Soft Dollar Brokerage:

Law and Ecomonics

by Stephen M. Horan, CFA, and

D. Bruce Johnsen 


\section{Conditional Performance Evaluation, Revisited}


The Research Foundation of CFA Institute and the Research Foundation logo are trademarks owned by The Research Foundation of CFA Institute. CFA ${ }^{\circledR}$, Chartered Financial Analyst ${ }^{\circledR}$, AIMR-PPS ${ }^{\circledR}$, and GIPS ${ }^{\circledR}$ are just a few of the trademarks owned by CFA Institute. To view a list of CFA Institute trademarks and a Guide for the Use of CFA Institute Marks, please visit our website at www.cfainstitute.org.

(C) 2004 The Research Foundation of CFA Institute

All rights reserved. No part of this publication may be reproduced, stored in a retrieval system, or transmitted, in any form or by any means, electronic, mechanical, photocopying, recording, or otherwise, without the prior written permission of the copyright holder.

This publication is designed to provide accurate and authoritative information in regard to the subject matter covered. It is sold with the understanding that the publisher is not engaged in rendering legal, accounting, or other professional service. If legal advice or other expert assistance is required, the services of a competent professional should be sought.

ISBN 0-943205-70-0

Printed in the United States of America

September 29, 2004

\title{
Editorial Staff \\ Maryann Dupes \\ Book Editor
}

\author{
Christine E. Kemper Kara H. Morris \\ Assistant Editor Production Manager \\ Lois A. Carrier/Jesse Kochis \\ Composition and Production
}




\section{Statement of Purpose}

The Research Foundation of CFA

Institute is a not-for-profit organization established to promote the development and dissemination of relevant research for investment practitioners worldwide. 


\section{Biographies}

Wayne E. Ferson is Collins Chair in Finance at the Carroll School of Management at Boston College and is a research associate of the National Bureau of Economic Research (NBER). He has served as president of the Western Finance Association, as an editor for the Review of Financial Studies and the Journal of Empirical Finance, and as a consultant to the Frank Russell Company on investment performance measurement. Professor Ferson holds a $\mathrm{PhD}$ in finance from Stanford University.

Meijun Qian is a PhD candidate in finance at the Carroll School of Management at Boston College. 


\section{Contents}

Foreword $\ldots \ldots \ldots \ldots \ldots \ldots \ldots \ldots \ldots \ldots \ldots$, viii

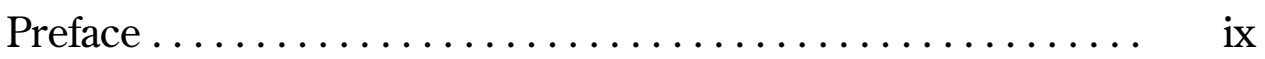

Conditional Performance Evaluation, Revisited .......... 1

Appendix A. Additional Tables .................... $\quad 70$

References ................................ 79 


\section{Foreword}

One of the most difficult challenges for investors is to assess whether a fund's performance arises from a manager's skill or is simply the product of chance. Track records by themselves are typically too short to distinguish skill from chance. Moreover, what shows up as alpha may instead be an artifact of a misspecified benchmark. The consequences of poor performance evaluation are significant. Investment managers are needlessly fired, and perhaps more often, unjustifiably hired. And the transaction costs associated with this turnover substantially and unnecessarily dilute investor savings.

Another, more subtle, cost of unnecessary turnover exists. If managers operate at different levels of risk, then in the absence of reliable information, switching managers into and out of a portfolio is riskier than maintaining a constant exposure to them. We are thus quite fortunate that Wayne Ferson and Meijun Qian have revisited the critically important topic of conditional performance evaluation.

Unlike the conventional approach to performance evaluation, which assumes that investment styles and economic states remain constant, this methodology compares a fund's returns with the returns of a dynamic strategy that matches the fund's time-varying risk exposures. It thus controls for a variety of biases that might lead an investor to mistakenly shift between managers. And as a nod to the more cynically inclined, conditional performance evaluation prevents managers from gaming less refined performance benchmarks.

Although the methodology is quite sophisticated, Ferson and Qian present the topic in a style that is accessible to practitioners, and they provide sufficient detail to facilitate implementation of their models. Yet, they do not bend to simplicity. Even the most quantitatively advanced scholars will be satisfied with their rigor and their comprehensive review of the extant literature.

Ferson and Qian present a compelling case for conditional performance evaluation, both conceptually and empirically. Managers who are truly confident of their skill should be eager to have it rendered transparent by conditional performance evaluation. And investors should be equally eager to move from a murky system that confounds alpha with shifting economic states to one that shines a light on true skill - or the lack thereof. The Research Foundation is extremely pleased to present Conditional Performance Evaluation, Revisited.

Mark Kritzman, CFA Research Director The Research Foundation of

CFA Institute 


\section{Preface}

Conditional performance evaluation compares a fund's return with the return of a dynamic strategy that attempts to match the fund's risk exposures. The risk exposures are matched as they vary through time by mechanically trading based on easily measured, predetermined variables. A fund's risk exposures and the related market premiums are said to be "conditioned," or allowed to vary over time with the state of the economy as measured by predetermined, public information variables. The performance measures that result are the conditional alphas. Our goal in this Research Foundation monograph is to revisit and extend the central empirical findings of the literature on conditional performance evaluation for U.S. equity mutual funds.

The early conditional performance evaluation studies found that controlling for time variation associated with the state of the economy makes the average performance (and also the market-timing ability) of mutual funds look better compared with traditional performance measures (e.g., Ferson and Schadt 1996). Performance net of expenses is mildly negative under traditional models that ignore conditioning but neutral under the conditional models. Ferson and Warther (1996) attributed the difference to predictable patterns of new money flows in and out of mutual funds at the aggregate level. These studies used small samples of mutual funds, subject to survival selection and ending in 1990.

In the present study, we revisit the main empirical results of the conditional performance evaluation literature using a large, updated sample of mutual funds. We assess the robustness of the conditional performance of mutual funds to fresh data that control for survival bias, which is important because survival bias in earlier datasets may have made performance look better than it was. We expand and refine the treatment of conditioning information and expand the list of measures of the state of the economy. Expanding the list of state variables is interesting because the early studies' results were mainly driven by the relationship of returns to an overall market dividend yield and the level of short-term interest rates. Consequently, we want to find out if fund performance responds to other measures of the economic state. We also use the predetermined variables to define discrete states, which helps to avoid statistical problems associated with persistent, lagged regressors.

Our study includes a number of refinements to the conditional performance evaluation methodology. We analyze the performance of funds relative to the funds' characteristics to determine the extent to which the conditional performance of mutual funds can be explained by such factors as fund size, turnover, 
fee structure, and new money flows. For example, we will answer questions like: Do low-expense-ratio funds have better conditional timing measures than high-expense-ratio funds? (We find that they do.) We also examine the relative performance of funds using cross-sectional regressions, which allows us to isolate the effects of fund style on performance. In addition to a standard market benchmark, we measure conditional performance relative to style-specific benchmarks using an approach similar to that of Sharpe (1992).

We confirm that conditional alphas tend to make funds look better than traditional performance measures in a broader sample of funds that uses fresh data constructed to control survivor-selection bias. Conditional performance, measured at the fund-style-group level, is essentially neutral. On a subsample of balanced and tactical asset allocation funds, we find that conditional timing ability is more likely to be found among the funds with the largest total net assets, the longest track records, and the lowest expense ratios.

Our list of lagged instruments is more inclusive than that of previous studies, thus establishing the robustness of these results to the choice of lagged instruments. The conditional performance analysis reveals patterns in expected performance across fund styles and states of the economy that traditional measures would miss. With our expanded list of instruments, we explore the question of which economic variables are the most informative to condition on. We find that in a list of 11 proxies for the state of the economy, the states of the term structure and interest rates are the most informative about overall fund performance relative to a broad market index. At the level of fund-style groups, we find the strongest evidence for time-varying market betas among the income funds. The variables representing the states of the macroeconomy are found to be informative about shifts in the risk exposure and performance of fund groups, relative to static style-specific benchmarks.

We begin this monograph by reviewing conditional performance evaluation and placing our study in context. We next discuss how we condition on the state of the economy and then introduce the empirical methods and describe the data. We continue by presenting empirical results on the performance of broad fund groups and then summarizing the cross-sectional distribution of individual fund performance. We further study relative performance in relation to fund characteristics as well as market timing. Finally, we review the implications of our findings for practicing investment managers and offer a summary and conclusions.

We hope the reader finds this monograph both intellectually stimulating and useful in a practical environment, and we are grateful to the Research Foundation of CFA Institute for the research support that allowed us to investigate these challenging issues. 


\section{Conditional Performance Evaluation, Revisited}

Traditional measures of risk-adjusted performance for mutual funds compare the average return of a fund with a benchmark designed to control for the fund's average risk. For example, Jensen's (1968) alpha is the difference between the return of a fund and a portfolio constructed from a market index and cash, where the portfolio has the same average market exposure, or beta risk, as the fund. The returns and beta risks are typically measured as averages over the evaluation period, and these averages are taken unconditionally, or without regard to variations in the state of financial markets or the broader economy. One weakness of this approach relates to the likelihood of changes in the state of the economy. For example, if the evaluation period covers a bear market but the period going forward is a bull market, the unconditional performance evaluation may not have much forward-looking value.

\section{Review of Conditional Performance Evaluation}

In the conditional performance evaluation (CPE) approach, fund managers' risk exposures and the related market premiums are allowed to vary over time with the state of the economy. The state of the economy is measured using predetermined, public information variables. Provided that the analysis period covers both bull and bear markets, one can estimate expected risk and performance in each type of market. Thus, knowing that the current state of the market is a bull market, for example, one can estimate the fund's expected performance given a bull state.

The conditional performance measure, the conditional alpha, is the difference between a fund's excess return and that of a strategy that attempts to match the fund's risk dynamics over time by mechanically trading based on the predetermined variables. The idea is a natural generalization of the classical performance measures, which compare a fund's return with a benchmark that carries the same average exposure to risk. In the CPE approach, for example, the risk adjustment for a bull market state may be different from that for a bear market state if the fund's strategy implies different risk exposures in the different states. The conditional alpha can also be estimated conditional on the state, as we will explain later. 
Conditional performance evaluation is consistent with a version of semistrong market efficiency as described by Fama (1970). The idea is that if the market is efficient, a fund manager whose performance can be replicated by mechanically trading on public information is not adding value. In order to add value and generate a positive conditional alpha, a manager should offer a higher return than the mechanical-trading strategy. Although market efficiency motivates the null hypothesis of our tests-that conditional alphas are zero-one need not be a proponent of market efficiency to use CPE. By choosing the lagged variables, it is possible to set the hurdle for superior ability at any desired level of information. Our results show that the choice of lagged variables should matter in practice and provide some practical guidance on the variables to use.

In addition to the lagged state variables, CPE, like any performance evaluation, requires a choice of benchmark portfolios. Traditional measures motivated by the capital asset pricing model [CAPM (Sharpe 1964)] use a broad equity index. Current practice is more likely to use a benchmark representing the fund manager's investment style. We use both types of benchmarks in this monograph. The idea, in any event, is that the portfolio formed from the benchmark should capture an alternative to employing the manager's services. If alpha is positive, the manager adds value relative to the alternative of holding the benchmark portfolio strategy. It is important to recognize, however, the role of costs in this comparison. In most academic studies using the traditional measures and in our analysis using CPE, the benchmark strategy does not pay trading costs. Mutual fund returns, in contrast, are measured net of all expenses and trading costs. Therefore, the measure of value added should be interpreted as an increment to these costs. Roughly speaking, a manager with an alpha of zero has enough ability to cover his or her costs and fees.

Stylized Example. The theoretical appeal of CPE can be illustrated with the following highly stylized numerical example. Assume two equally likely states of the market as reflected in investors' expectations: a bull state and a bear state. In a bull market, assume that the expected return of the S\&P 500 Index is 20 percent, and in a bear market, assume it is 10 percent. 1 Take the risk-free return to cash to be 5 percent, and assume that all investors share these views-the current state of expected market returns is common knowledge. In this case, if one assumes an efficient market, an investment strategy that uses as its only information the current state will not yield abnormal returns.

1This definition, of course, differs from the conventional definition of a bear market, which some consider to be a 20 percent decline from a previous high. 
Now, imagine a mutual fund that holds the S\&P 500 in a bull market and holds cash in a bear market. Consider the performance of this fund based on $\mathrm{CPE}$ and Sharpe's CAPM. Conditional on a bull market, the beta of the fund is 1.0, the fund's expected return is 20 percent (equal to the S\&P 500), and the fund's conditional alpha is zero. ${ }^{2}$ Conditional on a bear market, the fund's beta is zero, the expected return of the fund is the risk-free return (5 percent), and the conditional alpha is, again, zero. A conditional approach to performance evaluation correctly reports an alpha of zero in each state, which is essentially the null hypothesis of a CPE analysis.

By contrast, an unconditional approach to performance evaluation would incorrectly report a nonzero alpha for the hypothetical mutual fund. Without conditioning on the state, the returns of this fund would seem to be highly sensitive to the market return, and the unconditional beta of the fund would be 1.5 .3 The unconditional expected return of the fund would be $0.5(0.20)+$ $0.5(0.05)=0.125$. The unconditional expected return of the S\&P 500 would be $0.5(0.20)+0.5(0.10)=0.15$, and the unconditional alpha of the fund, therefore, would be $(0.125-0.05)-1.5(0.15-0.05)=-7.5$ percent .

The unconditional approach leads to the mistaken conclusion that the manager has negative abnormal performance. But the manager's performance does not reflect poor investment choices or wasted resources; it merely reflects common variation over time in the fund's conditional risk exposure and the market premium. In this example, the correlation between the two is positive, meaning that the manager takes more risk when the market premium is higher, which makes the unconditional risk exposure look high. The traditional model, therefore, overadjusts for market risk and assigns the manager a negative alpha. But investors who have access to information about the economic state would not use the inflated risk exposure and would, therefore, not ascribe negative performance to the manager.

2The conditional alpha given a bull state, according to the CAPM, is the fund's excess return over cash minus its conditional beta multiplied by the market excess return over cash, which is equal to $(0.20-0.05)-1(0.20-0.05)=0$.

3 The calculation is as follows. The unconditional beta is $\operatorname{cov}(F, M) / \operatorname{var}(M)$, where $F$ is the fund return and $M$ is the market return. The numerator is:

$$
\begin{aligned}
\operatorname{cov}(F, M)= & E\{[F-E(F)][M-E(M)] \mid \text { Bull }\} \times \operatorname{prob}(\text { Bull })+ \\
& E\{[F-E(F)][M-E(M)] \mid \text { Bear }\} \times \operatorname{prob}(\text { Bear }) \\
= & {[(0.20-0.125)(0.20-0.15)] \times 0.5+[(0.05-0.125)(0.10-0.15)] \times 0.5 } \\
= & 0.00375 .
\end{aligned}
$$

The denominator is:

$$
\begin{aligned}
\operatorname{var}(M) & =E\left\{[M-E(M)]^{2 \mid B u l l}\right\} \times \operatorname{prob}(\text { Bull })+E\left\{[M-E(M)]^{2 \mid B e a r}\right\} \times \operatorname{prob}(\text { Bear }) \\
& =\left[(0.20-0.15)^{2}\right] \times 0.5+\left[(0.10-0.15)^{2}\right] \times 0.5 \\
& =0.0025
\end{aligned}
$$

The beta is, therefore, $0.00375 / 0.0025=1.5$. Note that the unconditional beta is not the same as the average conditional beta because the latter is 0.5 in this example. 
Previous Empirical Evidence. The first conditional performance evaluation studies-by Chen and Knez (1996), Ferson and Schadt (1996), and Ferson and Warther (1996) - found that conditioning on the state of the economy is both statistically and economically significant for measuring investment performance. Conditioning also helps control biases in traditional market-timing models. Jagannathan and Korajczyk (1986) and Ferson and Schadt showed that traditional measures of market timing can assign "negative" timing ability to a passive portfolio strategy, and earlier studies had found that measures of timing ability for mutual funds were typically close to zero or negative. Negative timing coefficients make no sense because if funds could time the market but got the direction systematically wrong, investors could profit by taking the opposite position. Ferson and Schadt showed how such a result arises as a statistical bias when funds' betas vary over time with the state of the economy. By using a conditional approach to control for time-varying betas, the bias is removed.

The original studies found that conditioning makes the average performance of mutual funds look better. This result may seem puzzling given that CPE sets a higher information standard for abnormal performance than traditional methods do. But this result can occur, as the stylized example in the previous section suggests. CPE does not penalize a fund for patterns in its risk exposures that are predictable based on public information, even if that predictability may hurt average returns. Early studies suggested that this is the case for U.S. equity funds. Ferson and Warther attributed the higher alphas in the conditional approach to predictable patterns of new money flows in and out of mutual funds. They argued that managers respond passively to new money flows, so their market exposures are lower when more new money flows in. Ferson and Warther also showed that more new money comes in for a typical equity fund when market indicators predict high expected returns. The combined effect lowers the unconditional performance, but not the conditional performance. Such results illustrate the refinements in performance attribution that $\mathrm{CPE}$ makes possible in combination with traditional methods.

The original CPE studies used small samples of mutual funds, which were subject to survival selection, ending in 1990. In this study, we use a much larger sample that ends in 2001. Samples limited to survivors are likely to produce biased estimates of performance, as explained by Brown, Goetzmann, Ibbotson, and Ross (1992, 1995); Elton, Gruber, and Blake (1996); and others. If funds that survive have higher new money flows than funds that do not survive, survival screening of the dataset may also affect the relationship between unconditional and conditional performance measures. This hypothesis motivates our use of mutual fund data that avoids survivor-selection bias. 
Edelen (1999) considered the effects of new money flows on unconditional measures of performance at the fund level. He argued that flows beyond the manager's control require disadvantageous trades that hurt performance and that discretionary trades should produce better performance. He found that unconditional alphas and timing measures are negatively related to the part of fund turnover that is explained by flows and that performance is positively related to the part of fund turnover that is uncorrelated with flows. He did not, however, examine conditional measures of performance directly. But Rakowski (2003) did find evidence that the volatility of flows hurts fund performance. We thus use a measure of discretionary turnover, following Edelen, in our CPE analysis.

Zheng (1999) and Becker, Ferson, Myers, and Schill (1999) also found that conditional alphas make mutual funds look better than unconditional alphas and that conditional timing models remove spurious negative timing. Christopherson, Ferson, and Glassman (1998) found that the overall distribution of conditional alphas for pension funds is similar to that of the unconditional alphas, unlike the case for mutual funds as found by Ferson and Schadt. Pension funds present a setting where high-frequency flows of new public money are not at issue, and Christopherson, Ferson, and Glassman suggested that these results are consistent with the interpretation of Ferson and Warther. These studies also used limited samples of funds and conditioning variables. No systematic re-examination of these major results has occurred for a large, current database that controls for survival bias. In addition, little analysis has been done on how sensitive conditional performance measures are to the choice of conditioning variables. We provide a detailed analysis of this issue.

Christopherson, Ferson, and Glassman as well as Christopherson, Ferson, and Turner (1999) found that conditional alphas are informative predictors about the cross-section of future performance in samples of pension funds. High-conditional-alpha funds deliver high future returns, and conditional alphas predict future returns better than the traditional, or unconditional, alphas. Del Guercio and Tkac (2002) found that new money flows into pension funds are more responsive than those into mutual funds to "sophisticated” measures of performance, such as Jensen's alpha, but they reported no evidence of fund flows in response to conditional measures of performance.

Most of the conditional performance evaluation of mutual funds has used standard marketwide benchmarks for capturing risk exposure. We refine the approach by also using style-based benchmarks in the performance measurement. Myers (1999) studied the role of investment style and survivorship bias in the evidence for persistence of performance in pension funds. He suggested that much of the persistence in pension fund performance, such as found in 
Christopherson, Ferson, and Glassman, is related to fund style. These results for pension funds suggest that examining the conditional performance of mutual funds, controlling for style, should be useful. Because performance relative to a peer group receives so much attention in practice and has been found to be a determinant of new money flows into mutual funds (e.g., Sirri and Tufano 1998), comparing and evaluating these alternative approaches should also be interesting.

\section{Measuring the States of the Economy}

Previous studies have used a standard set of lagged variables-level of interest rates, yield spread, aggregate market dividend/price or similar ratios, and so on-to measure the state of the economy. For example, Ferson and Warther used a short-term interest rate and a dividend yield, and these are the most important instruments in Ferson and Schadt. In addition, previous studies have modeled the time variation in the CPE measures as linear functions of these variables. For the purposes of checking the robustness and validity of the previous results, we include similar lagged variables. We also expand the list of instruments beyond those of the earlier studies.

We use a list of 11 instruments for the economic state. The first is the level of short-term interest rates, measured as the bid yield to maturity on a 90-day Treasury bill. The second is the term-structure slope, measured as the difference between a five-year and a one-month discount Treasury yield. Termstructure concavity is $y_{3}-\left(y_{1}+y_{5}\right) / 2$, where $y_{j}$ is a $j$-year fixed-maturity yield. Interest rate volatility is the monthly standard deviation of three-month Treasury rates, computed from the days within the month. ${ }^{4}$ All the interest rate data are from the U.S. Federal Reserve database. Stock market volatility is constructed similarly using daily returns for the S\&P 500. Dividend yield is the annual dividend yield of the Center for Research in Security Prices (CRSP) value-weighted stock index. Inflation is the percentage change in the U.S.

4 One complication is that the daily three-month spot rates are highly autocorrelated. Because the interest rates refer to overlapping periods longer than one month, the data should follow a moving-average process with more terms than the number of days in the month, which causes a bias in the sample variance. We approximately control this bias by modeling the autocorrelation as a first-order autoregressive, or $A R(1)$, process. Let the $A R(1)$ coefficient be $\rho$, let the number of daily observations in the month be $T$, and let $s^{2}(r)$ be the maximum likelihood estimator of the variance, ignoring the autocorrelation. It is easy to show that the expected value of $s^{2}(r)$ differs from $\sigma^{2}(r)$, the true variance. An unbiased estimator, in the sense that its expected value under the $A R(1)$ assumption is $\sigma^{2}(r)$, may be constructed as: $s_{\star}^{2}=s^{2}(r) /$ $\left\{1-(1 / T)-\left(2 / T^{2}\right)[\rho /(1-\rho)]\left[T\left(1-\rho^{T-1}\right)-\left(1-\rho^{T-1}\right) /(1-\rho)+(T-1) \rho^{T-1}\right]\right\}$. We use $s_{\star}^{2}$ as our estimate of the monthly variance, where $T$ is the number of daily observations in the month and $\rho=0.99$, the value estimated using all the daily observations in the sample. 
Consumer Price Index (CPI). Industrial production growth is the monthly growth rate of the seasonally adjusted industrial production index. Short-term corporate illiquidity is the percentage spread of three-month high-grade commercial paper rates over three-month Treasury rates, which follows Gatev and Strahan (2003). Stock market liquidity is the measure from Pastor and Stambaugh (2003), based on price reversals.

Discrete State Approach. In addition to using the lagged variables themselves, we also measure the state of the economy using discrete state variables. These discrete measures may help to resolve some of the potential econometric problems associated with the continuous measures. By using dummy variables to condition performance, we also avoid the linear functional forms assumed by previous studies.

For each state variable, we measure the average abnormal performance, conditional on the state variable being higher than normal, lower than normal, or normal. This approach follows Ferson, Henry, and Kisgen (2003), who used a similar approach to study fixed-income funds in a stochastic discount factor framework. Consider the example where the lagged instrument is the level of a short-term interest rate, $r_{t}$. We first convert the rate into a deviation from its recent level, measured as the average value over the last 60 months: $x_{t}=r_{t}-(1 / 60) \Sigma_{j=1, \ldots, 60} r_{t-j}$. We then use the last 60 months of data to estimate the standard deviation of $r_{t}, \sigma\left(r_{t}\right)$. The dummy variable $D_{t, h i}$ for a higher-than-normal level of the interest rate is defined as the indicator function: $I\left\{\left[x_{t} / \sigma\left(x_{t}\right)\right]>1\right\}$. Thus, higher than normal is defined as being greater than one standard deviation above the trailing mean. Similarly, the dummy variable $D_{t, l o}$ for a lower-than-normal level of the rate is defined as the indicator function: $I\left\{\left[x_{t} / \sigma\left(x_{t}\right)\right]<-1\right\}$. If the data are approximately normally distributed, we should get about two-thirds of the observations in the normal category and one-sixth of the observations each in the high and low categories.

Dummy variables for the other state variables are similarly defined. For example, we measure performance conditional on high versus low market volatility. To construct this series, we use the daily CRSP market index returns within each month to compute a monthly standard deviation. The time series of the monthly standard deviations replaces $r_{t}$ above, and the dummy variables for high and low volatility are computed in the same fashion.

Summary Statistics. Panel B of Table 1 presents summary statistics for the instruments used in constructing the state variable dummies. Many of the instruments are highly persistent series, as can be seen from their high first-order autocorrelations. For example, the short-term interest rate, credit spread, and dividend yield have autocorrelations in excess of 95 percent. High 
Table 1. Benchmark Returns and Lagged Instruments: Summary Statistics

\begin{tabular}{lccccc}
\hline Series & Mean & Min & Max & Std. Dev. & $\rho_{1}{ }^{\mathrm{a}}$ \\
\hline A. Benchmark returns (January & 1973 & through & December 2000, $N=336$ ) & & \\
90-day bill & 0.606 & 0.19 & 2.13 & 0.272 & 0.7730 \\
One-year bond & 0.661 & -1.72 & 5.61 & 0.630 & 0.2748 \\
Government bond & 0.772 & -8.40 & 15.23 & 3.051 & 0.1120 \\
BAA corporate bond & 0.819 & -10.29 & 14.27 & 2.785 & 0.1930 \\
Broad equity index & 1.105 & -22.49 & 16.56 & 4.618 & 0.0193 \\
Growth stocks & 1.048 & -27.45 & 17.69 & 5.834 & 0.1044 \\
Value stocks & 1.373 & -23.33 & 25.12 & 4.639 & 0.1208 \\
Small-cap stocks & 1.279 & -29.07 & 26.73 & 5.701 & 0.1643 \\
& & & & & \\
B. Lagged instruments (December & $1967-$ November & 2000 ) & & & \\
Short-term interest rate & 6.897 & 2.785 & 16.71 & 2.690 & 0.9714 \\
Term-structure slope & 0.9075 & -4.259 & 5.208 & 1.331 & 0.8759 \\
Term-structure concavity & 0.09855 & -0.6265 & 0.9035 & 0.2007 & 0.7811 \\
Interest rate volatility & 0.5980 & 0.000 & 1.552 & 0.2449 & 0.9121 \\
Stock market volatility & 0.03577 & 0.0001126 & 0.2512 & 0.01841 & 0.4666 \\
Credit spread & 1.079 & 0.5500 & 2.690 & 0.4395 & 0.9639 \\
Dividend yield & 3.458 & 1.450 & 6.125 & 1.044 & 0.9810 \\
Inflation & 4.964 & -5.412 & 21.47 & 3.905 & 0.5966 \\
Industrial output growth & 2.884 & -50.96 & 40.14 & 9.410 & 0.3804 \\
Short-term corporate illiquidity & 0.07933 & -0.09977 & 1.149 & 0.1332 & 0.7382 \\
Stock market liquidity & -0.03129 & -0.4689 & 0.2025 & 0.05798 & 0.2100 \\
\hline Not & & & &
\end{tabular}

Note: Returns are monthly rate of return in percent.

${ }^{a} \rho_{1}$ is the first-order sample autocorrelation of the series.

persistence, however, can create econometric problems as reviewed by Ferson, Sarkissian, and Simin (2003a, 2003b). With persistent variables, finding "spurious" predictability in a given sample is likely because standard statistical analysis suggests the predictability is there but it really is not there when needed, outside the given sample. Our expanded list of instruments includes variables without so much persistence. For example, six of the instruments we introduce in Table 1 have first-order autocorrelations less than 0.80 . Ferson, Sarkissian, and Simin showed that spurious regression is not a significant issue at these levels of persistence.

In Appendix A, Table $\mathbf{A} 1$ and Table $\mathbf{A} 2$ report summary statistics for the dummy variable indicators for the various states. The dummy variables are less persistent than the underlying continuous variables from which they are constructed, which reduces concerns about spurious regression biases. For 
the dummy variables, the largest first-order autocorrelation is 85 percent, and most are much smaller. The lower persistence of the dummy variables is one of their attractive features.

Table A2 shows that the state variable dummies are mutually correlated. The highest correlation between the low-state dummies is 83 percent (shortrate level with its volatility). The highest correlation between the high-state dummies is 89 percent (again, short-rate level with its volatility). The other correlations are typically much smaller. For example, the next highest correlations between the dummies are 64 percent and 58 percent; the rest are below 50 percent.

Figure 1 presents plots of the lagged state variables and their associated discrete dummy variables. The dummies are shown as positive for a higherthan-normal state, negative for a low state, and zero for a normal state. The graph for the 90-day Treasury bill (short rate) in Panel A shows an overall declining trend in the levels since 1981 but with enough cyclicality that the dummy variables are not simply subperiod indicators for early and late in the sample. At the end of 1989 and in much of 2000, Panel A shows brief periods of high-rate states, and since 1994, it shows long periods of normal rate levels as well. The graph for the slope of the term structure in Panel B reveals a more uniform distribution of shorter-duration high, low, and normal episodes over the sample period. High slopes occur in 1976, 1983-1985, mid-1988, and 19921993, interspersed with normal slopes during those periods. Low slopes occur in 1979-1981, 1989-1991, and 1995-1999, also interspersed with normal periods. The graph for concavity in Panel $\mathrm{C}$ appears similar to the slope graph. (The dummy variables are scaled as indicated in the titles of the graphs.) When the slope of the term structure is high, it tends to be concave (the two high-state dummies have a correlation of 58 percent), and low slopes tend to be associated with less concavity (the low-state dummies have a correlation of 64 percent). Interest rate volatility, Panel $\mathrm{D}$, displays a decreasing trend since 1982, similar to the interest rate levels. (The dummies for low rates and low volatility have a correlation of 77 percent.) Periods of high interest rate volatility are evident during the 1979-82 monetary experiment, and periods of low volatility occur during 1985-1988 and 1992-1994.

The first state of the financial market variables in Figure 1 is stock market volatility, shown in Panel E. The spike in volatility corresponding to October 1987 is the most prominent feature of the series. Volatility was mostly normal over the 1988-92 period. The dummies oscillate between low and normal periods during 1984-1986 and 1993-1995, and they oscillate between high and normal periods during 1973-1975, 1980-1983, and 1996-1999. Credit spreads, plotted in Panel F, show a downward drift since 1982, similar to the interest rate level and volatility series. Brief high-spread periods occur in 1975-1976, 
Figure 1. Lagged State Variables and Their Associated Dummy Variables, 1973-2001
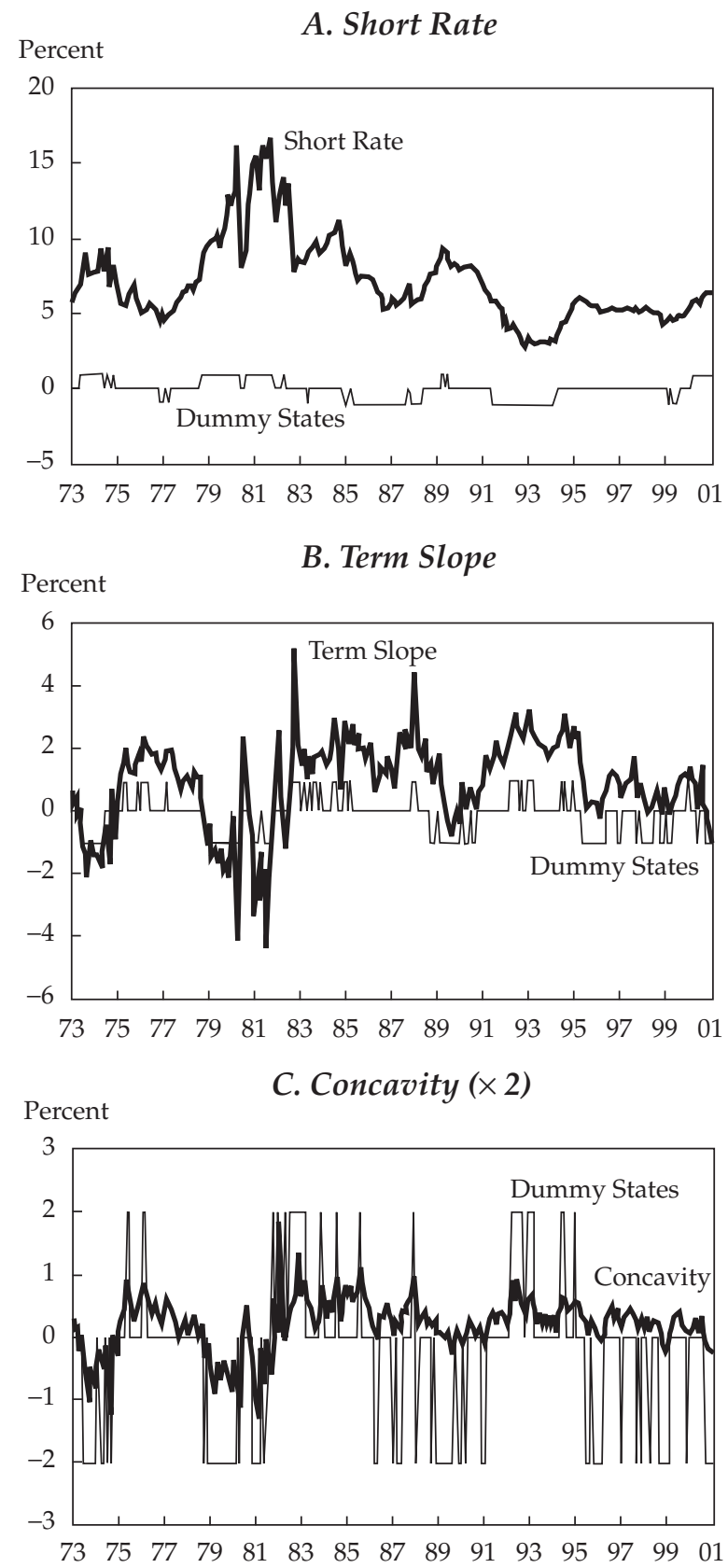
Figure 1. Lagged State Variables and Their Associated Dummy Variables, 1973-2001 (continued)

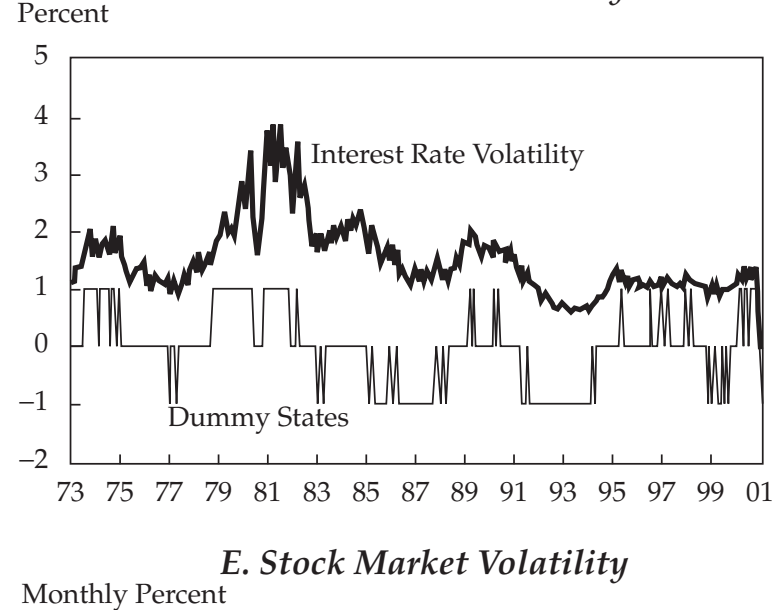

\section{Interest Rate Volatility}

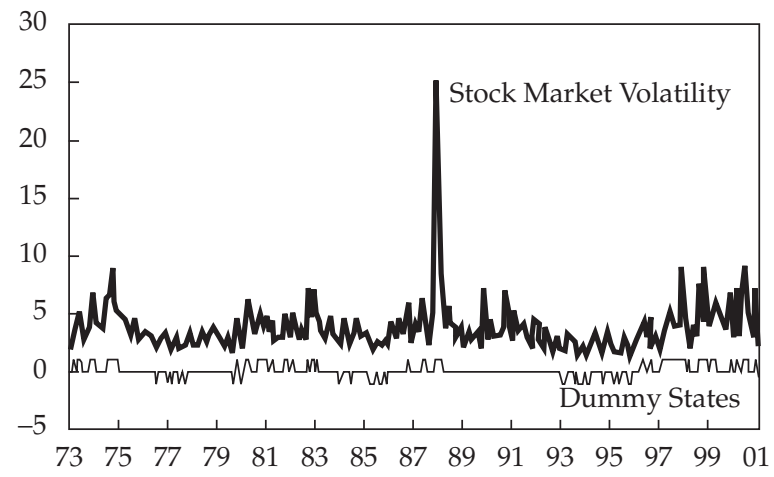

Percent

\section{F. Credit Spread}

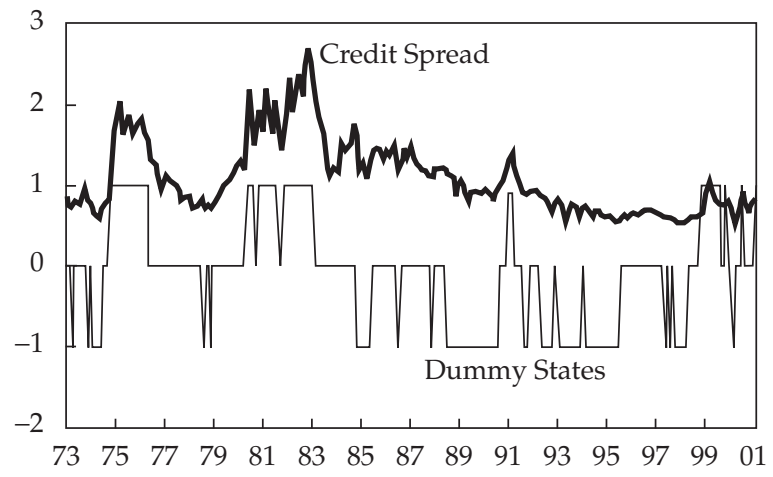


Figure 1. Lagged State Variables and Their Associated Dummy Variables, 1973-2001 (continued)

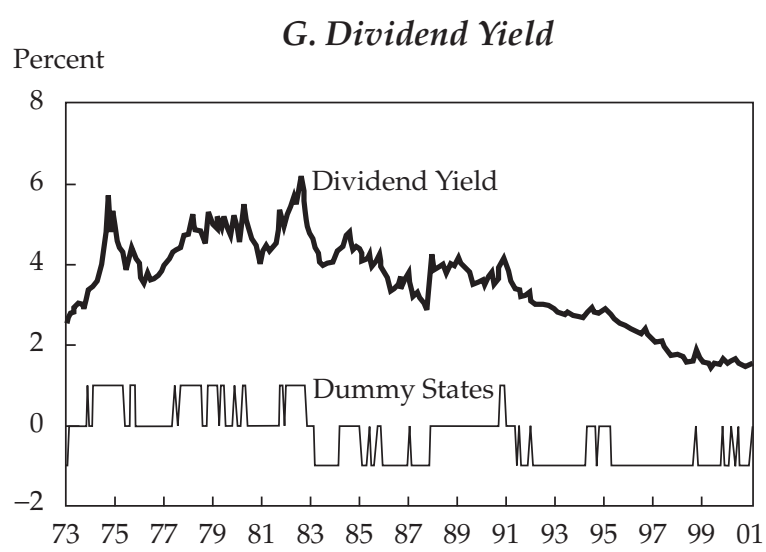

H. Short-Term Corporate Illiquidity $(\times 15)$

Basis Points

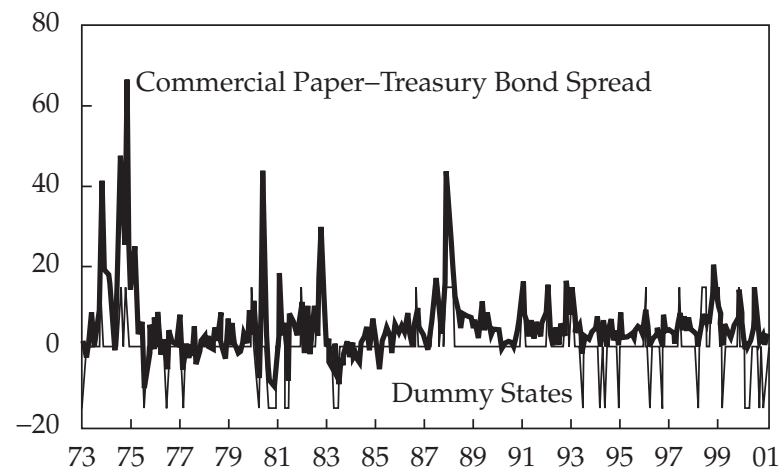

I. Stock Market Liquidity $(\times 20)$

Basis Points / \$ (millions)

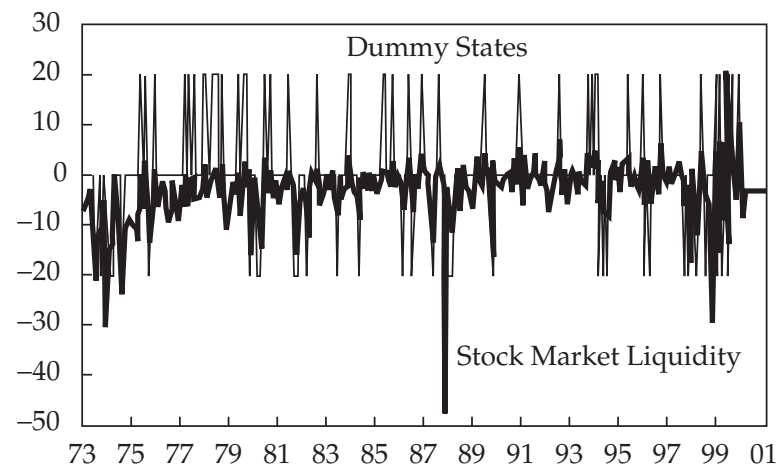


Figure 1. Lagged State Variables and Their Associated Dummy Variables, 1973-2001 (continued)

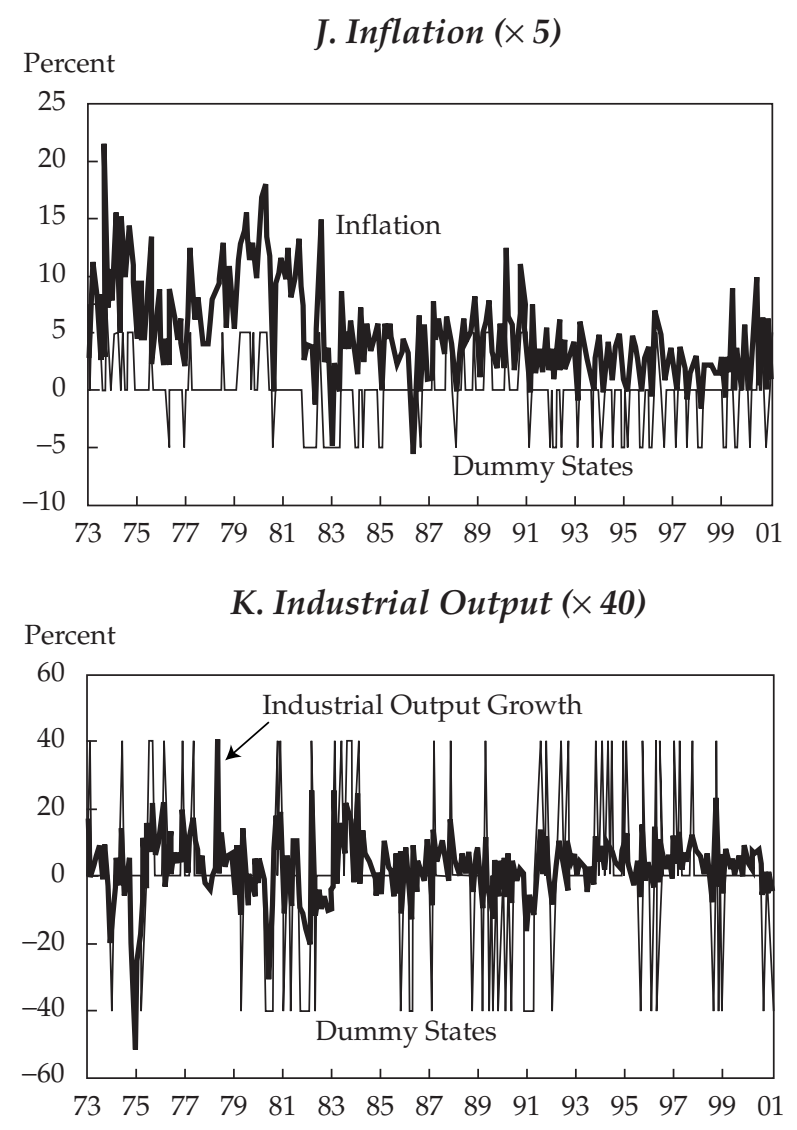

1981-1983, and since 1999. Much of the period since 1982 is characterized by oscillation between normal and low spreads. Panel G shows the dividend yield, which is the series that appears most likely to be nonstationary. It displays a smooth downward trend since 1982. The dummies indicate mostly high or normal yields during 1973-1982 and mostly low or normal after that. The commercial paper-Treasury spread, our measure of short-term corporate illiquidity shown in Panel H, displays sharp peaks during 1974, 1980, 1983, and 1988. The dummy variables indicate primarily normal or high spreads during 1973-1975 and 1983-1993, with seemingly random patterns over other periods. The stock market liquidity variable, plotted in Panel I, is the most random looking of the financial market indicators, except for a brief period of frequently low liquidity during 1973-1975 and a negative liquidity spike in October 1987. 
Finally, Figure 1 includes graphs of the state variables for the macroeconomy. The inflation rate series, shown in Panel J, looks like a noisier version of the short-term interest rate series, with high, low, and normal states scattered throughout the sample. This similarity makes sense if variation in the short-term rate largely tracks variation in expected inflation, as suggested by Fama (1975). Under this interpretation, the short rate would appear as a smoothed version of the inflation rate. The dummy variables indicate a concentration of low-inflation states during 1982-1988, normal interspersed with low during 1991-1999, and a concentration of high inflation states during 1973-1980. Finally, the industrial output growth rate series, shown in Panel $\mathrm{K}$, appears stationary and largely random. But the dummy variables can pick out business cycle patterns in the growth rate. Frequent high-growth states, although interspersed with normal states, occur during 1983-1984 and 1994-95. Frequent low-growth states, again interspersed with normal states, occur during 1975, 1981-1982, and 19891991. Overall, the state variables track interesting variation in interest rates, financial markets, and the macroeconomy.

\section{Empirical Models}

We focus on two versions of conditional performance regressions and two conditional market-timing models, and we compare these with the classical performance measures that they generalize. Three of these conditional models were developed by Ferson and Schadt and one by Christopherson, Ferson, and Glassman. Let $r_{m, t+1}$ be the excess return on a market or benchmark index. For example, it could be the S\&P 500, a style index (such as a small-cap growth index), or a vector of excess returns if a multifactor model is used.

Our first model is one proposed by Ferson and Schadt:

$$
r_{p, t+1}=\alpha_{p}+\beta_{0} r_{m, t+1}+\beta^{\prime}\left(r_{m, t+1} \otimes \mathbf{Z}_{t}\right)+u_{p, t+1},
$$

where $r_{p, t+1}$ is the return of the fund in excess of a short-term "cash" instrument, and $\boldsymbol{Z}_{\mathbf{t}}$ is the vector of lagged conditioning variables, in demeaned form. The symbol $\otimes$ denotes the Kronecker product, or elementby-element multiplication when $r_{m, t+1}$ is a single market index. The symbol $u_{p, t+1}$ is the regression error. A special case of Equation 1 is the classical CAPM regression, where the terms involving $\mathbf{Z}_{\mathbf{t}}$ are omitted. In this case, $\alpha_{p}$ is Jensen's alpha.

When $r_{m, t+1}$ is the excess return on a broad market index, then Equation 1 can be used to estimate a version of the conditional CAPM, which says that

$$
E\left(r_{t+1} \mid \mathbf{Z}_{\mathbf{t}}\right)=\beta\left(\mathbf{Z}_{\mathbf{t}}\right) E\left(r_{m, t+1} \mid \mathbf{Z}_{\mathbf{t}}\right),
$$


where $\beta\left(\mathbf{Z}_{t}\right)$ is the conditional beta and $\alpha_{p}=0$ indicates no abnormal performance. The conditional CAPM is examined empirically by Harvey (1989), Shanken (1990), Ferson and Harvey (1991), and Jagannathan and Wang (1996), among others. These authors applied the model to hypothetical, passive portfolios of common stocks. Jagannathan and Wang emphasized that the conditional CAPM can be boiled down to an unconditional model-that is, a model for average expected returns with more than one "beta." This interpretation can also be seen in Equation 1 , where $\left(\beta_{0}, \beta\right)$ is a vector of regression coefficients or betas on the multiple factors defined by $\left(r_{m, t+1}, r_{m, t+1} \otimes \mathbf{Z}_{t}\right)$.

To see more explicitly how the model in Equation 1 arises, consider a market model regression allowing for a time-varying fund beta, $\beta\left(\mathbf{Z}_{\mathbf{t}}\right)$, that may depend on public information, $\mathbf{Z}_{\mathbf{t}}$ :

$$
r_{p, t+1}=\alpha_{p}+\beta\left(\mathbf{Z}_{t}\right) r_{m, t+1}+u_{p, t+1} .
$$

Now, assume that the time-varying beta can be modeled as a linear function: $\beta\left(\mathbf{Z}_{\mathbf{t}}\right)=\beta_{0}+\beta^{\prime} \mathbf{Z}_{\mathbf{t}}$. The coefficient $\beta_{0}$ is the average beta of the fund (because $\mathbf{Z}$ is normalized to mean zero), and the term $\beta^{\prime} \mathbf{Z}_{\mathbf{t}}$ captures the time-varying conditional beta. Substituting this expression into Equation 2, the result is Equation 1. Note that because $E\left(\mathbf{Z}_{\mathbf{t}}\right)=0$, it follows that:

$$
\begin{aligned}
E\left[\beta^{\prime}\left(r_{m, t+1} \otimes \mathbf{Z}_{\mathbf{t}}\right)\right] & =\operatorname{cov}\left[\beta\left(\mathbf{Z}_{\mathbf{t}}\right), r_{m, t+1}\right] \\
& =\operatorname{cov}\left[\beta\left(\mathbf{Z}_{\mathbf{t}}\right), E\left(r_{m, t+1} \mid \mathbf{Z}_{\mathbf{t}}\right)\right],
\end{aligned}
$$

where the second equality follows from representing $r_{m, t+1}=E\left(r_{m, t+1} \mid \mathbf{Z}_{t}\right)+$ $u_{m, t+1}$, with $\operatorname{cov}\left[u_{m, t+1}, \beta\left(\mathbf{Z}_{\mathbf{t}}\right)\right]=0$. Thus, the additional factors defined by the interaction term $\beta^{\prime}\left(r_{m, t+1} \otimes \boldsymbol{Z}_{\mathrm{t}}\right)$ in Equation 1 arise as a control for common movements in the fund's conditional beta and the conditional expected benchmark return. The conditional alpha, $\alpha_{p}$, is measured net of the effects of these risk dynamics.

Christopherson, Ferson, and Glassman proposed a refinement of Equation 1 to allow for a time-varying conditional alpha. Our second model is as follows:

$$
r_{p, t+1}=\alpha_{p 0}+\alpha_{p} \mathbf{Z}_{\mathbf{t}}+\beta_{0} r_{m, t+1}+\beta^{\prime}\left(r_{m, t+1} \otimes \mathbf{Z}_{\mathbf{t}}\right)+u_{p, t+1} .
$$

In this model, $\alpha_{p 0}+\alpha_{p}^{\prime} \mathbf{Z t}$ measures the time-varying conditional alpha. This refinement of the model may have more power to detect abnormal performance if performance varies with the state of the economy. For example, if a manager generates positive alpha when the yield curve is steep but negative alpha when it is shallow, the average abnormal performance may be close to zero so that it cannot be detected using Equation 1. In such a case, Equation 4 would track the time variation in alpha and record it as a nonzero coefficient, $\alpha_{p}$, on the instrument for the term-structure slope. 


\section{Data}

Our study involves several datasets. This section describes these data, including our sample of mutual fund returns and characteristics.

Benchmark Returns. We use a number of "passive" index returns as benchmarks for the mutual fund performance. Summary statistics for the eight standard indexes are in Panel A of Table 1, and their conditional mean returns are presented in Table 2 . The benchmark indexes cover a range of asset classes with different risks and returns. They include the monthly returns on a "cash" instrument, measured by the 90-day U.S. Treasury bill; a government bond return, measured by the 20-year bond from Ibbotson Associates; a BAA corporate bond index return; a broad equity market index, measured by the CRSP value-weighted market index; a small-cap stock index; and two indexes of stocks grouped according to their lagged book-to-market ratios. The growth index consists of stocks with low book-to-market ratios, and the value index has high book-to-market ratios. 5

The summary statistics of the benchmark returns, reported in Table 1, show the expected result that average return and volatility go together as one moves from cash to government bonds, to corporate bonds, to equities. The cash market returns have significant autocorrelation, at 77 percent, but none of the other autocorrelations are larger than 28 percent.

Over the 1973-2000 period, the value stock index slightly outperformed the small stock index, which, in turn, slightly beat the broad equity index. The growth stock index delivered the lowest equity returns. Growth stocks and small-cap stocks were the most volatile. Previous studies, including Basu (1977), Fama and French (1992), and Lakonishok, Shleifer, and Vishny (1994), have claimed that value strategies, which choose stocks with high book-tomarket or earnings-to-price ratios, outperform growth strategies.

Benchmark Returns Conditioned on Economic States. Table 2 shows the average return and standard deviation of return for seven of the benchmark indexes conditional on the high, low, and normal values of the economic state dummies. The columns show the various asset returns, from low to high risk as one moves from left to right across the table; the rows correspond to the state variables. The state variables are organized into three groups, with one panel for each group. The first group measures the state of the term structure; the second group measures the state of general financial markets; and the third measures the state of the macroeconomy. In each case,

5The broad market, small-cap, value, and growth indexes are courtesy of Kenneth French, via his website at Dartmouth College (mba.tuck.dartmouth.edu/pages/faculty/ken.french/), and are formed from data on CRSP and Compustat. 


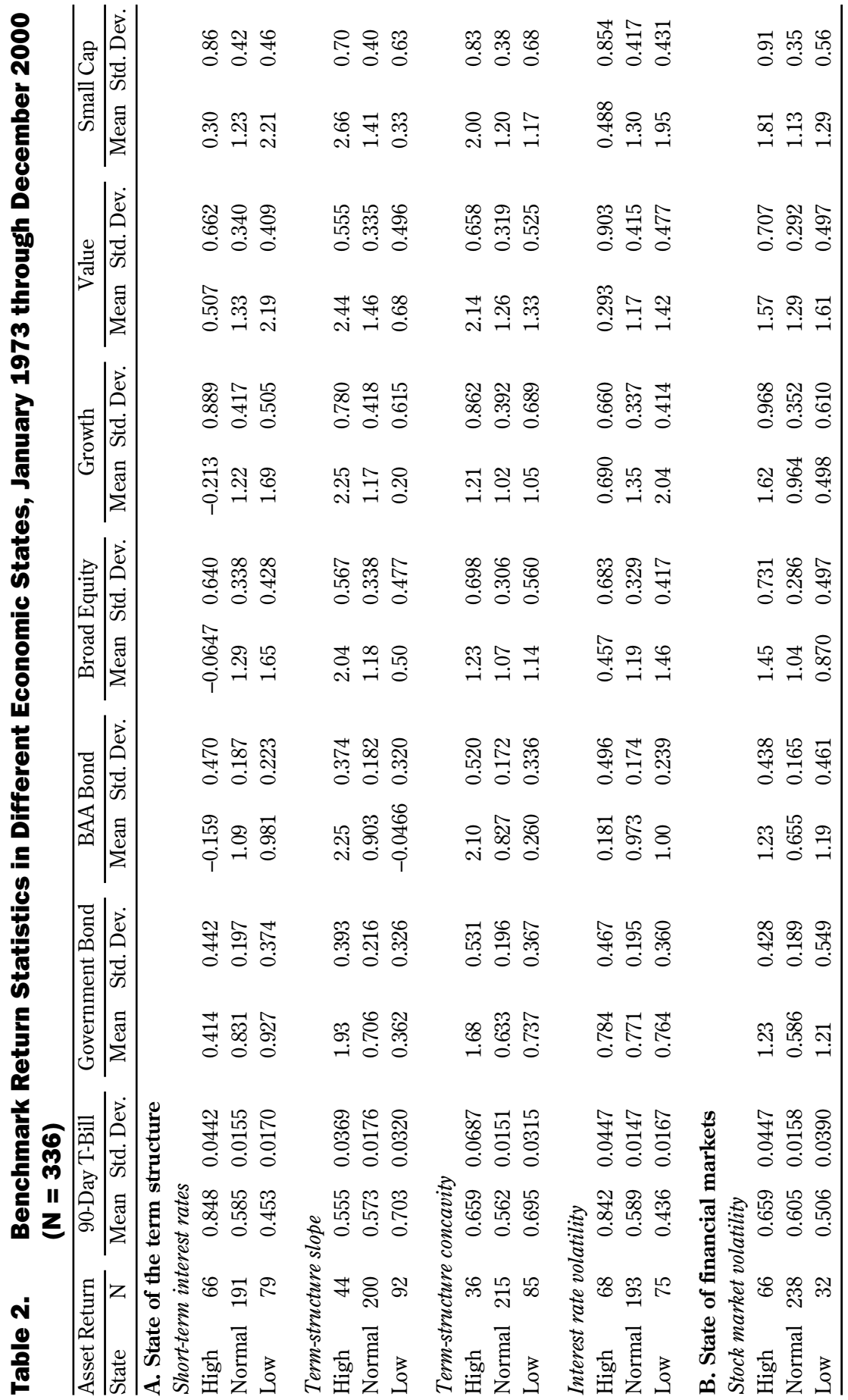




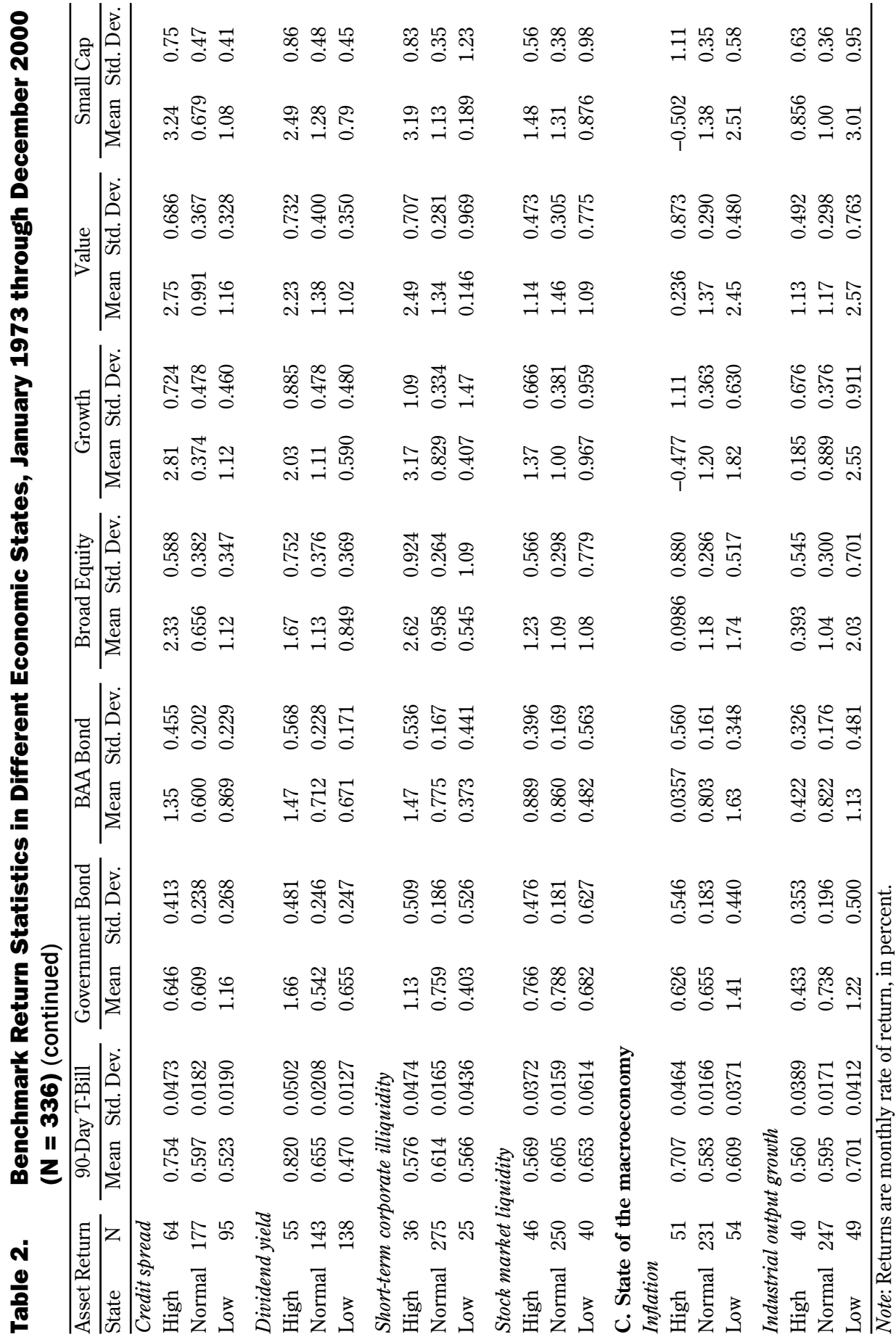


the state variable dummy is used to predict the future returns in real time. For example, the state is defined at the end of January using data prior to the last day of the month, and this information is used to predict the return over the month of February.

Starting with the term-structure state variables in Panel A, we find that the states of the term structure are powerful predictors, not just for fixed-income but also for equity returns. Campbell (1987) and others have observed that termstructure variables could be used to model time variation in expected bond and stock returns. The evidence in Table 2 both confirms these claims using more recent data and refines the descriptive relationships using our discrete states. High levels of short-term interest rates predict relatively high and volatile shortterm bond returns and low stock returns. A gradual transition occurs between the two cases across the columns as one moves to the longer-term, riskier asset classes. The difference in the broad equity stock return, predicted by low versus high spot rates, is 1.7 percent per month (1.65 percent given low rates and -0.06 percent given high rates) and strongly statistically significant. These results are generally consistent with previous evidence, such as Fama and Schwert (1977) and Ferson (1989), but appear striking in the discrete state design.

A steeply sloped term structure predicts high long-term bond returns and stock returns. The former reflects a failure of the constant-premium version of the expectations hypothesis of the term structure (e.g., Campbell and Shiller 1991). The latter result is consistent with consumption-based model predictions, such as Breeden (1986), which emphasize a positive relationship between the slope of the term structure and expected economic growth and stock returns. Harvey also found that a steep slope predicts high economic growth.

The level and slope seem to be the most informative indicators from the term-structure data about future investment returns, with concavity being less important. This result is not surprising as far as predicting fixed-income returns is concerned, given the evidence in studies such as Litterman and Sheinkman (1988). Table 2 shows that higher term-structure concavity predicts higher returns on the longer-term government and BAA corporate bonds but has little predictive power for equity returns. High interest rate volatility states are highly correlated with high interest rate levels; Table A2 shows the conditioning dummy variables have correlations between 83 and 89 percent. It is, therefore, not surprising to find that high interest rate volatility is associated with higher and more volatile short-term bond returns and with lower returns on stocks and bonds exposed to default risks. 
The variables associated with the state of general financial markets in Panel B of Table 2 are also associated with interesting return differences. High credit spreads predict high returns on stocks, consistent with Keim and Stambaugh (1986). High dividend yields predict high returns on stocks and bonds, consistent with Fama and French (1989), but the effect is not statistically significant for the broad equity index or the value stock index. Goyal and Welch (2003) and others have found that the predictive ability of dividend yields is weak in post-1990 data, and the dominant downward trend in yields displayed in Figure 1 could be an explanatory factor. The most economically significant predictor among the financial market instruments, judging from the magnitudes of the expected return differences, is the commercial paperTreasury spread, measuring short-term corporate illiquidity. When the spread is high, all the long-term bonds and stock indexes earn high returns over the next month. For example, the difference in monthly expected returns in high versus low spread states is about 0.70 percentage points (pps) per month for the long-term government bond, $2.1 \mathrm{pps}$ per month for the broad equity index, and an impressive 3 pps per month for the small-cap index. Finally, the stock market liquidity measure predicts no reliable differences in the returns.

The last set of variables measures the state of the macroeconomy. Table 2 shows that high inflation is bad news for stocks and corporate bonds. When output growth is abnormally low, it predicts high returns, especially for the riskier assets. In the case of the broad equity index, the difference between the low output state and the high output state is an average return of 1.7 pps per month, while for growth stocks the difference is 2.3 pps per month. The patterns are consistent with the positive relationship between expected economic growth and risky asset returns that most asset-pricing models would predict if economic growth is mean reverting. The intuition is that when the real economy is performing poorly, investors expect it to get better, so expected growth and stock returns are high at such times. 6

In summary, this section shows that by conditioning on the state of the term structure, general financial markets, and the macroeconomy, predicting differences in the expected returns and volatilities of benchmark asset class returns is possible. Our discrete state approach reveals a number of interesting patterns that have not been exploited by previous studies of conditional fund performance. The discrete variables should also avoid problems with persistent lagged instruments that previous studies were subject to and allow us to check the robustness of CPE results to the choice of state variables.

6See Chen (1991) for related empirical evidence. 
Mutual Funds. In this study, we use the CRSP mutual fund database, 2001 version, which allows us to expand the coverage of funds to the 19732000 period. Ferson and Schadt as well as Ferson and Warther studied the 1968-1990 time period, and the data in Christopherson, Ferson, and Glassman also ended in 1990. Thus, the last 10 years of our study represent an out-ofsample check on the robustness of these earlier findings. The total sample of funds, from which we select a subset, includes all funds for which monthly return data exist in a given month. The number ranges from a low of 146 in January 1962 to a high of 27,289 in June 2001, much larger than the sample of 67 large funds studied by Ferson and Schadt as well as Ferson and Warther. By including funds that do not survive until the end of the sample period, we provide some control of sample-selection bias related to fund survival. We exclude fund years for which the current year is earlier than the reported year in which the fund was organized. This step is done to reduce biases associated with back-filled data. For example, data may be back filled when incubator funds with good track records enter the sample, resulting in a selection bias. ${ }^{7}$

We build two samples of U.S. equity mutual funds. The first is a general sample, which we group by fund style. Styles are defined by their Wiesenberger objective codes, which are available for 1962-2001. These codes are matched with ICDI fund objective codes, available for 1993-2001, and Strategic Insight codes, available starting in 1992. The main style groups are growth, growth and income, income, maximum capital gain, small-cap growth, sector, other aggressive growth, and timing funds. We use the first four groups for comparability with Ferson and Schadt as well as Ferson and Warther, who used the same fund groupings. 8

The main reason we classify funds by style using the self-reported groups indicated on the CRSP database is for comparability with the earlier CPE

7Elton, Gruber, and Blake (2001), however, argue that the CRSP database may have other selection biases, so the control for sample-selection bias is not perfect.

8The CRSP codes that define each style group are the same as in Pastor and Stambaugh (2002) and are as follows. The objective codes from Wiesenberger are denoted by OBJ, those from ICDI are denoted ICDI, and those from Strategic Insight are denoted SI. Small-company growth funds are coded OBJ SCG or SI SCG. Other aggressive growth funds are coded OBJ AGG, ICDI AG or AGG, or SI AGG. Growth funds are coded OBJ G, G-S, S-G, GRO or LTG, or ICDI LG or GRO. Income funds are coded OBJ I, I-S, IEQ, or ING or ICDI IN or ING. Growth and income funds are coded OBJ GCI, G-I, G-I-S, G-S-I, I-G, I-G-S, I-S-G, S-G-I, S-I-G, or GRI, or ICDI GI or GRI. Maximum capital gains funds are coded OBJ MCG. Sector funds are coded OBJ ENR, FIN, HLT, TCH, or UTL, or ICDI SF, UT, ENV, FIN, HLT, TEC, UTI, RLE, NTR, or SEC. Timing funds include those whose OBJ code is BAL or AAL, whose POLICY is Bal or Flex, whose ICDI_OBJ code is BL, or whose SI_OBJ code is BAL. 
studies of mutual funds. A variety of alternative classification schemes, of course, exist. Brown and Goetzmann (1997) developed a returns-based style classification scheme that minimizes the mean within-group sum of squares. Like a conditional performance analysis, their approach allows time variation in funds' conditional betas. They compared their classification scheme with seven other approaches to style classification, including self-reported categories, principal components analysis, and various types of loadings on prespecified factors. They found that their returns-based approach performed relatively well at predicting future fund returns. They also found considerable overlap between the interpretation of their style classifications and the selfreported style groups. 9

Alternative approaches to fund classification and performance analysis use the reported holdings of the funds. Two versions of this approach exist in the literature. In the first version, the portfolio weights are directly examined to see if they contain information about the future returns of the securities held by the fund. This approach to performance measurement was developed by Grinblatt and Titman (1989). Ferson and Khang (2002) further developed a conditional version of this measure and showed that it has several advantages. In the second version of weight-based approaches, various characteristics of the stocks held by a fund are measured, and using the fund's reported holdings, a characteristics-based style benchmark is constructed. Average performance can be measured as the difference between the fund and benchmark returns. An example of this approach is the style box provided by Morningstar, which is based on the market capitalization, book-to-market, and earnings-to-price ratios of the stocks held by the fund. Daniel, Grinblatt, and Titman (1997) and Wermers (2000) refined and further developed this approach.

Weight-based approaches have advantages and disadvantages compared with the methods used in this monograph. By using more information, weightbased methods may provide more precise performance measures. As Ferson and Khang emphasized, conditional weight-based approaches can avoid biases that arise in returns-based measures as a result of frequent trading by fund managers. But portfolio weights for mutual funds are required to be publicly reported only every six months, while returns are available more frequently. Portfolio weights are subject to "window dressing," whereby endof-period holdings may not accurately reflect a fund's strategy. Because

${ }^{9}$ Brown and Goetzmann identified eight style categories that they interpreted as growth and income, growth, income, global timing, international, value, glamour, and metal funds. 
reported weights are a snapshot, they obviously will not capture dynamic trading strategies that affect returns. Finally, weight-based approaches do not capture actual trading costs as reflected in fund returns.

Funds Grouped by Style. Summary statistics are shown in Table $\mathbf{3}$ for equally weighted portfolios of the mutual funds in each style group. The three largest categories are the growth, growth and income, and income funds. The number of growth funds ranged from 42 in January 1962 to a high of 6,995 in October 2000. The growth and income funds started with 62 and ended with 3,806 over the same period. Income funds started with 20 and ended with 850 over the same period. Data for the other fund groups are available over more limited periods. The maximum capital gain style was discontinued in 1992, and the small-company growth and sector series were not usable until 1990 because only a few funds existed prior to that date. For the same reason, the other aggressive growth group was not used until 1992.10

The summary statistics in Table 3 show that among the groups available beginning in 1961, 1962, or 1968, the growth funds earned the highest average return, while income funds returned the least. The relative volatilities are as expected, with maximum capital gain and growth funds the most volatile, income funds the least volatile, and growth and income funds in between the two. Over the latter part of the sample period, small-company growth funds earned more than sector funds and the other aggressive growth category and also had the highest volatility among those fund groups. The autocorrelations of the equally weighted portfolios of funds vary from less than 1 percent to almost 18 percent. This finding is similar to the passive benchmarks summarized in Table 1, except for the higher autocorrelation of the short-term cash return.

We study fund performance in relation to various fund characteristics available in the CRSP database. For example, the characteristics observed at the end of a given calendar year are used to predict relative performance over the next three years in subsequent analysis. Each year the funds are grouped into thirds on the basis of a characteristic at the end of the previous year, and equally weighted portfolios of the funds are formed for the next calendar year. The characteristics are: (1) new cash flow over the past year, defined as $\left[T N A_{t}-\left(1+R_{t}\right) T N A_{t-1} / T N A_{t-1}\right]$, where $T N A$ is the total net assets of the fund and $R_{t}$ is the annual return; (2) age of the fund; (3) income passed through to investors in the previous year; (4) capital gains distributions over the past year; (5) reported turnover for the past year; (6) reported total load charges; (7) fund size, measured by total net assets; (8) expense ratio; and (9) lagged annual return over the previous year.

10For example, the other aggressive growth group had one to three funds in 1989 but no data during the May 1990-November 1991 period. Panel A of Table 3 uses all the available data on these funds. 
Table 3. Mutual Fund Monthly Returns: Summary Statistics

\begin{tabular}{lccccccc}
\hline $\begin{array}{l}\text { A. Overall equally weighted portfolios } \\
\text { Series }\end{array}$ & Begin & End & Mean & Min & Max & Std. & $\rho_{1}{ }^{\text {a }}$ \\
\hline Growth & 1961 & 2001 & 0.9148 & -23.41 & 15.11 & 4.583 & 0.1106 \\
Maximum gain & 1968 & 1992 & 0.8420 & -25.53 & 15.96 & 5.925 & 0.1775 \\
Growth and income & 1961 & 2001 & 0.8843 & -16.27 & 23.19 & 3.757 & 0.0707 \\
Income & 1961 & 2001 & 0.6949 & -11.78 & 9.08 & 2.320 & 0.0838 \\
Sector & 1988 & 2001 & 0.9197 & -14.71 & 10.70 & 3.686 & 0.0019 \\
Small-company growth & 1989 & 2001 & 1.1740 & -19.97 & 15.35 & 5.207 & 0.1020 \\
Other aggressive growth & 1989 & 2001 & 0.9141 & -19.38 & 15.21 & 4.604 & 0.0650 \\
Timing & 1962 & 2000 & 0.8614 & -11.90 & 9.69 & 2.843 & 0.0661
\end{tabular}

B. Means, conditioning on states

Equally Weighted Portfolio of Mutual Funds by Group

\begin{tabular}{ccccc}
\cline { 2 - 5 } No. & & Growth & \multicolumn{2}{c}{ Small- } \\
Obs. Growth Cap Gains & Other & Income & and & Company \\
Income & Sector & Growth & Timers \\
\hline
\end{tabular}

State of the term-structure variables

Short-term rates

\begin{tabular}{lccccccccc} 
High & 66 & -0.7709 & -0.6995 & 0.0542 & -0.5095 & -0.6764 & 0.1334 & 0.359 & -0.525 \\
Low & 79 & 1.212 & 1.557 & 0.8779 & 0.4729 & 1.021 & 0.9296 & 1.220 & 0.896 \\
$t$-Statistic & & $\mathbf{- 2 . 5 6 9}$ & $\mathbf{- 2 . 0 8 2}$ & -0.3242 & $\mathbf{- 2 . 8 0 3}$ & $\mathbf{- 2 . 7 5 9}$ & -0.4684 & -0.334 & $\mathbf{- 3 . 0 5 6}$ \\
Term-structure slope & & & & & & & & & \\
High & 44 & 1.560 & 1.862 & 0.4643 & 0.4494 & 1.370 & 0.5186 & 0.411 & 0.388 \\
Low & 92 & -0.406 & -1.388 & 1.225 & -0.0613 & -0.2155 & 0.6936 & 0.752 & -0.264 \\
$t$-Statistic & & $\mathbf{2 . 5 9 9}$ & $\mathbf{2 . 7 7 5}$ & -0.5412 & 1.622 & $\mathbf{2 . 6 1 8}$ & -0.1890 & -0.229 & 1.161 \\
Concavity & & & & & & & & & \\
High & 36 & 0.6472 & 1.126 & -0.7201 & 0.3473 & 0.5973 & -0.2091 & -0.749 & -0.230 \\
Low & 85 & 0.3810 & 0.3946 & 0.9286 & 0.05392 & 0.3328 & 0.9348 & 1.412 & -0.070 \\
$t$-Statistic & & 0.3096 & 0.6082 & -1.042 & 0.7598 & 0.3742 & -1.020 & -1.388 & -0.290 \\
Interest rate volatility & & & & & & & & & \\
High & 68 & -0.9893 & -1.115 & -0.5759 & -0.5926 & -0.8631 & -0.0101 & -0.458 & -0.367 \\
Low & 76 & 1.315 & 1.480 & 0.9985 & 0.6274 & 1.172 & 1.130 & 1.362 & 0.644 \\
$t$-Statistic & & $\mathbf{- 3 . 0 3 1}$ & $\mathbf{- 2 . 3 2 8}$ & -0.8939 & $\mathbf{- 3 . 4 7 4}$ & $-\mathbf{3 . 3 5 9}$ & -1.087 & -1.148 & $\mathbf{- 2 . 1 6 4}$ \\
State of the financial markets variables & & & & & & & \\
Stock market volatility & & & & & & & & & \\
High & 66 & 0.4649 & 0.3877 & 0.9449 & 0.2780 & 0.4144 & 0.6671 & 0.899 & 0.272 \\
Low & 32 & 0.2364 & -0.2894 & 1.268 & 0.5007 & 0.4070 & 0.923 & 1.409 & 0.909 \\
$t$-Statistic & & 0.2580 & 0.4466 & -0.2095 & -0.4828 & 0.0102 & -0.2347 & -0.319 & -1.089 \\
Credit spread & & & & & & & & & \\
High & 64 & 1.611 & 1.659 & 3.740 & 0.6488 & 1.297 & 3.071 & 4.245 & -0.282 \\
Low & 95 & 0.3523 & -0.4880 & 1.346 & 0.2194 & 0.3058 & 0.9107 & 1.231 & -0.210 \\
$t$-Statistic & & 1.791 & $\mathbf{2 . 0 3 9}$ & 1.851 & 1.254 & 1.720 & $\mathbf{2 . 5 9 5}$ & $\mathbf{2 . 3 6 0}$ & -0.136 \\
Dividend yield & & & & & & & & & \\
High & 55 & 0.6094 & 1.081 & 0.000 & 0.1633 & 0.466 & 1.764 & 1.567 & -0.565 \\
Low & & 0.2532 & -0.5716 & 0.000 & 0.2461 & 0.303 & 0.567 & 0.677 & 0.790 \\
$t$-Statistic & 0.4177 & 1.473 & 0.000 & -0.2350 & 0.238 & 0.4907 & 0.2098 & $\mathbf{- 3 . 0 8 8}$ \\
\hline & & & & & & & & &
\end{tabular}


Table 3. Mutual Fund Monthly Returns: Summary Statistics (continued)

\begin{tabular}{|c|c|c|c|c|c|c|c|}
\hline No. & Max & & & $\begin{array}{l}\text { Growth } \\
\text { and }\end{array}$ & & $\begin{array}{c}\text { Small- } \\
\text { Company }\end{array}$ & \\
\hline Obs. & Growth Cap Gains & Other & Income & Income & Sector & Growth & Timers \\
\hline
\end{tabular}

Short-term corporate illiquidity

$\begin{array}{lcccccccrr}\text { High } & 36 & 2.139 & 2.125 & 3.078 & 0.7176 & 1.599 & 2.496 & 3.311 & 0.342 \\ \text { Low } & 25 & 0.0627 & 0.2727 & -0.1695 & -0.1282 & 0.0466 & 0.0029 & -0.160 & 0.587 \\ t \text {-Statistic } & & 1.561 & 0.7649 & 1.577 & 1.274 & 1.420 & 1.804 & 1.691 & -0.351 \\ \text { Stock market liquidity } & & & & & & & & & \\ \text { High } & 46 & 0.7608 & 1.204 & 0.709 & 0.112 & 0.6481 & 0.617 & 1.096 & 0.309 \\ \text { Low } & 40 & 0.0866 & -1.447 & 1.988 & 0.4062 & 0.2212 & 2.111 & 1.741 & 0.304 \\ t \text {-Statistic } & & 0.6987 & 1.699 & -0.8193 & -0.6645 & 0.5334 & -1.287 & -0.397 & 0.009\end{array}$

State of the macroeconomy variables

Inflation

\begin{tabular}{lcccccccrc} 
High & 51 & -0.5654 & -0.8200 & -0.3999 & -0.1917 & -0.276 & -0.1982 & -0.477 & -0.513 \\
Low & 54 & 1.041 & 1.695 & 0.568 & 0.3842 & 0.958 & 0.6780 & 0.634 & 0.766 \\
$t$-Statistic & & -1.565 & -1.741 & -0.5588 & -1.343 & -1.521 & -0.8024 & -0.653 & $\mathbf{- 2 . 2 7 8}$ \\
& & & & & & & & & \\
Industrial output growth & & & & & & & & & \\
High & 40 & -0.1757 & -0.5759 & 0.1082 & 0.1284 & 0.0153 & 0.7709 & 0.231 & 0.475 \\
Low & 49 & 1.296 & 2.053 & 0.2571 & 0.5288 & 0.9059 & 1.320 & 2.576 & -0.478 \\
$t$-Statistic & & -1.591 & $\mathbf{- 2 . 2 7 4}$ & -0.0528 & -0.7830 & -1.184 & -0.3601 & -1.188 & 1.522 \\
\hline
\end{tabular}

Notes: The sample periods for the returns are indicated under begin and end. The sample period in Panel B is January 1973-December 2000 (336 observations) or the shorter period beginning when the data are available for a given fund group as indicated in Panel A. The returns are percent per month.

${ }^{\mathrm{a}} \rho_{1}$ is the first-order sample autocorrelation of the series.

Market-Timing Funds. A broad sample of U.S. equity funds is unlikely to contain many funds that attempt to aggressively time the market. We, therefore, concentrate our study of conditional market timing on the subsample of funds that are relatively likely to be engaged in market-timing activities as indicated by their declared style.11 Our group of market-timing funds is dominated by balanced funds but also includes all the funds identified as asset allocation style funds. The initial number of fund years in this sample is 9,626. The number of funds in any given month ranges from a low of 34 in January 1962 to a high of 2,510 in April 2000. As for the broader sample, we exclude fund years for which the current year is earlier than the reported year in which the fund was organized. We find seven such cases.

11We do not study "market timing" taken to mean trading on stale prices in net asset values, or "later trading" - potentially fraudulent trading after the close of the market. These practices are under legal investigation at some mutual fund companies as this is written. 
Summary statistics for an equally weighted portfolio of our market-timing funds are reported in Table 3 . The average returns and volatility of timing funds are below those of any other group, except the income funds. This result makes sense if the timing funds are out of the market, or holding reduced market exposure, in a substantial fraction of the months.

We form subgroups of the market-timing funds based on the various fund characteristics described previously. Figure 2 plots the annual time series of the cutoff values for the fund characteristics that define the upper and lower thirds of the distributions. These figures present a nice illustration of some trends in the mutual fund industry. Because the sample of timing funds is dominated by balanced funds, the figures present a microcosm of how these fund characteristics have evolved over time while abstracting from variation across the fund styles in our broader sample. (We produced similar figures for the growth, income, and sector style groups, and the overall impressions were similar.)

The graph of the fund age breakpoints over time in Panel A of Figure 2 illustrates how the large number of new funds entering the sample, starting in the mid-1980s, has driven down the age distribution. The cutoff for the oldest third of the funds peaked at 38 years in 1983-1985, then subsequently fell to a low of only 3 years in 1994-1995. The total net assets per fund, shown in Panel B, has trended up mildly during the sample, with a peak in 1987 and then falling to less than half the peak value by 1994 before resuming a slow upward trend through 1999.

The income return passed through by funds to their shareholders displays an inverted U-shape in Panel $\mathrm{C}$ of Figure 2 during the sample period. The upper-third cutoff for income rose from about 0.4 percent per month in 19611962 to just less than 1 percent per month in the high interest rate period ending in 1982-1983 and then fell back to less than 0.4 percent by 1999 as interest rates fell. The capital gains distributions present a different pattern in Panel D. The lower-third cutoff was zero for most of the years between 1970 and 1985. The upper-third cutoff shows peaks in 1968, 1986, and again in 19961997. The bull market of the 1990s is clearly evident.

Panel E of Figure 2 shows that most funds charged load fees in the 7.58.5 percent range during 1961-1967, and funds clustered even more tightly on the maximum 8.5 percent load charge during 1970-1974. Starting in 1975, the lower-third cutoff began to fall, followed by the higher-third cutoff in 1984 . By 1978, the lower-third charged no load fees at all, and by the end of the sample, the upper-third cutoff had fallen to 4.75 percent. It is well known that during this period funds began to substitute load charges with $12 \mathrm{~b}-1$ fees, and expense ratios have thus risen. The graph of the expense ratios in Panel $\mathrm{F}$ 
Figure 2. Annual Time-Series of Cutoff Values for the Fund Characteristics That Define the Upper and Lower Thirds of the Distributions of Market-Timing Funds

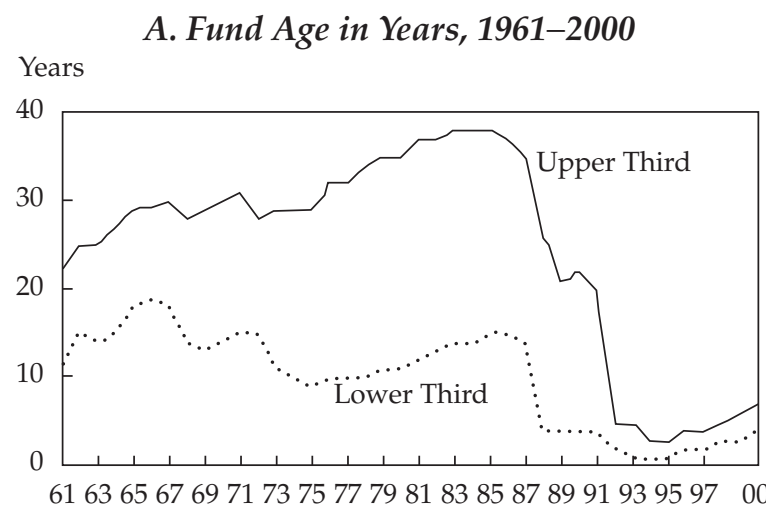

B. Total Net Assets per Fund, 1961-2000 $\$$ (millions)

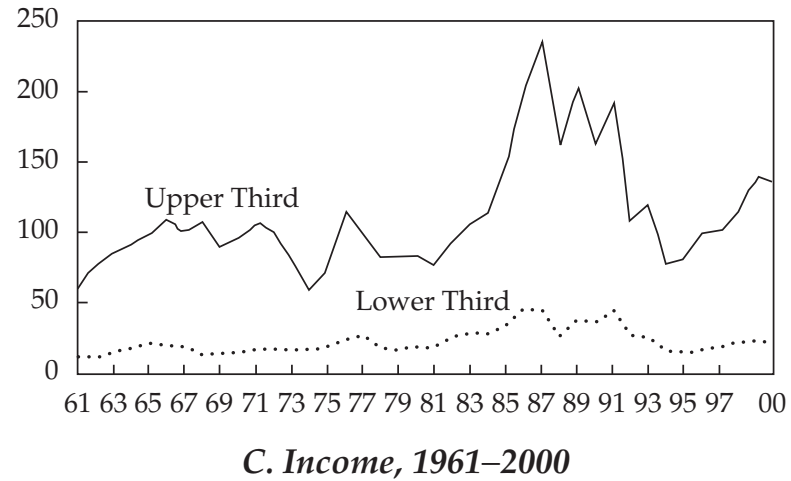

Percent per Month

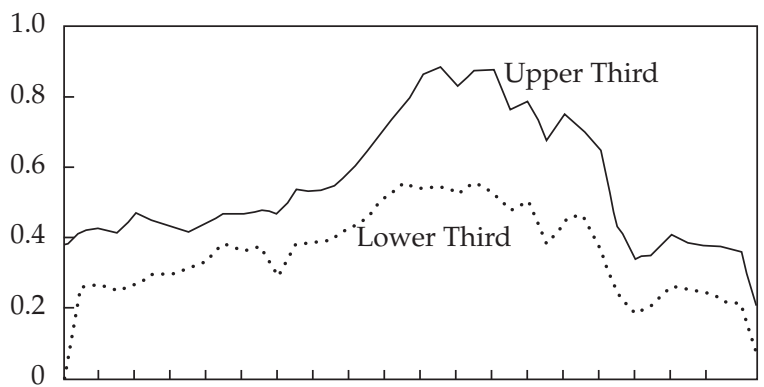

$61636567697173757779818385878991939597 \quad 00$ 
Figure 2. Annual Time-Series of Cutoff Values for the Fund Characteristics That Define the Upper and Lower Thirds of the Distributions of Market-Timing Funds (continued)

D. Capital Gains, 1961-2000

Percent per Month

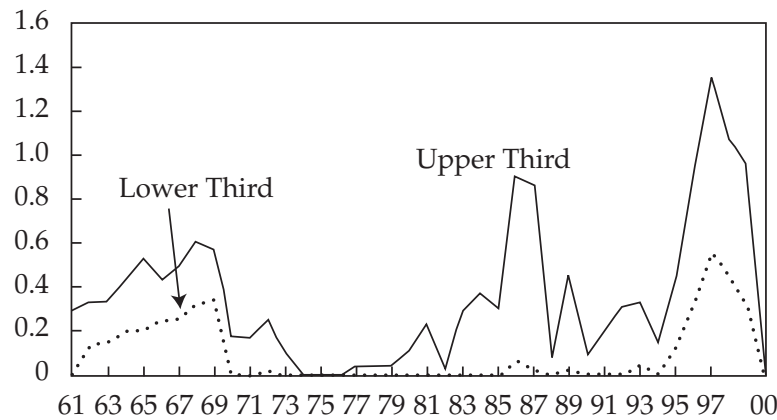

E. Total Loads, 1961-2000

Percent

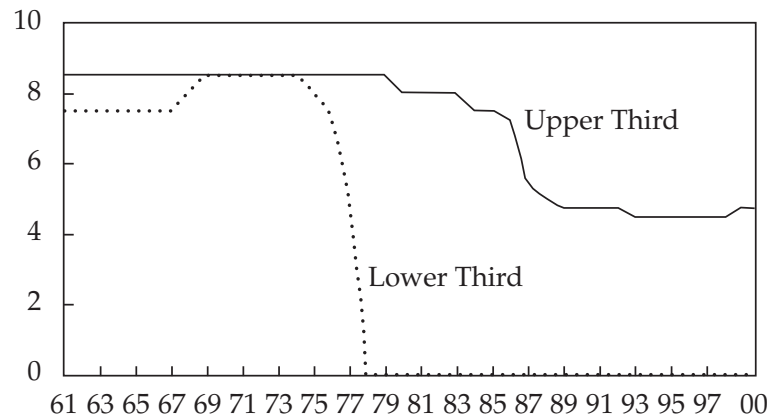

F. Expense Ratios, 1961-2000

Percent

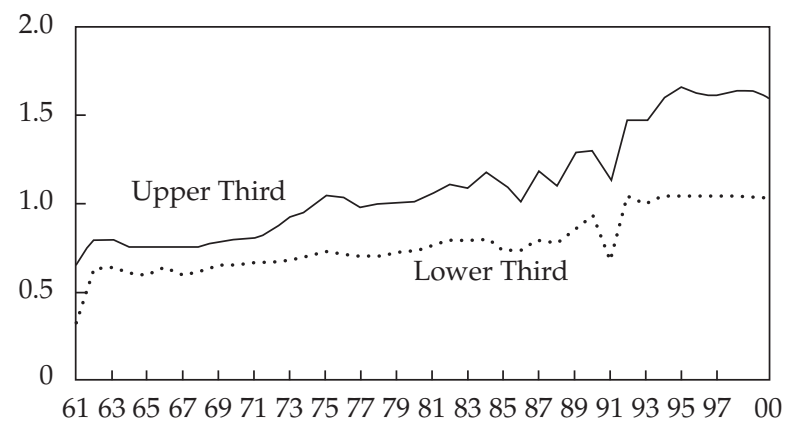


Figure 2. Annual Time-Series of Cutoff Values for the Fund Characteristics That Define the Upper and Lower Thirds of the Distributions of Market-Timing Funds (continued)

G. Fund Turnover, 1966-2000

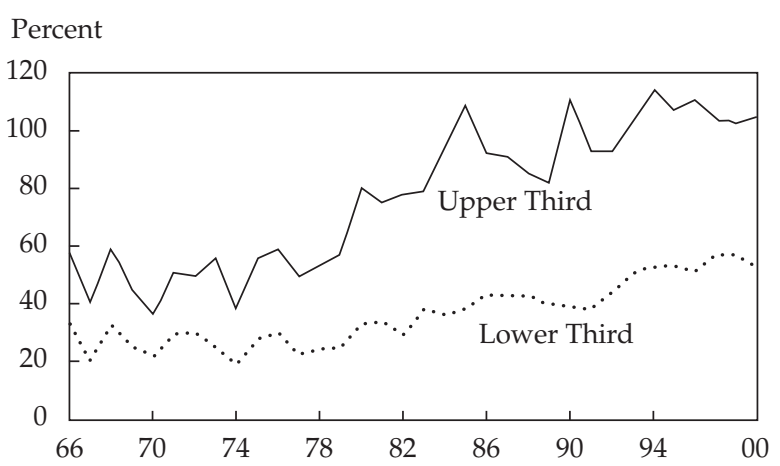

H. Previous Year's New Money Flow, 1963-1999 Percent

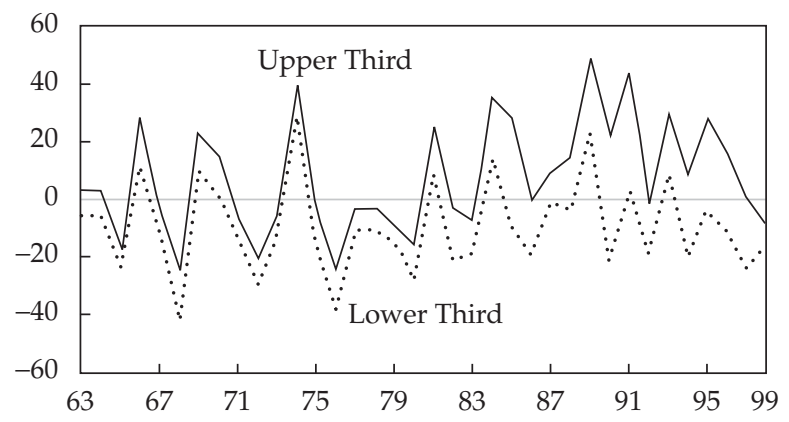

I. Previous Year's Return, 1961-1999

Percent

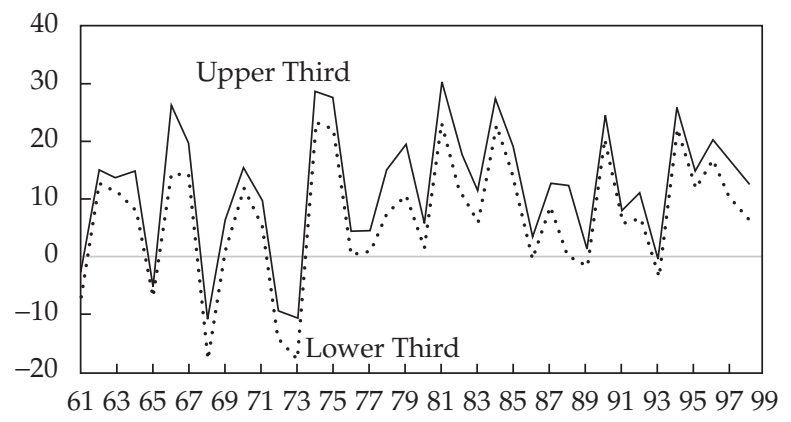


shows a clear upward trend over the sample. The upper-third cutoff was 0.65 percent at the beginning of the sample, rising to 1.6 percent by the end. Fund turnover, shown in Panel G, has risen as well, and the spread between lowturnover and high-turnover funds has widened. Until 1979, the upper-third cutoff for turnover hovered near 50 percent per year; then it began to rise, finishing the sample period at more than 100 percent per year.

The final characteristics relate to the flows of new money and the lagged return performance over the preceding year. In Figure 2, Panels $\mathrm{H}$ and I show that the year-to-year fluctuations in these characteristics are greater than for the other characteristics. New money flows were low during 1975-1980 and relatively high during 1988-1998.

\section{Performance of Broad Fund Groups}

In this section, we present an analysis of conditional performance at the level of the fund-style groups. We first examine the fund returns without any risk adjustment, focusing on the conditional behavior across states of the economy. We then use the CAPM for risk adjustment and examine both the unconditional and conditional alphas, which extends the evidence in studies such as Ferson and Schadt. To evaluate the sensitivity of these results to the model for risk, we then replace the market index benchmark of the CAPM with a fund-style-specific benchmark, constructed from the indexes described in Table 3. The style-specific benchmarks are constructed using a methodology similar to that of Sharpe $(1988,1992)$. We then provide a CPE analysis based on the discrete dummy versions of the state variables. By using the discrete state variables in comparison with the continuous versions of the state variables, we conclude this section with an analysis of the time variation in risk exposures at the fund-style-group level.

Panel B of Table 3 presents the conditional expected returns of the funds, grouped by style, across the various discrete economic states. For each state variable there are three rows. The first two rows show the expected returns given high and low values of a state variable, and then the third row gives a $t$-statistic for the difference in the conditional means in the high versus low state. The calculations for each group of funds are based on the data for every month in which a return is available for the fund group, starting in January 1973. Like in Table 2, the state variables are predetermined, so they could be used to predict the subsequent monthly returns in real time. In many respects, the conditional returns of the funds mirror those of the benchmarks in Table 2. But with the shorter sample period available for some of the fund groups, the conditional mean effects do not as often attain statistical significance. 
The term-structure state variables seem to be the most powerful predictors of future fund returns. Low short-term interest rates predict high fund returns, and high interest rates predict low returns. The differences in the conditional mean returns given high versus low short-term interest rates are significant, with $t$-statistics larger than 2.0 for five of the eight fund groups, indicated in bold. The expected returns given low interest rates are more than 2 percent per month greater than given high interest rates for the maximum capital gains funds and almost that large for the growth funds. A steep termstructure slope also predicts high subsequent returns for most groups, statistically significant for three of the eight based on the $t$-statistics. The differences are often economically large, at 3.2 percent per month for the maximum capital gains funds and just less than 2 percent for the growth funds. High interest rate volatility is bad news for most fund groups, and the differences are significant for five of the eight fund groups. ${ }^{12}$ Finally, term-structure concavity has little predictive ability for fund returns.

The second group of variables captures the general state of financial markets. In this case, we find fewer instances where the conditional expected returns differ significantly across the states. The credit spread indicator produces $t$-statistics larger than 2.0 in three of the eight fund groups, with high spreads predicting high fund returns. The differences exceed 2 percent per month in three cases. Dividend yield, stock market volatility, and market liquidity measures produce no statistically significant effects. But the point estimates under the short-term corporate liquidity variable suggest economic significance, where the high-liquidity states predict higher fund returns for every fund group, with the magnitudes ranging from 0.5 percent to almost 3.5 percent per month across the fund groups.

The final set of state variables reflects the state of the macroeconomy. We find few statistically significant differences in the fund returns across these states. In the case of inflation, the point estimates suggest that low inflation is good news for subsequent fund returns, similar to the long-maturity bonds and passive equity benchmark returns described earlier. But the high volatility of fund returns in high inflation states results in small values of the tstatistics that measure the statistical significance of the difference across states. One exception is the case of the timing funds, where the $t$-statistic is 2.3. In the case of industrial output growth, the point estimates suggest that low current growth is good news for subsequent fund returns, again similar to the passive benchmarks, but the $t$-statistic is larger than 2 only in the case of the maximum capital gains funds.

12 Recall that the level and volatility of interest rates are the two most highly correlated state variable dummies, so we are conditioning on periods with significant overlap in these two cases. 
Overall, the conditional mean returns of the funds suggest significant differences predicted by the state of the term structure of interest rates and credit spreads but only statistically weak evidence of conditional mean return differences related to the other state variables. The single state variable with the most predictive ability seems to be the level of the short-term interest rate. Ferson and Schadt found the short-term interest rate to be the most important conditioning variable among the more limited set of variables that they examined, so our evidence supports this finding in fresh data. The next question is whether the differences in conditional returns reflect abnormal performance or if these return differences can be explained by fund risk exposures that vary over time.

Conditional and Unconditional Alphas. Our first set of risk-adjusted performance results, summarized in Table 4, uses the equally weighted fund portfolios to examine average performance at the level of the fund-style groups. Although it would be unusual to find significant abnormal performance for entire groups of funds, this section allows us to explore the robustness of the results of previous studies where unconditional and conditional performance was compared for broad fund groups.

We first compare fund performance in conditional and unconditional versions of the CAPM. Panel A of Table 4 starts with the unconditional CAPM regression, which is Equation 1 without the $\left(r_{m, t+1} \otimes \mathbf{Z}_{\mathbf{t}}\right)$ term. All of the point estimates of alpha are negative except for the sector funds, but they are small-10 bps per month or less-and are not statistically significant based on the $t$-statistics, which are denoted $t$ (alpha) in the table. Thus, our sample of funds reproduces the findings of previous studies that found that the unconditional performance of mutual funds tends to be slightly negative. The negative unconditional alphas are of the same order of magnitude as funds' expense ratios, which averaged about 1.2 percent per year over this period according to Figure 2 . The CAPM betas, as expected, are strongly significant. The betas are sensibly ordered across the fund groups, with small-company growth funds having the largest beta (1.13) and income funds the smallest beta (0.37). The regression model $R^{2}$ s indicate how much of the volatility of fund returns is associated with fluctuations in the market index. This measure also presents reasonable patterns across the fund groups. For example, the largest regression $R^{2}$ is for growth funds, at 92 percent, and the smallest is 58 percent, for the income funds.

Panel B of Table 4 presents the Ferson and Schadt regression for the conditional CAPM, as given by Equation 1. In this panel, we run the lagged instruments one at a time. The lagged instruments are used in this model to track variation through time in the funds' market betas. We conduct $F$-tests 
Table 4. Unconditional and Conditional CAPM Regressions Using Equally Weighted Fund Portfolios

\begin{tabular}{|c|c|c|c|c|c|c|c|}
\hline Funds & Alpha & $t$ (Alpha) & Beta & $t$ (Beta) & $R^{2}$ & & \\
\hline \multicolumn{8}{|c|}{ A. Unconditional CAPM regressions } \\
\hline Growth & -0.0659 & -0.8938 & 0.974 & 67.88 & 0.920 & & \\
\hline Maximum capital gains & -0.0004 & -0.0028 & 1.118 & 40.44 & 0.856 & & \\
\hline Other & -0.1007 & -0.3956 & 1.101 & 17.43 & 0.7078 & & \\
\hline Income & -0.0126 & -0.1514 & 0.369 & 11.32 & 0.5781 & & \\
\hline Growth and income & -0.0003 & -0.0052 & 0.781 & 62.21 & 0.9157 & & \\
\hline Sector & 0.0456 & 0.3853 & 0.860 & 28.88 & 0.8668 & & \\
\hline \multirow[t]{2}{*}{ Small-company growth } & -0.0255 & -0.1060 & 1.127 & 21.16 & 0.7242 & & \\
\hline & Instrument & Alpha & $t$ (Alpha) & Bet0 & $t(\operatorname{Bet} 0)$ & $R^{2} 1$ & $p$-Value \\
\hline \multicolumn{8}{|c|}{ B. Conditional CAPM regressions using individual instruments } \\
\hline Maximum capital gains & Corporate illiquidity & 0.00848 & 0.05956 & 1.143 & 43.22 & 0.8593 & 0.021 \\
\hline \multirow[t]{6}{*}{ Income } & Interest rates & -0.07219 & -0.8688 & 0.3847 & 11.37 & 0.6191 & 0.000 \\
\hline & Term slope & 0.01915 & 0.2161 & 0.3631 & 11.25 & 0.5843 & 0.090 \\
\hline & Interest rate volatility & -0.07328 & -0.8980 & 0.3833 & 11.69 & 0.6220 & 0.000 \\
\hline & Credit spread & 0.03231 & 0.4272 & 0.3798 & 12.45 & 0.6458 & 0.000 \\
\hline & Dividend yield & 0.00216 & 0.0282 & 0.3827 & 11.00 & 0.6436 & 0.000 \\
\hline & Inflation & -0.04619 & -0.5450 & 0.3803 & 11.22 & 0.5890 & 0.014 \\
\hline \multirow[t]{2}{*}{ Sector } & Credit spread & 0.04136 & 0.3481 & 0.9332 & 26.77 & 0.8689 & 0.066 \\
\hline & Stock liquidity & 0.05151 & 0.4350 & 0.8541 & 27.20 & 0.8689 & 0.070 \\
\hline \multirow[t]{2}{*}{ Small-company growth } & Credit spread & -0.03595 & -0.1496 & 1.304 & 15.58 & 0.7305 & 0.023 \\
\hline & Stock liquidity & -0.01310 & -0.05461 & 1.114 & 20.57 & 0.7289 & 0.060 \\
\hline Other aggressive growth & Stock liquidity & -0.07269 & -0.2845 & 1.101 & 17.48 & 0.7136 & 0.037 \\
\hline \multicolumn{8}{|c|}{ C. Conditional CAPM regressions using grouped instruments } \\
\hline Income & Term structure & -0.0089 & -0.1150 & 0.8735 & 10.34 & 0.6666 & 0.000 \\
\hline Maximum capital gains & Financial markets & 0.0648 & 0.4247 & 1.382 & 8.511 & 0.8618 & 0.0409 \\
\hline Growth and income & Financial markets & -0.0722 & -0.2458 & 0.8128 & 1.456 & 0.7183 & 0.0689 \\
\hline Income & Financial markets & 0.0102 & 0.1354 & 0.8979 & 10.39 & 0.6743 & 0.000 \\
\hline Income & Macroeconomy & -0.0482 & -0.5622 & 0.4371 & 8.584 & 0.5893 & 0.0330 \\
\hline
\end{tabular}

Notes: The sample periods for the returns are January 1973 through December 2000 (336 observations), or a shorter period when indicated by fund availability in Table 3 . Alphas are the abnormal returns, monthly percent; $t$ (alpha) is a heteroscedasticity-consistent $t$-statistic. Beta is the CAPM beta, and $t$ (beta) is its $t$ statistic. $R^{2}$ is the coefficient of determination of the regression. In Panels $\mathrm{B}$ and $\mathrm{C}$, Bet0 is the average conditional beta, $t$ (bet 0 ) is its $t$-statistic, $R^{2} 1$ is the regression coefficient of determination, and $p$-value is the right-tail $p$-value of the $F$-statistic for excluding the lagged instrument multiplied by the style index excess return. In Panel C, the instruments are grouped as follows: Term-structure instruments include the interest rate level, slope, convexity, and volatility. The financial markets variables include stock market volatility, credit spread, dividend yield, short-term corporate illiquidity, and stock market liquidity. The macroeconomy variables are inflation and industrial output growth. 
for the null hypothesis that the additional terms implied by the conditional models may be excluded from the regression. That is, the null hypothesis is that beta is constant over time; the alternative hypothesis is that beta moves as a linear function of the state variable. Only the results for those instruments whose $F$-tests reject the null hypothesis by producing $p$-values less than 0.10 are shown. This is a conservative inclusion criterion, and even if no instrument is individually useful, we would expect to find 10 percent of the cases, or 8-9 examples, that meet the inclusion criterion. We find that only 13 of the 88 cases examined meet the criterion. 13 But the cases are not randomly distributed across fund groups; half of them are the income funds. Thus, Table 4 suggests that among the various fund groups, income funds are the most likely to shift their stock market betas in response to the state of the economy.

Another pattern that does not appear to be random in Table 4 is the frequent presence of the stock market liquidity variable in the regressions with small $p$-values for the $F$-statistic. Stock liquidity appears three times, for three fund groups. This finding is interesting because no previous study of funds used a liquidity instrument to condition performance, and we did not find the stock market liquidity variable to be a significant predictor of either the passive benchmark returns or the fund returns. Nevertheless, Panel B suggests that some of the more aggressive fund styles may shift their market betas in response to the state of liquidity in the stock market.

Ferson and Schadt, using data that ended in 1990, found that conditional alphas tended to make funds look better than unconditional alphas and that conditional alphas were centered around zero. This result is consistent with a market where the typical fund manager has enough ability to cover trading costs and expense ratios once the biases have been removed by conditioning on the public information about the state of the economy. A comparison of Panels A with Panels B and C of Table 4 is consistent with this result. Although none of the estimates of alpha is statistically significant, seven of the eight in Panel A are negative, while in the conditional models, about half are positive and half are negative. Thus, the conditional performance is roughly centered at zero.

The original CPE studies used multiple lagged instruments in their regressions, whereas Panel $\mathrm{B}$ of Table 4 uses only one instrument at a time. In Panel C of Table 4, we thus use multiple lagged instruments in the models, where the instruments are grouped as in Table 2 . The results tend to confirm

13It is necessary to account for the multiple comparisons in order to conduct meaningful inferences about this finding. Under the null hypothesis of no predictability in fund betas using the lagged instruments and assuming independent Bernoulli trials, the $t$-statistic for the significance of finding 13 cases is $(13 / 88-8.8 / 88) /[(0.10)(0.90) / 88]^{1 / 2}=1.5$. 
the impressions from Panel B. (The table reports only the cases where the $p$-values are less than 10 percent.) Overall, of the 24 cases, 9 of the conditional alpha point estimates are positive and 15 are negative. But in some of these cases, the additional regressors in the conditional models are not significant, and we would expect to get results similar to the unconditional model when the coefficients on the conditional terms are zero. In other words, some of these cases are essentially unconditional alphas. If we restrict our attention to the subset of cases where the $p$-value of the $F$-statistics for the conditional terms is less than 0.10 , we find 6 of the 24 cases, which is statistically significant. 14 Three of these alphas are positive, and three are negative. This finding confirms two of the main results of the earlier CPE studies: First, the conditioning variables are jointly statistically significant, and second, the conditional alphas are centered around zero.

Because our sample of funds is much broader than that in Ferson and Schadt, Table 4 shows that the general flavor of their results on conditional alphas holds in a broader sample of funds constructed to control survivorselection bias. Our list of lagged instruments is also more inclusive, which shows that the central results are robust to the choice of instruments. Finally, Table 4 shows that the main results are robust to including a decade of new data.

Performance against Style-Based Benchmarks. Given the cumulative empirical evidence against the accuracy of the CAPM in describing riskadjusted required returns, it is increasingly common to evaluate funds relative to benchmark indexes that control for the manager's investment style. This adjustment can be accomplished by using multiple risk factor indexes in place of the market portfolio of the CAPM, as in the arbitrage pricing model (APT, Ross 1976) or the Merton (1973) multifactor asset pricing model. This approach was developed for unconditional fund performance measures by Lehmann and Modest (1987) and Connor and Korajczyk (1986) and applied to style indexes by Carhart (1997). Alternatively, a single index can be constructed from a set of primitive asset class returns, with fund-style-specific weights, and the single index can replace the market return in the CAPM. We use the latter approach. The asset class returns are the passive benchmark returns described in Table 1 and whose conditional returns are studied in Table 2.

We construct style-matched benchmarks using an approach similar to Sharpe $(1988,1992)$. The problem is to combine the asset class index returns, denoted by $R_{i}$, using a set of portfolio weights, denoted by $\left(w_{i}\right)$, so as to

14 Under the null hypothesis of no predictability and assuming independent Bernoulli trials, the $t$-statistic for the significance of finding 6 of $24 p$-values less than 0.10 is $(6 / 24-0.10) /$ $[(0.10)(0.90) / 24]^{1 / 2}=2.45$. 
minimize the "tracking error" between the return of the fund or fund-style group in question, denoted by $R_{p}$, and the style-matched benchmark portfolio, denoted by $\Sigma_{i} w_{i} R_{i}$. The portfolio weights are required to sum to 1.0 and must be nonnegative, which effectively rules out short positions. 15 We formally state the problem to be solved as:

$\operatorname{Min}_{(w i)} \operatorname{var}\left(R_{p}-\Sigma_{i} w_{i} R_{i}\right)$,

subject to:

$\Sigma_{i} w_{i}=1, w_{i} \geq 0$ for all $i$,

where $\operatorname{var}(\cdot)$ denotes the variance. We solve the problem numerically for each of the fund style groups and derive a set of weights for each group.

In returns-based style analysis as conducted by Sharpe $(1988,1992)$ and others (and as reviewed recently by Dor, Jagannathan, and Meier), it is common to use the return difference, $R_{p}-\Sigma_{i} w_{i} R_{i}$, to measure performance. The average difference over an evaluation period is a measure of alpha. The variance of the difference is a measure of tracking error, or active management. But these interpretations are correct only if the style of the fund does not change over the estimation period, as emphasized by Christopherson (1995).16 Furthermore, this approach assumes that the "beta" of the fund on the style-matched benchmark is constant over time and equal to 1.0. Our approach relaxes the restriction that the beta of the fund on the style-matched benchmark is exactly 1.0. In addition, our conditional models allow the betas to vary over time with the state of the economy.

In Appendix A, Table A3 presents the style index weights for each asset class (Panel A) and summary statistics for the style-matched benchmark returns that result from applying these weights to the asset class returns (Panel B). Note that although the weights reported in the table do not sum exactly to 1.0 because of rounding errors, we carry many more digits of precision in the actual calculations. In a fair number of cases, the assigned weight is zero ( 26 out of 64 weights), which indicates that the no-short-selling constraint is binding. The largest weights are for sector funds in growth stocks (78 percent) and small-company growth funds in growth stocks (72 percent), which both make intuitive sense. Other large weights include the weight of growth and income funds on the broad equity index (67 percent) and of timing funds on the one-year government bond return (60 percent). The most concentrated weights are assigned to the sector funds, where the benchmark comprises 78 percent growth stocks and 11 percent each value stocks and

15 Dor, Jagannathan, and Meier (2003) argued that when returns-based style analysis is applied to hedge funds, the restriction against short sales may be relaxed.

16 Sharpe (1992) and Dor, Jagannathan, and Meier use a rolling, 60-month estimation period. 
long-term government debt. The most disperse set of weights is applied to the maximum capital gains funds, where the benchmark holds six of the eight asset classes and sports five weights in the 4-15 percent range.

The weights applied to the fixed-income asset classes are nontrivial. Timing funds have the highest total fixed-income weight at 82 percent ( 60 percent in government and 22 percent in corporate bonds) followed somewhat paradoxically by the maximum capital gains funds at 60 percent total fixed income. This finding could indicate a misspecification of the style analysis for maximum capital gains funds. Other cases with large fixedincome weights are income funds (37 percent), other aggressive growth funds (34 percent), growth and income funds (22 percent), and small-company growth funds ( 28 percent). These large fixed-income weights no doubt reflect the fact that mutual funds hold cash balances in reserve against investor withdrawals.

Panel B of Table A3 presents summary statistics for the returns that result when the weights in Panel A are applied to the asset class benchmark returns to construct the style-based benchmark for each fund group. The highest mean return, more than 1 percent per month, is associated with the benchmark for sector funds. This style-based benchmark also has the largest standard deviation of return, more than 5 percent per month. The high mean and high standard deviation reflect the concentration of the sector fund benchmark in growth stocks and its small fixed-income exposure. The lowest mean return and the lowest standard deviation are both associated with the timing-fund benchmark, which earned 0.8 percent per month with a standard deviation of only 1.4 percent. This result reflects the fact that 82 percent of this benchmark consists of fixed-income securities.

In Appendix A, Table A4 repeats the performance analysis of Table 4 but with the style-based benchmarks replacing the market index of the CAPM. The analysis conducted is otherwise identical to that in Table 4. Panel A of Table A4, which reports the unconditional regressions, reveals the higher precision that becomes available using style-matched benchmarks. The regression $R^{2}$ s are higher for seven of the eight fund groups, and they exceed 79 percent in each case except income funds. Using the market index of the CAPM in Table 4 , we had $R^{2}$ s as low as 58 percent. Many of the betas are significantly different from 1.0 , which supports our approach of not constraining the betas to equal 1.0. The estimated alphas, however, are similar in their overall magnitudes to what we found using the CAPM. Five of the eight are negative. This is weak evidence that the funds look better against their style benchmarks than against the market, where seven of the eight alphas were negative. Because of the greater precision using style benchmarks, we have 
smaller standard errors, and the absolute values of the $t$-statistics attached to the alphas are larger than in Table 4. Still, no $t$-statistic for the unconditional alpha of any fund group is larger than 2.0.

Panel B of Table A4 presents the regressions estimating the conditional alphas, one instrument at a time. Compared with the model using the market index, we find a larger number of cases where the $F$-test can reject the hypothesis that the lagged state variables may be excluded from the regression. Using a 10 percent significance level, we find that this null is rejected for 26 of the 88 cases examined; when using a 5 percent level, we find 17 cases. The multiple-comparisons $t$-statistics for the significance of this finding are 6.11 and 6.16 , respectively, at the two significance levels. Thus, we have strong evidence for the statistical significance of conditioning on the state variables when the style benchmarks are used.17

The lagged state variables are used here to model time variation in the style index betas. The evidence supports our approach of allowing the betas to vary over time and rejects the restriction that they are always equal to 1.0, as assumed in the traditional returns-based style analysis. This result provides evidence of a form of style drift at the fund group level. That is, funds tend to vary their sensitivity to the average style exposures depending on economic conditions. Income funds and market-timing funds seem most prone to this behavior.

The average conditional alphas remain centered near zero when measured relative to the style benchmarks. In Panel B of Table A4 are 12 positive alphas and 14 negative alphas. The only statistically significant conditional alphas are for the timing funds, where the alphas are negative and where four of the six $t$-statistics are below -2.0. Negative alphas for timing funds are to be expected, according to the analysis of Grant (1977), Jagannathan and Korajczyk, and others, as discussed later in the section on market timing.

Panel C of Table A4 summarizes the conditional model regressions when multiple instruments are used, grouped according to the states of the term structure, financial markets, and macroeconomy. Again, we report only the groups where the $p$-values are below 10 percent. The $F$-test for the exclusion of the instruments produces $p$-values this small in 14 of the 24 cases. This result implies a multiple-comparisons $t$-statistic of 7.9 , again producing strong evidence that loadings on the style benchmarks vary with the state of the economy. Interestingly, the state variables related to the macroeconomy produce the most frequent examples of changing loadings, whereas it was the term-structure state

17 These inferences are conditioned on the weights of the style-based indexes in the sense that the standard errors do not incorporate the estimation errors involved in the construction of the style-based indexes. Accounting for this additional sampling variation is likely to lower the $t$-statistics. 
variables when the market index of the CAPM was used that showed the most frequent examples of changing loadings. Of the 14 cases where the conditioning variables appear significant, the conditional alphas remain centered near zero, with six of the estimates negative and eight positive. Only two of the $t$-statistics for the alphas are larger than 2.0, which is about what should be expected when 24 cases are examined and the true alphas are zero.

Performance Conditioned on Discrete States. In the unconditional CAPM, we regress the fund excess returns on the market excess return and the intercept is Jensen's alpha. The conditional model, however, adds interaction terms to the regression. These terms are motivated, as explained earlier, by models in which a fund manager responds linearly to information. The fund's portfolio betas, in particular, are assumed to vary as a linear function of the instruments. But the assumption of linear betas is only an approximation of convenience, and funds may respond nonlinearly to information in practice. For example, the use of derivatives is likely to induce a nonlinear relationship between a fund and the market. But little direct evidence exists in the previous literature on how important beta nonlinearity is for mutual funds. If the true relationship is far from linear, the interactive regressions are likely to be biased and inefficient. If we can measure conditional performance while avoiding the linear beta assumption, we should obtain a more reliable picture of the true performance in cases where nonlinearity is important.

The model of Ferson and Schadt allows only a single conditional alpha and, therefore, only captures the overall average conditional performance. 18 This limitation may obscure conditional performance that depends on the state. For example, some funds may have positive conditional performance in high values of a state variable and negative performance conditional on low states. The returns in Table 3 suggest just such a possibility. In this case, by averaging the conditional performances together in a fixed measure, as in Ferson and Schadt, we may produce a neutral measure for the average performance. The desire to measure time-varying conditional performance motivated Christopherson, Ferson, and Glassman to generalize the Ferson and Schadt Equation 1 to Equation 4, with a time-varying conditional alpha.

This section uses the discrete dummy versions of the lagged state variables to assess performance at the level of the fund groups. We estimate Equation 4, where $\mathbf{Z}$ is the vector of dummy variables corresponding to a given state variable. The vector consists of a constant, the dummy variable indicating a high

18 The average conditional alpha differs from the unconditional alpha to the extent that the conditional beta differs from the unconditional beta and is correlated with the expected market return (see Christopherson, Ferson, and Glassman). 
value of the state variable, and the dummy indicating a low value of the state variable. Using the dummy variable instruments in Equation 4, we do not assume that betas respond with any particular functional form. The approach, in this sense, is nonparametric. We simply measure the average conditional beta and the average conditional alpha given that the economy is in one of the three states. We allow both the conditional alphas and betas to vary across the states. We do not model how betas or alphas vary over time within a state. The potential cost of this dummy-variable approach is that it will not capture time variation in alphas or betas that may occur within a regime. For example, if the economy stays in a low interest rate state for an extended period of time, we capture only the average conditional performance given the low rate state but not any time variation in conditional performance during the low interest rate regime.

Table 5 presents the conditional alphas based on the discrete state variables. The figures may be compared with those in Panel B of Table 3, which gives the conditional returns before risk adjustment. The differences between the two tables are dramatic. In Table 3, we found 19 cases where the differences in returns between high and low states produced $t$-statistics larger than 2.0. After adjustment using the conditional CAPM in Table 5, we find only two such instances (shown in bold). Only 8 of the 176 conditional alphas examined have $t$-statistics larger than 1.6; among those, five are positive and three are negative. The conditional alphas are also typically small in economic terms compared with the return differences before risk adjustment. In Table 3 , we found 41 cases where the difference in the conditional mean returns for high- and low-state variables was larger than 1 percent per month, and many were much larger. Only 5 of the 176 conditional alphas examined to construct Table 5 are larger than 1 percent in absolute magnitude, and the largest conditional alpha is 1.5 percent per month. The conditional alphas are generally small, and their distribution is centered near zero.

The results of Table 5 confirm that the conclusions from the continuous instrument specifications are robust. 19 The strong impression is that the overall conditional performance of the broad fund groups is neutral.

In Appendix A, Table A5 repeats the analysis of Table 5, replacing the market index with the fund-group-specific style benchmarks. Many of the results confirm the findings of Table 5. For example, only 9 of the 88 alphas examined in producing the table have absolute $t$-statistics larger than 2.0, and

19 Such studies as Harvey(1989), Ferson and Korajczyk (1995), and Jagannathan and Wang found that conditional versions of the CAPM explain equity portfolio returns better than the traditional model, which ignores conditioning. It remains an interesting topic for future research to explore the performance of conditional CAPMs with nonparametric dummy variables for explaining the cross-section of stock returns. 
Table 5. Alphas Conditioned on Discrete State Variables for Equally Weighted Portfolio of Mutual Funds, by Group

\begin{tabular}{|c|c|c|c|c|c|c|c|c|c|}
\hline Item & No. Obs. & Growth & $\begin{array}{c}\text { Maximum } \\
\text { Capital } \\
\text { Gains }\end{array}$ & $\begin{array}{l}\text { Other } \\
\text { Aggressive } \\
\text { Growth }\end{array}$ & Income & $\begin{array}{l}\text { Growth } \\
\text { and } \\
\text { Income }\end{array}$ & Sector & $\begin{array}{l}\text { Small- } \\
\text { Company } \\
\text { Growth }\end{array}$ & Timers \\
\hline \multicolumn{10}{|c|}{ A. Term-structure slope } \\
\hline High & 44 & 0.1963 & 0.1434 & -0.3582 & 0.1606 & 0.3259 & -0.0447 & -0.4531 & 0.3851 \\
\hline Low & 92 & -0.2053 & -0.0653 & -0.1201 & 0.0253 & -0.0538 & 0.0031 & -0.1125 & -0.2594 \\
\hline$t$-Statistic & & 1.183 & 0.3352 & -0.3176 & 0.5756 & 1.202 & -0.1489 & -0.4181 & 3.192 \\
\hline \multicolumn{10}{|c|}{ B. Term-structure concavity } \\
\hline High & 36 & 0.1261 & 0.2281 & -0.6000 & 0.1766 & 0.1566 & -0.1149 & -0.6229 & 0.2497 \\
\hline Low & 85 & -0.0517 & 0.0683 & 0.0406 & -0.1300 & -0.0166 & 0.0439 & 0.2778 & -0.1936 \\
\hline$t$-Statistic & & 0.7776 & 0.3356 & -0.9690 & 1.265 & 1.014 & -0.4008 & -1.161 & 2.657 \\
\hline
\end{tabular}

Notes: Monthly fund group returns in excess of the 90-day T-bill are regressed on a broad equity market excess return and its product with dummy variables for the state of the economy, as in Equation 2 of the text. The dummy variables are the same as in Table 2 . No. obs. is the number of observations for the growth fund sample period, which is January of 1973 through December of 2000 (336 total observations). Other fund groups may have fewer observations, as indicated in Table 3. Cases with fewer than 12 nonmissing observations are excluded and shown as $0.000 ; t$-statistic is the heteroscedasticity-consistent $t$-statistic for the difference between the high- and low-state conditional alphas. Only states producing an absolute $t$ statistic larger than 2.0 are shown. The units for alpha are percent per month.

only 3 of the conditional alphas are larger than 1 percent per month. (We only report cases where the absolute $t$-statistic is larger than 2.0.) The conditional alphas are small and centered near zero, indicating that the conditional performance is neutral.

Evaluation of the Time Variation in Risk Exposures. Tables 4 and A4 present evidence of significant time variation in funds' betas. Betas may vary within an economic regime and also across economic regimes. We now ask how important is time variation across versus within the economic regimes defined by the state variables. Using the discrete dummy versions of the state variables in Equation 4, we estimate the averages of the conditional betas across the months assigned to the high, low, and normal states. The differences in these betas show how much of the beta variation occurs across the regimes. If the differences across the regimes are small, we conclude that most of the variation through time that we documented earlier occurs within the regimes, most likely at higher frequencies than the long swings depicted by the state variable dummies in Figure 1. Such high-frequency beta variation may be induced by the relatively high-frequency flow of monies in and out of 
mutual funds. ${ }^{20}$ Beta variation across the states, in contrast, is more likely related to strategic investment choices by the funds.

Conditional betas are shown in Table 6 for the high and low values of the state variables for each fund group, along with a $t$-statistic for the significance of the difference between the high- and low-state conditional betas (with those greater than 2.0 shown in bold). Only states that produced an absolute $t$-statistic larger than 2.0 are shown. The term-structure-slope variable is where most of the action occurs. This variable is associated with significant shifts in betas for four of the seven fund groups. The betas are higher for the pure equity funds and lower for the income funds when the term-structure slope is steeper than when it is shallow. The differences are substantial. For example, the conditional market beta of small-company growth funds is 1.66 when the slope of the term structure is steep and only 1.02 when it is shallow. The income funds' betas average 0.19 given a steep term structure and 0.43 when it is flat. This finding is consistent with the view that equity funds become more aggressive in their market exposure when the term structure is steep, perhaps in anticipation of the higher expected market returns illustrated in Table 2 at such times. Although these extreme examples are intriguing, overall only a little evidence exists of shifts in the conditional betas at the fund group level in Table 6 . About 5 percent of the $t$-statistics examined in producing the table are larger than 2.0, just as would be expected if beta does not vary across the regimes.

In Appendix A, Table A6 summarizes the results of replicating Table 6 but using the style-specific benchmarks instead of the market index. The results are largely confirmatory. The timing funds seem to show the most significant tendencies to shift betas across the states, producing $t$-statistics for the hypothesis of no beta shift that exceed 2.0 in 3 of the 11 cases. Overall, however, only 9 of 88 cases present absolute $t$-statistics larger than 2.0 and no clear patterns exist in the estimates. 21

In summary, we find that although there is significant time variation in funds' market and style betas, little of this variation is associated with the discrete shifts in the economic states. It seems likely that much of the time variation in beta is related to higher-frequency behavior, perhaps associated with redemptions and new money flows. The broad implications for investors

20Spiegel, Mamaysky, and Zhang (2003) found that a Kalman filter approach to modeling monthly time variation in mutual fund betas works well, which is consistent with the importance of relatively high-frequency variation.

21 Of course, we may lose some power to detect beta variation by coarsening the states to three discrete regimes and by concentrating on one state variable at a time, compared with the multivariate analysis in Panels C of Tables 4 and A4. But the strong results in Tables 2 and 3 , which find that expected returns differ across the states, suggest that the loss of power should not be large. 
Table 6. Betas Conditioned on Discrete State Variables for Equally Weighted Portfolio of Mutual Funds, by Group

\begin{tabular}{lcccccccc}
\hline & \multicolumn{3}{c}{$\begin{array}{c}\text { Maximum } \\
\text { Capital } \\
\text { Gains }\end{array}$} & $\begin{array}{c}\text { Other } \\
\text { Aggressive } \\
\text { Growth }\end{array}$ & $\begin{array}{c}\text { Growth } \\
\text { and } \\
\text { Item }\end{array}$ & $\begin{array}{c}\text { Income } \\
\text { Income }\end{array}$ & \multicolumn{3}{c}{$\begin{array}{c}\text { Small- } \\
\text { Company }\end{array}$} \\
\hline $\begin{array}{l}\text { A. State of the term-structure variables } \\
\text { Term-structure slope }\end{array}$ & & & & & & & \\
Growth & Timers \\
High & 0.9165 & 1.099 & 1.577 & 0.1940 & 0.7018 & 1.080 & 1.658 & 0.5322 \\
Low & 0.9960 & 1.236 & 0.992 & 0.4286 & 0.8008 & 0.8159 & 1.021 & 0.5941 \\
$t$-Statistic & -1.157 & -1.082 & 2.230 & -3.829 & -1.676 & 2.449 & 2.219 & -1.293 \\
& & & & & & & & \\
Interest rate volatility & & & & & & & & \\
High & 0.9857 & 1.176 & 1.082 & 0.3675 & 0.7738 & 0.8629 & 1.066 & 0.5838 \\
Low & 0.9028 & 1.015 & 1.005 & 0.3567 & 0.7825 & 0.8809 & 1.049 & 0.5925 \\
$t$-Statistic & 2.217 & 2.131 & 0.3510 & 0.1411 & -0.2546 & -0.1630 & 0.0958 & -0.2569
\end{tabular}

B. State of the financial markets variables

Credit spread

$\begin{array}{lrcccccrr}\text { High } & 0.9274 & 1.040 & 0.9016 & 0.3217 & 0.7498 & 0.7106 & 0.882 & 0.5792 \\ \text { Low } & 0.9776 & 1.129 & 1.161 & 0.4823 & 0.7939 & 0.8858 & 1.143 & 0.6005 \\ t \text {-Statistic } & -0.8497 & -0.9571 & -1.018 & -2.414 & -0.9331 & -1.585 & -0.927 & -0.5186\end{array}$

Short-term corporate illiquidity

\begin{tabular}{lrrrrrrrr} 
High & 0.8791 & 0.958 & 1.028 & 0.3068 & 0.7422 & 0.7577 & 1.019 & 0.5591 \\
Low & 0.9653 & 1.154 & 0.9905 & 0.3364 & 0.7591 & 0.8118 & 0.946 & 0.5176 \\
$t$-Statistic & -2.428 & -2.327 & 0.1272 & -0.3198 & -0.3528 & -0.2812 & 0.228 & 0.9474 \\
\hline
\end{tabular}

Notes: Monthly fund group returns in excess of the 90-day T-bill are regressed on a broad equity market excess return and the products with dummy variables for the state of the economy. The dummy variables are the same as in Table 2. The growth fund sample period is January of 1973 through December of 2000 (336 total observations). Other fund groups may have fewer observations, as indicated in Table 3. Cases with fewer than 12 nonmissing observations are excluded and shown as 0.000 ; $t$-statistic is the heteroscedasticity-consistent $t$-statistic for the difference between the high- and low-state conditional betas. Only states producing an absolute $t$-statistic greater than 2.0 are shown.

and their advisors relate to strategic asset allocation. Some investors may wish to adjust the risk exposures of their portfolios with respect to the states of the economy. For example, an investor who is more risk averse than average about bad economic times may wish to take less risk when the current state has high volatility or when expected economic performance is poor than at other times during an economic cycle. Our results suggest that such strategies should be implemented by changing the allocation across fund categories. The funds themselves are unlikely to come with such strategic allocations built in, at least at this aggregate level. 


\section{Individual Fund Performance}

Although it may not be surprising to find little evidence of significant performance for entire groups of funds with different styles, the groups may mask significant performance at the fund level. Some funds are likely to perform well and others poorly, even in the same fund group, and the performance of individual funds is of central interest to financial advisors and investors. The next two tables explore the patterns in individual-fund performance.

In Table 7 we estimate the performance evaluation regressions for each individual fund with at least 12 months of data available. The instruments are the continuous versions of the lagged variables, grouped as in Panel C of Table 4. We summarize the results by recording the fractions of the individual-fund $t$-statistics that lie between standard critical values for a normal distribution, which is the asymptotic distribution for the $t$-statistics. The left-most column shows the fraction that would be expected under the null hypothesis of no abnormal performance if the normal distribution provides a good approximation for the $t$-statistics.

Ferson and Schadt provided an analysis similar to the column labeled "All” in Panels A and B of Table 7, where all the individual funds are pooled. Their sample was much smaller (with only 67 funds), and it used data ending in 1990. They found that the distribution of the unconditional alphas was centered slightly to the left of the distribution under the null hypothesis. We find a similar result in Table 7. The unconditional performance measures suggest a slightly negative performance distribution. Also similar to Ferson and Schadt, the overall distributions of the $t$-statistics have fatter tails than a normal distribution. That is, we find more extreme negative and more extreme positive alphas for individual funds than would be observed with a normal distribution. 22

Ferson and Schadt found that conditional models shift the distribution of individual-fund alphas toward better measured performance. We find no such evidence in Table 7. For example, 9 percent of the sample delivers $t$-statistics for unconditional alpha less than -2.36 , while only 0.5 percent is expected if the distribution is normal and centered at zero. Using conditional alphas, we find that the fractions are 8-11 percent, depending on the state variable groups, with no clear shifts in the distributions.

22The nonnormality, per se, in the distribution of the $t$-statistics is difficult to interpret. It could reflect the presence of extreme abnormal performers. Alternatively, nonnormality could reflect a sample size too small for the asymptotic distribution to be accurate. See Kosloski, Timmermann, Wermers, and White (2003) for a bootstrap analysis that addresses these issues. 
Table 7. Cross-Sectional Distribution of $t$-Statistics for Alpha

\begin{tabular}{|c|c|c|c|c|c|c|c|c|c|}
\hline Item & Null & All & Growth & $\begin{array}{c}\text { Maximum } \\
\text { Capital } \\
\text { Gains }\end{array}$ & $\begin{array}{c}\text { Other } \\
\text { Aggressive } \\
\text { Growth }\end{array}$ & Income & $\begin{array}{l}\text { Growth } \\
\text { and } \\
\text { Income }\end{array}$ & Sector & $\begin{array}{c}\text { Small- } \\
\text { Company } \\
\text { Growth }\end{array}$ \\
\hline \multicolumn{10}{|c|}{ A. Unconditional alphas } \\
\hline$t>2.36$ & 0.005 & 0.03 & 0.02 & 0.08 & 0.05 & 0.02 & 0.02 & 0.02 & 0.05 \\
\hline $2.36>t>1.96$ & 0.02 & 0.02 & 0.01 & 0.04 & 0.02 & 0.01 & 0.02 & 0.02 & 0.03 \\
\hline $1.96>t>1.65$ & 0.025 & 0.02 & 0.03 & 0.05 & 0.02 & 0.02 & 0.02 & 0.04 & 0.03 \\
\hline $1.65>t>0$ & 0.45 & 0.38 & 0.39 & 0.34 & 0.39 & 0.29 & 0.40 & 0.54 & 0.40 \\
\hline $0>t>-1.65$ & 0.45 & 0.40 & 0.40 & 0.34 & 0.41 & 0.37 & 0.41 & 0.32 & 0.42 \\
\hline$-1.65>t>-1.96$ & 0.025 & 0.03 & 0.04 & 0.05 & 0.03 & 0.03 & 0.03 & 0.01 & 0.03 \\
\hline$-1.96>t>-2.36$ & 0.02 & 0.03 & 0.03 & 0.04 & 0.02 & 0.03 & 0.03 & 0.01 & 0.02 \\
\hline$t<-2.36$ & 0.005 & 0.09 & 0.08 & 0.05 & 0.05 & 0.24 & 0.07 & 0.03 & 0.04 \\
\hline \multicolumn{10}{|c|}{ B. Alphas conditioned on term structure } \\
\hline$t>2.36$ & 0.005 & 0.03 & 0.03 & 0.09 & 0.06 & 0.02 & 0.02 & 0.03 & 0.06 \\
\hline $2.36>t>1.96$ & 0.02 & 0.02 & 0.02 & 0.04 & 0.02 & 0.01 & 0.01 & 0.03 & 0.02 \\
\hline $1.96>t>1.65$ & 0.025 & 0.02 & 0.02 & 0.05 & 0.03 & 0.01 & 0.01 & 0.04 & 0.03 \\
\hline $1.65>t>0$ & 0.45 & 0.38 & 0.39 & 0.34 & 0.48 & 0.24 & 0.33 & 0.55 & 0.50 \\
\hline $0>t>-1.65$ & 0.45 & 0.40 & 0.40 & 0.37 & 0.35 & 0.40 & 0.48 & 0.29 & 0.35 \\
\hline$-1.65>t>-1.96$ & 0.025 & 0.03 & 0.04 & 0.03 & 0.02 & 0.03 & 0.04 & 0.01 & 0.01 \\
\hline$-1.96>t>-2.36$ & 0.02 & 0.03 & 0.04 & 0.02 & 0.01 & 0.03 & 0.04 & 0.02 & 0.01 \\
\hline$t<-2.36$ & 0.005 & 0.08 & 0.07 & 0.05 & 0.02 & 0.25 & 0.06 & 0.02 & 0.01 \\
\hline \multicolumn{10}{|c|}{ C. Alphas conditioned on financial markets } \\
\hline$t>2.36$ & 0.005 & 0.03 & 0.04 & 0.07 & 0.04 & 0.02 & 0.03 & 0.05 & 0.02 \\
\hline $2.36>t>1.96$ & 0.02 & 0.01 & 0.02 & 0.05 & 0.01 & 0.00 & 0.01 & 0.01 & 0.00 \\
\hline $1.96>t>1.65$ & 0.025 & 0.02 & 0.02 & 0.05 & 0.02 & 0.01 & 0.01 & 0.03 & 0.02 \\
\hline $1.65>t>0$ & 0.45 & 0.25 & 0.27 & 0.37 & 0.29 & 0.15 & 0.26 & 0.35 & 0.29 \\
\hline $0>t>-1.65$ & 0.45 & 0.45 & 0.43 & 0.34 & 0.48 & 0.45 & 0.42 & 0.43 & 0.53 \\
\hline$-1.65>t>-1.96$ & 0.025 & 0.06 & 0.05 & 0.05 & 0.07 & 0.06 & 0.07 & 0.06 & 0.07 \\
\hline$-1.96>t>-2.36$ & 0.02 & 0.05 & 0.06 & 0.01 & 0.04 & 0.05 & 0.07 & 0.03 & 0.04 \\
\hline$t<-2.36$ & 0.005 & 0.11 & 0.10 & 0.05 & 0.04 & 0.25 & 0.14 & 0.04 & 0.02 \\
\hline \multicolumn{10}{|c|}{ D. Alphas conditioned on real economy } \\
\hline$t>2.36$ & 0.005 & 0.03 & 0.02 & 0.11 & 0.05 & 0.02 & 0.02 & 0.02 & 0.05 \\
\hline $2.36>t>1.96$ & 0.02 & 0.02 & 0.02 & 0.05 & 0.03 & 0.01 & 0.01 & 0.01 & 0.02 \\
\hline $1.96>t>1.65$ & 0.025 & 0.02 & 0.03 & 0.03 & 0.02 & 0.01 & 0.02 & 0.04 & 0.03 \\
\hline $1.65>t>0$ & 0.45 & 0.38 & 0.40 & 0.34 & 0.40 & 0.27 & 0.39 & 0.54 & 0.40 \\
\hline $0>t>-1.65$ & 0.45 & 0.41 & 0.40 & 0.35 & 0.42 & 0.39 & 0.43 & 0.33 & 0.43 \\
\hline$-1.65>t>-1.96$ & 0.025 & 0.03 & 0.04 & 0.03 & 0.02 & 0.03 & 0.03 & 0.02 & 0.02 \\
\hline$-1.96>t>-2.36$ & 0.02 & 0.03 & 0.03 & 0.04 & 0.02 & 0.03 & 0.03 & 0.01 & 0.02 \\
\hline$t<-2.36$ & 0.005 & 0.08 & 0.06 & 0.05 & 0.05 & 0.23 & 0.06 & 0.03 & 0.03 \\
\hline
\end{tabular}

Notes: The time-series Equation 1 is estimated for each fund in a style group using the continuous versions of the state variables in the conditional models. Funds with less than 12 observations are excluded. The figures are the fractions of the $t$-statistics located between standard critical values for a normal distribution. The fraction implied by a normal distribution is listed under the heading "Null." 
Ferson and Schadt were not able to provide distributions of performance for individual funds within their style groups because of their small sample. With the larger sample in this study, we can examine the conditional performance of individual funds relative to other funds with the same style, thus controlling for performance differences associated with style. Table 7 shows that for some fund groups (e.g., maximum capital gains) the conditional alpha distribution looks more favorable than the distribution of unconditional alphas. For other groups (e.g., growth), the conditional alpha distribution is less favorable than the unconditional alpha distribution. Perhaps most striking is the result for income funds, which seem to produce an outsized fraction of low alphas under all versions of the model. Thus, the patterns in individualfund performance are richer than a pooled analysis can reveal.

In Appendix A, Table $\mathbf{A 7}$ repeats the analysis of Table 7 but replaces the market index of the CAPM with the style-specific benchmarks. Therefore, the overall results are similar. The poor conditional performance of the bottom quarter or so of income funds cannot be explained by biases resulting from the use of the broad market index as the benchmark in the CAPM. In practical terms, this analysis suggests that investors and their advisors should be especially careful in their selection of individual income-style funds. Poor riskadjusted performance is easy to find, and a randomly chosen fund has about a 25 percent chance of significant negative performance.

Although the results in Table 7 control for the state of the economy through time-varying betas, those models do not allow the actual performance, measured by the alphas, to vary over time with the economic state. Table 5 looked at models where the alphas are conditioned on the discrete state variable indicators taken one at a time, applied to the equally weighted portfolios according to fund-style groups. This approach allows the alphas to vary over time across the various states. Now, we look inside the groups at the performance of individual funds, allowing the conditional alphas to shift over time with the states.

Table 8 presents an analysis of the conditional performance of the individual funds using the conditioning dummy variables one at a time. We summarize the results by comparing the individual funds with all other funds in the same style group, again controlling for the performance effects of fund style. Because of the large number of cases to summarize, we simplify the table by reporting only those instances where the distribution of the performance measures' $t$-statistics depart from the asymptotic distribution under the null hypothesis of no performance. We select those cases using a chi-square test for the hypothesis that the distributions are normal. Similar to Table 7, the performance measures are divided into eight bins and the frequency of 
funds observed in bin $i$, is $f_{i}, i=1, \ldots, 8$. The theoretical frequency under the null is $g_{i}, i=1, \ldots, 8$. The statistic $\chi^{2}=\sum_{i=1, \ldots, 8} \frac{\left(f_{i}-g_{i}\right)^{2}}{g_{i}}$ is distributed as a chisquare with seven degrees of freedom if the null hypothesis is correct (see, for example, Freund 1992, p. 487-488).

Table 8. Distribution of $t$-Statistics for Alphas in High vs. Low Economic States Using a Broad Market Benchmark

\begin{tabular}{|c|c|c|c|c|c|c|c|}
\hline \multicolumn{4}{|c|}{ Interest Rate Volatility } & \multicolumn{4}{|c|}{ Dividend Yield } \\
\hline Income & Income & SCG & Other AG & MCG & Income & G\&I & Sector \\
\hline High & Low & High & High & High & Low & High & High \\
\hline 0.07 & 0.08 & 0.01 & 0.01 & 0.26 & 0.02 & 0.24 & 0.40 \\
\hline 0.02 & 0.01 & 0.00 & 0.00 & 0.11 & 0.01 & 0.04 & 0.00 \\
\hline 0.01 & 0.02 & 0.00 & 0.01 & 0.04 & 0.02 & 0.03 & 0.00 \\
\hline 0.26 & 0.25 & 0.10 & 0.08 & 0.37 & 0.25 & 0.36 & 0.30 \\
\hline 0.36 & 0.27 & 0.40 & 0.41 & 0.20 & 0.27 & 0.29 & 0.30 \\
\hline 0.02 & 0.03 & 0.11 & 0.10 & 0.00 & 0.00 & 0.01 & 0.00 \\
\hline 0.02 & 0.04 & 0.13 & 0.12 & 0.00 & 0.04 & 0.02 & 0.00 \\
\hline 0.23 & 0.31 & 0.25 & 0.26 & 0.01 & 0.41 & 0.02 & 0.00 \\
\hline
\end{tabular}

\begin{tabular}{|c|c|c|c|c|c|c|c|}
\hline \multicolumn{2}{|c|}{$\begin{array}{l}\text { Short-Term } \\
\text { Interest Rate }\end{array}$} & Inflation & $\begin{array}{c}\text { Stock Market } \\
\text { Volatility }\end{array}$ & $\begin{array}{c}\text { Term Structure } \\
\text { Slope }\end{array}$ & \multicolumn{3}{|c|}{ Stock Market Liquidity } \\
\hline Income & Income & G\&I & Income & Income & $\mathrm{SCG}$ & Other AG & Sector \\
\hline High & Low & High & Low & High & Low & Low & Low \\
\hline 0.06 & 0.05 & 0.22 & 0.10 & 0.22 & 0.02 & 0.04 & 0.09 \\
\hline 0.02 & 0.02 & 0.09 & 0.02 & 0.05 & 0.00 & 0.01 & 0.02 \\
\hline 0.03 & 0.02 & 0.09 & 0.03 & 0.05 & 0.00 & 0.00 & 0.01 \\
\hline 0.39 & 0.32 & 0.37 & 0.31 & 0.29 & 0.07 & 0.12 & 0.22 \\
\hline 0.17 & 0.27 & 0.17 & 0.23 & 0.21 & 0.29 & 0.31 & 0.36 \\
\hline 0.03 & 0.02 & 0.01 & 0.03 & 0.02 & 0.07 & 0.06 & 0.05 \\
\hline 0.04 & 0.03 & 0.02 & 0.03 & 0.01 & 0.10 & 0.08 & 0.04 \\
\hline 0.25 & 0.26 & 0.04 & 0.25 & 0.15 & 0.46 & 0.37 & 0.22 \\
\hline
\end{tabular}

Notes: $\mathrm{MCG}=$ maximum capital gains; $\mathrm{SCG}=$ small company growth; Other $\mathrm{AG}=$ other aggressive growth; and G\&I = growth and income. Alphas and their $t$-statistics are based on the regression Equation 4 using the conditioning dummy variables one at a time. High (low) means that the value of the state variable is higher (lower) than one standard deviation from its moving average over the past 60 months. The distributions of the $t$-statistics for alpha are presented in the table for those cases where chi-square tests for departures from a normal distribution produce right-tail $p$-values of 10 percent or less. 
One interesting question that this analysis can address is whether the subset of individual funds with good or bad conditional performance generates that performance mainly in particular economic states. For example, we saw that the bottom 20-25 percent of income funds in Table 7 turned in highly significant negative alphas. Table 8 shows that their poor performance is not concentrated in particular economic regimes. Consider the states defined by the level of interest rates, for example. About 25 percent of the income funds have negative alphas with $t$-statistics larger than 2.36 when interest rates are high, and a similar fraction is found when interest rates are low.

Although the poor conditional performance of income funds cannot be attributed to any particular state of the economy, some interesting cases in Table 8 show that the extreme performance of individual funds is concentrated in particular economic states. For example, other aggressive growth funds have a concentration of poor performers when interest rate volatility is high or stock market liquidity is low, and poor performance is relatively rare in this group when interest rate volatility is low. High dividend yield states reveal a large number of individual funds with good performance among the maximum capital gains, growth and income, and sector funds, where none of these funds appears in low dividend yield states. Growth and income funds produce a large number of positive performers when inflation is high but not when inflation is low. Many small-company growth funds perform poorly when interest rate volatility is high or stock market liquidity is low. These patterns in the conditional performance of individual funds are interesting, both from a style allocation and a fund selection perspective. For style allocation, the results suggest that considering the current economic state in setting expectations for individual fund performance is useful depending on the style. For fund selection, the results indicate where poor performance is likely to be harder to avoid and where extra care in fund selection is relatively likely to pay off.

The analysis of Table 8 suggests that in several cases the abnormal measured performance of the extreme-performing individual funds in a style group is concentrated in particular economic states. In Appendix A, Table A8 replicates the analysis of Table 8 but replaces the market index benchmark of the CAPM with the fund-style-specific benchmarks. Most of the results just emphasized are robust to this change in the model. These results should be of interest to analysts attempting to pick funds in particular style groups in search of abnormal risk-adjusted returns or in an attempt to avoid poor riskadjusted performance. The results suggest that certain styles of funds deserve more scrutiny in particular economic states because the likelihood of finding extreme performers may be higher at some times than at other times. 


\section{Performance and Individual-Fund Characteristics}

In this section, we expand our fund-level analysis of performance to include the objective, fund-specific characteristics. We conduct this analysis using cross-sectional regressions, as illustrated by Equation 6:

$$
\begin{aligned}
\alpha_{i t} & =\alpha_{0 t}+\alpha_{1 t}{ }^{\prime} \mathbf{X}_{i t-1}+\varepsilon_{i t}, \\
i & =1, \ldots, N_{t} .
\end{aligned}
$$

At the end of each year, we record the vector of fund characteristics denoted by $X_{i t-1}$ for fund $i$. We use the following 36 months of data to estimate a measure of performance for each fund, denoted by $\alpha_{i t}$. We estimate the crosssectional regression each year in an attempt to predict fund performance using the lagged fund characteristics.

In each cross-sectional year, we Studentize the fund characteristics, borrowing a technique from quantitative equity models. We subtract the crosssectional mean from each characteristic and divide by the cross-sectional standard deviation. Thus, the coefficients in Equation 6 are interpreted as the percentage increment to alpha associated with a characteristic that is one standard deviation above the mean. For example, for the growth-style funds, the slope coefficient on the characteristic "gains" is about 0.2 percent per month, with a huge $t$-statistic in the regression predicting unconditional alphas. This result means that, all other things being equal, an individual growth fund that earned capital gains in the top third of all growth funds last year (one standard deviation above the mean) is expected to produce $20 \mathrm{bps}$ per month of extra alpha over the next three years.

The number of observations in a given year, $N_{t}$, is the number of funds for which we have the characteristics data at the end of year $t-1$ and for which we also have at least 24 months of return data over the next 36 months to estimate the performance measure. $23 \mathrm{We}$ aggregate the results across years using the methods of Fama and MacBeth (1973), who advocated using the average over time of the cross-sectional regression estimates of $\alpha_{1 t}$ to make inferences about the performance differences associated with the characteristics. The standard error for the average coefficient is computed as the standard error of the mean using the time series of the estimated coefficients. 24

23This selection criteria may introduce a mild survival-selection bias, which seems unavoidable. 24 Because of the overlapping nature of the data used in constructing the performance estimates, the time series of the regression coefficients inherits a moving average structure of order two, or MA(2). We adjust the standard errors of the coefficients for this effect using Hansen's (1992) consistent covariance matrix estimator. 
The standard properties of a regression model imply that the analysis using Equation 6 automatically focuses on relative fund performance because a regression slope coefficient is invariant to subtracting the sample mean from the dependent variables. We, therefore, conduct the cross-sectional analysis within fund-style groups, so the coefficients describe individual-fund performance relative to funds with the same style. In our dataset, only three fund-style groups have enough funds to conduct a reasonable cross-sectional analysis, starting with the characteristics in 1972. These are the growth funds, income funds, and growth and income funds. We focus on the growth funds and the income funds here.

One of the interesting fund characteristics is a fund's turnover. Edelen argued that decomposing the cross-section of turnover into two parts is useful. The first component, which we will call "nondiscretionary" turnover, reflects trading in response to flows of new money in or out of the fund. Edelen argued that such nondiscretionary trades may hurt fund performance. The second component is "discretionary" turnover, which reflects the trading that managers conduct not because they are forced to but because they want to. Edelen argued that these are the trades that should enhance performance when managers have skill.

Following Edelen, we use the following cross-sectional regression to decompose a fund's reported turnover each year into discretionary and nondiscretionary components:

$$
\begin{aligned}
\text { Turn }_{i t} & =d_{0 t}+d_{1 t} \text { Flow }_{i t}+v_{i t}, \\
i & =1, \ldots, N_{t},
\end{aligned}
$$

where $d_{0 t}$ and $d_{1 t}$ are the regression coefficients and $v_{i t}$ is the regression error. The fitted values of the regression for each fund in each year, given by the estimates of $d_{1 t}$ Flow $_{i t}$, measure nondiscretionary turnover; this is the portion of turnover that is explained by the cross-sectional relationship between flow and turnover that year. The intercept plus the residuals of the regression, $d_{0 t}$ $+v_{i t}$, are used as our estimate of discretionary turnover; this is the portion of turnover that is uncorrelated with fund flow in the cross-section that year.

Table 9 summarizes the results of the cross-sectional regression analysis of the individual funds. Panel A presents the results when the unconditional CAPM alpha is the measure of performance. Panel B summarizes the regressions for growth funds using the conditional CAPM alphas as the performance measures, and Panel $\mathrm{C}$ summarizes the regressions for the income funds. Panels D, E, and F repeat the analysis substituting the Sharpe style benchmarks for the broad equity index benchmark. We summarize the conditional model results by focusing on the term-structure state variables. The coefficients associated with each characteristic are shown with the Fama-MacBeth $t$-statistics on the second line. 
Table 9. Fund Style: Coefficient and $t$-Statistic for Mutual Fund Characteristic

\begin{tabular}{|c|c|c|c|c|c|c|c|c|c|}
\hline $\begin{array}{l}\text { Group or State } \\
\text { Variable }\end{array}$ & Flow & Age & $\begin{array}{l}\text { Total Net } \\
\text { Assets }\end{array}$ & Income & $\begin{array}{l}\text { Capital } \\
\text { Gains }\end{array}$ & $\begin{array}{l}\text { Discretionary } \\
\text { Turnover }\end{array}$ & Load & Expense & Lagret \\
\hline \multicolumn{10}{|c|}{ A. Performance measured using the unconditional CAPM } \\
\hline Growth & -6.03 & 0.046 & 0.473 & -0.150 & 0.213 & -0.0329 & 0.237 & 0.135 & 0.506 \\
\hline$t$-Statistic & -1.02 & 3.42 & 1.52 & -1.01 & 9.66 & -1.37 & 4.31 & 1.76 & 9.04 \\
\hline \multirow[t]{2}{*}{ Income } & 0.707 & 0.177 & 0.181 & 0.215 & 0.059 & 0.023 & 0.127 & 0.033 & -0.0724 \\
\hline & 1.06 & 0.551 & 1.04 & 1.34 & 0.753 & 1.68 & 1.97 & 0.582 & -1.86 \\
\hline \multicolumn{10}{|c|}{ B. Performance measured using conditional CAPM, growth funds } \\
\hline Short-rate level & -8.77 & 0.032 & 0.453 & -0.141 & 0.195 & -0.029 & 0.224 & 0.106 & 0.502 \\
\hline$t$-Statistic & -1.02 & 2.32 & 1.48 & -0.947 & 8.48 & -1.24 & 4.14 & 1.76 & 8.48 \\
\hline Term slope & -11.4 & 0.0405 & 0.437 & -0.175 & 0.205 & -0.0333 & 0.235 & 0.119 & 0.504 \\
\hline$t$-Statistic & -1.03 & 3.26 & 1.55 & -0.990 & 9.37 & -1.39 & 4.29 & 1.84 & 8.33 \\
\hline \multicolumn{10}{|c|}{ C. Performance measured using conditional CAPM, income funds } \\
\hline Short-rate level & 0.471 & 0.177 & 0.182 & 0.219 & 0.0565 & 0.0197 & 0.107 & 0.0364 & -0.0679 \\
\hline$t$-Statistic & 1.11 & 0.557 & 1.01 & 1.34 & 0.732 & 1.33 & 1.67 & 0.620 & -1.96 \\
\hline Term slope & 0.480 & 0.162 & 0.176 & 0.200 & 0.0574 & 0.0227 & 0.121 & 0.0375 & -0.0739 \\
\hline$t$-Statistic & 1.08 & 0.531 & 1.02 & 1.32 & 0.740 & 1.66 & 1.95 & 0.710 & -2.06 \\
\hline \multicolumn{10}{|c|}{ D. Performance measured using the unconditional style model } \\
\hline Growth & -3.64 & 0.049 & 0.462 & -0.152 & 0.214 & -0.034 & 0.241 & 0.135 & 0.511 \\
\hline$t$-Statistic & -1.01 & 3.35 & 1.50 & -1.03 & 9.74 & -1.40 & 4.54 & 1.75 & 8.62 \\
\hline Income & 0.838 & 0.166 & 0.183 & 0.207 & 0.062 & 0.023 & 0.127 & 0.031 & -0.072 \\
\hline$t$-Statistic & 1.04 & 0.529 & 1.04 & 1.28 & 0.762 & 1.71 & 1.97 & 0.558 & -1.83 \\
\hline \multicolumn{10}{|c|}{ E. Performance measured using the conditional style model, growth funds } \\
\hline Short-rate level & -1.88 & 0.033 & 0.461 & -0.109 & 0.196 & -0.029 & 0.228 & 0.106 & 0.506 \\
\hline$t$-Statistic & -0.981 & 2.31 & 1.47 & -0.966 & 8.83 & -1.14 & 4.32 & 1.70 & 8.20 \\
\hline Term slope & -10.6 & 0.044 & 0.421 & -0.181 & 0.21 & -0.034 & 0.240 & 0.116 & 0.510 \\
\hline$t$-Statistic & -1.03 & 3.23 & 1.55 & -1.03 & 9.66 & -1.39 & 4.61 & 1.77 & 8.12 \\
\hline \multicolumn{10}{|c|}{ F. Performance measured using conditional style model, income funds } \\
\hline Short-rate level & 1.01 & 0.166 & 0.183 & 0.217 & 0.060 & 0.020 & 0.113 & 0.028 & -0.070 \\
\hline$t$-Statistic & 1.05 & 0.539 & 1.01 & 1.25 & 0.740 & 1.45 & 1.67 & 0.519 & -1.98 \\
\hline Term slope & 0.034 & 0.159 & 0.181 & 0.174 & 0.062 & 0.022 & 0.125 & 0.033 & -0.075 \\
\hline$t$-Statistic & 0.793 & 0.533 & 1.04 & 1.26 & 0.767 & 1.70 & 1.97 & 0.668 & -2.04 \\
\hline
\end{tabular}

Notes: Cross-sectional regressions of abnormal performance measures on lagged fund characteristics. Characteristics are measured each year from 1972-1997, and future returns for the subsequent 36 months are used to estimate the measures of performance. The regressions are aggregated across years using the methods of Fama and MacBeth (1973), adjusting for overlapping data in the standard errors. The units of the average coefficients are percent per month. 
The regressions suggest a number of interesting patterns. In Panels A and D, older growth funds with a longer track record turn in significantly larger unconditional alphas than younger growth funds, although the magnitude of the difference, at less than $5 \mathrm{bps}$, is not large. So, a fund that is one standard deviation older than the average fund is expected to generate just less than 5 bps per month of extra alpha over the next three years. The coefficients also suggest that funds with large total net assets have higher alphas than small funds and that higher load fees are associated with higher unconditional alphas. All of these results are robust to the choice of the benchmark index.

The result for fund loads is consistent with earlier findings from Ippolito (1989), who observed that load funds offer higher average returns than no-load funds. Our regressions show that this result extends to conditional measures of performance, at least for growth funds. Among income funds, however, the predictive power of loads for individual fund alpha is diminished. The coefficient is about half the size, and the $t$-statistic is less than 2.0. Of course, some funds may substitute load fees, which are not reflected in the measured returns, for 12b-1 fees, which are taken out of the returns as part of the expense ratio. In practice, it would be important to consider the cost of the load fee in relation to the investor's horizon when using these results to guide fund selection decisions.

The strongest results for the unconditional alphas relate to the capital gains and total returns of a fund over the previous year. Both gains and lagged return (lagret) have large positive coefficients (20-50 bps per month) and $t$-statistics larger than 9.0 in the growth fund regressions, but in the income funds, neither effect is significant. This finding may be interpreted in terms of "momentum" in stock returns and funds. Jegadeesh and Titman (1993) described momentum as a cross-sectional pattern in stock returns. Stocks whose relative return was large over the last year or so also tend to have large returns over the next year or so relative to the overall market. Grinblatt, Titman, and Wermers (1995) found a similar pattern in equity fund returns. They found that growth funds, in particular, tend to hold momentum stocks. Ferson and Khang, while examining the holdings of pension funds, also found that growth-style funds tend to hold momentum stocks and that value-style funds tend to be contrarian, concentrating their holdings in those stocks that have recently performed poorly. The regressions in Table 9 are consistent with these findings. The large positive coefficients on capital gains and lagret among the growth funds indicate a momentum effect: Growth funds with relatively high returns over the past year tend to have larger unconditional alphas going forward. Income funds, in contrast, display no such momentum. This finding makes sense because income funds are more likely to hold stocks whose prices are low, relative to dividends and cash flow measures. Such a strategy is unlikely to imply momentum. 
We estimate the regressions using conditional performance measures in Panels B, C, E, and F. The findings are easy to summarize. Every effect that is significant for the growth funds using unconditional alphas is also observed using the conditional alphas. The signs of the coefficients agree in each of these cases, but the effects are reduced relative to the unconditional case: The coefficients are uniformly closer to zero, and the $t$-statistics are uniformly smaller. The effects of fund age, load fees, and the momentum effects still produce $t$-statistics larger than 2.0. For the income funds, the conditional results are also similar to the unconditional results, and the only case where an absolute $t$-statistic is larger than 2.0 is lagret, where the coefficient is negative. The effects of fund flows, discretionary turnover, and expense ratios are all insignificant.

\section{Market Timing}

A classical market-timing model follows from Treynor and Mazuy (1966):

$$
r_{p, t+1}=a_{p}+b_{p} r_{m, t+1}+\Lambda_{p} r_{m, t+1}{ }^{2}+w_{t+1},
$$

where $a_{p}, b_{p}$, and $\Lambda_{p}$ are the regression coefficients and $w_{t+1}$ is the regression error. Treynor and Mazuy argued that $\Lambda_{p}>0$ indicates market-timing ability. The logic is that a market-timing manager will generate a return that bears a convex relationship to the market: When the market is up, the fund will be up by a disproportionate amount. When the market is down, the fund will be down by a lesser amount. But a convex relationship may arise for a number of other reasons, one of which is common time variation in the fund's beta risk and the expected market risk premium resulting from public information on the state of the economy. Ferson and Schadt proposed a refinement of the TreynorMazuy model to handle this situation:

$$
r_{p t+1}=a_{p}+b_{p} r_{m, t+1}+C_{p}{ }^{\prime}\left(\mathbf{Z}_{\mathbf{t}} r_{m, t+1}\right)+\Lambda_{p} r_{m, t+1}{ }^{2}+w_{t+1} .
$$

In Equation 9, the term $C_{p}{ }^{\prime}\left(\mathbf{Z}_{t} r_{m, t+1}\right)$ controls for common time variation in the market risk premium and the fund's beta, just like it did in Equation 1.25

In theoretical market-timing models (see Admati, Bhattacharya, Pfleiderer, and Ross 1986, or Becker, Myers, and Schill), the timing coefficient is shown to depend on both the precision of the manager's market-timing signal and the manager's risk aversion. Precision probably varies over time

\footnotetext{
25 Ferson and Schadt also derived a conditional version of the market-timing model of Merton and Henriksson (1981), which views successful market timing as analogous to producing cheap call options. This model is considerably more complex than the conditional Treynor-Mazuy model, and they found that it produced very similar results. We, therefore, do not study conditional Merton-Henriksson models in this monograph.
} 
because fund managers are likely to receive information of varying uncertainty about economic conditions at different times. Risk aversion may also vary over time, according to arguments describing mutual fund "tournaments" for new money flows (e.g., Brown, Harlow, and Starks 1996), which may induce managers to take more risks when their performance is lagging and to be more conservative when they want to "lock in" favorable recent performance. Therefore, it seems likely that the timing coefficient that measures the convexity of a fund's conditional relationship to the market is likely to vary over time. We take account of such effects by allowing the timing coefficient to vary over time as a function of the state of the economy. We replace the fixed timing coefficient in Equation 9 with $\Lambda_{p}=\Lambda_{0 p}+\Lambda_{1 p}{ }^{\prime} Z_{\mathbf{t}}$. Substituting this equivalence into Equation 9, we derive a new conditional timing model with time-varying performance:

$$
r_{p t+1}=a_{p}+b_{p} r_{m, t+1}+C_{p}{ }^{\prime}\left(\mathbf{Z}_{\mathbf{t}} r_{m, t+1}\right)+\Lambda_{0 p} r_{m, t+1}{ }^{2}+\Lambda_{1 p}{ }^{\prime}\left(\mathbf{Z}_{\mathbf{t}} r_{m, t+1}{ }^{2}\right)+w_{t+1} .
$$

In this model, the new interaction term $\left(\mathbf{Z}_{\mathbf{t}} r_{m, t+1}{ }^{2}\right)$ captures the variability in the managers' timing ability, if any, over the states of the economy. By examining the significance of the coefficients in $\Lambda_{1 p}$, we test the null hypothesis that the timing ability is fixed against the alternative hypothesis that timing ability varies with the economic state.

A special case of the model of Equation 10 occurs when we use the dummy variable versions of the lagged state variables. In this version of the model, we estimate the average conditional timing coefficient given high, low, and normal values of the state variable. The trade-offs here are similar to what we faced in the estimation of conditional alphas. With the dummy variables, we avoid the functional form assumptions, and so the results are robust to misspecification of the functional forms of time-varying betas or conditional timing coefficients, but we capture variation through time only in the aspects of the model that occur across the regimes defined by the state variables.

Lehmann and Modest, Grinblatt and Titman (1988), Cumby and Glen (1990), Ferson and Schadt, and others estimated Treynor-Mazuy regressions and found a tendency for negative estimates of $\Lambda_{p}$ for equity mutual funds in Equation 8. Ferson and Schadt found that this result is spurious in that negative $\Lambda_{p}$ is also found for a buy-and-hold strategy, while negative $\Lambda_{p}$ 's are not commonly found in the conditional model of Equation 9. These studies used broad samples of U.S. equity funds and did not focus in on those funds most likely to engage in timing behavior. Becker, Myers, and Schill, however, found similar results using a different model in a broad sample of funds, and they found less of a tendency for negative timing coefficients in a subsample focused on market-timing-style mutual funds. 26

26 They used balanced and asset allocator style funds, as we do here, but their data from Morningstar suffered from survivor-selection bias. 
Table 10 summarizes the results of estimating the market-timing models, Equations 8 and 9, on our sample of market-timing funds for the 1973-2000 period. We concentrate on the estimates of the timing coefficients and on the marginal explanatory power of the lagged state variables in the conditional models. The state variables are measured in their continuous forms and grouped according to the states of the term structure, financial market, and macroeconomy. The alphas in these models are difficult to interpret as a measure of abnormal return because the timing term is a squared market return instead of the excess return on an asset. The expected value of the squared term, multiplied by the timing coefficient, is essentially deducted from the alpha, and this expected value has no clean interpretation as a return premium. Although it is possible to modify the timing term in order to interpret the modified alpha as a timing-adjusted excess return (e.g., Glosten and Jagannathan 1994), such modifications rely on highly stylized assumptions. The magnitudes of the timing coefficients in Table 10 suggest that such an exercise would offer few new insights, so we avoid the extra complexity here. 27

The first panel of Table 10 presents the unconditional timing coefficients, $\gamma_{u}$; their $t$-statistics, $t\left(\gamma_{u}\right)$; and the $R^{2} \mathrm{~s}$ summarizing the explanatory power of the unconditional timing of Equation 8. The next three panels present similar information for the conditional models [with $\gamma_{u}$ the unconditional model timing coefficient and $t\left(\gamma_{u}\right)$ its heteroscedasticity consistent $t$-statistic] along with $p$-values for the $F$-test of the significance of the lagged state variables. Panel $B$ uses the continuous versions of the state variables related to the term structure, Panel C uses the continuous financial market state variables, and Panel D uses the state variables for the macroeconomy. Each row of the table summarizes a particular characteristics-based fund portfolio. To save space, we only show those cases where a $t$-statistic for a timing coefficient is larger than 2.0 or the $p$-value for the additional conditioning variables is less than 10 percent.

27 The largest timing coefficients in Table 10 are about 0.3 . Multiplied by the average squared excess return on the market index, the effect of the timing term is no larger than $(0.0105-$ $0.00606)^{2} \times 0.3=0.0006$ percent. Thus, the intercepts in the timing models are very similar to the alphas in the corresponding models that do not include the squared market term, which were studied earlier. In order to adjust the intercepts to compute a timing-adjusted alpha, it is necessary to multiply the timing coefficient by the expected excess return on a strategy that buys call options on the market portfolio with strike prices indexed to the Treasury rate. Because call options are much riskier than the market index, the expected risk premiums attached to the options should be much larger than the squared market return, and the timingadjusted alphas could be very different from the intercepts in our regressions. 


\section{Table 10. Conditional and Unconditional Market-Timing Models}

\begin{tabular}{|c|c|c|c|c|}
\hline Fund Characteristics & $\gamma_{u}$ & $t\left(\gamma_{u}\right)$ & $R^{2} 0$ & \\
\hline \multicolumn{5}{|l|}{ A. Unconditional models } \\
\hline High age & 0.2545 & 2.744 & 0.9054 & \\
\hline High total net assets & 0.3383 & 3.730 & 0.8851 & \\
\hline Low capital gains & 0.4658 & 2.102 & 0.8176 & \\
\hline \multirow[t]{2}{*}{ Low expense } & 0.2299 & 2.697 & 0.8992 & \\
\hline & $\gamma_{c}$ & $t\left(\gamma_{c}\right)$ & $R^{21}$ & $p$-Value \\
\hline \multicolumn{5}{|c|}{ B. Conditioning on term-structure state variables } \\
\hline High flow & 0.2407 & 1.888 & 0.8525 & 0.0610 \\
\hline Medium flow & 0.2007 & 2.197 & 0.8838 & 0.2119 \\
\hline High age & 0.2629 & 3.187 & 0.9063 & 0.6882 \\
\hline High total net assets & 0.3541 & 3.999 & 0.8859 & 0.8370 \\
\hline High income & 0.2423 & 2.551 & 0.8518 & 0.1833 \\
\hline Medium capital gains & -0.06412 & -0.4409 & 0.8539 & 0.0528 \\
\hline Low capital gains & 0.5242 & 3.261 & 0.8241 & 0.0412 \\
\hline Low turnover & 0.3267 & 2.053 & 0.8748 & 0.0715 \\
\hline Medium load & 0.1941 & 1.763 & 0.8586 & 0.0408 \\
\hline Medium expense & 0.1823 & 1.702 & 0.8541 & 0.0374 \\
\hline Low expense & 0.2487 & 3.176 & 0.9004 & 0.5601 \\
\hline Medium lagret & 0.2842 & 2.210 & 0.8774 & 0.2155 \\
\hline \multicolumn{5}{|c|}{ C. Conditioning on financial market state variables } \\
\hline High flow & 0.1271 & 0.8113 & 0.8540 & 0.03306 \\
\hline Medium flow & 0.1198 & 1.158 & 0.8881 & 0.00514 \\
\hline Low flow & -0.05503 & -0.3742 & 0.8972 & 0.00446 \\
\hline High age & 0.1964 & 2.126 & 0.9090 & 0.05495 \\
\hline Medium age & -0.08550 & -0.6139 & 0.8641 & 0.01069 \\
\hline Low age & -0.05436 & -0.4814 & 0.8349 & 0.2120 \\
\hline High total net assets & 0.2158 & 2.248 & 0.8908 & 0.01388 \\
\hline Medium total net assets & -0.01504 & -0.1193 & 0.8582 & 0.07998 \\
\hline High income & 0.1341 & 1.020 & 0.8564 & 0.00878 \\
\hline Medium income & 0.01187 & 0.1137 & 0.8871 & 0.04133 \\
\hline High capital gains & -0.1691 & -1.284 & 0.9085 & 0.01484 \\
\hline Low capital gains & 0.4060 & 1.805 & 0.8291 & 0.00256 \\
\hline High turnover & -0.08277 & -0.6799 & 0.9020 & 0.02596 \\
\hline Medium turnover & 0.07848 & 0.6958 & 0.8691 & 0.00374 \\
\hline Low turnover & 0.3191 & 2.041 & 0.8774 & 0.01098 \\
\hline Medium load & 0.09496 & 0.7392 & 0.8619 & 0.00462 \\
\hline Low load & -0.09841 & -0.9495 & 0.9096 & 0.1150 \\
\hline Medium expense & 0.1130 & 0.8715 & 0.8550 & 0.03227 \\
\hline Low expense & 0.1105 & 1.323 & 0.9037 & 0.02641 \\
\hline Medium lagret & 0.1065 & 0.9001 & 0.8819 & 0.00489 \\
\hline
\end{tabular}


Table 10. Conditional and Unconditional Market-Timing Models (continued)

\begin{tabular}{lcccc}
\hline Fund Characteristics & $\gamma_{c}$ & $t\left(\gamma_{c}\right)$ & $R^{2}$ & $p$-Value \\
\hline D. Conditioning on macroeconomy state variables & & & \\
High flow & 0.1809 & 1.447 & 0.8512 & 0.04788 \\
Low flow & 0.05693 & 0.3770 & 0.8965 & 0.00068 \\
High age & 0.2421 & $\mathbf{2 . 7 6 9}$ & 0.9061 & 0.5051 \\
Medium age & 0.00622 & 0.0456 & 0.8602 & 0.04548 \\
High total net assets & 0.3353 & $\mathbf{3 . 5 6 9}$ & 0.8857 & 0.6458 \\
Low capital gains & 0.4637 & $\mathbf{2 . 0 2 9}$ & 0.8210 & 0.1043 \\
High turnover & 0.07905 & 0.6321 & 0.9001 & 0.0342 \\
Low expense & 0.2255 & $\mathbf{2 . 6 8 8}$ & 0.9003 & 0.3332 \\
High lagret & -0.05452 & -0.3298 & 0.8963 & 0.0367 \\
Medium lagret & 0.2342 & $\mathbf{2 . 3 7 8}$ & 0.8802 & 0.0024 \\
\hline
\end{tabular}

Notes: Monthly returns in excess of the 90-day T-bill return for market-timing funds grouped by characteristics are regressed on a broad equity market excess return, its square, and its products with lagged state variables, with the state variables grouped as in the previous tables. The fund sample period is January 1973 through December 2000 (336 total observations). $R^{2} 0$ is the regression $R^{2}$ for the unconditional model, and $R^{2} 1$ is the conditional model $R^{2} ; p$-value is the right-tail $p$-value of the $F$-test for the null hypothesis that the conditional model's variables may be excluded from the regression.

From the $p$-values of the $F$-tests, we can draw inferences about the significance of the lagged state variables in the conditional models. The state variables in these models capture variation over time in the funds' market betas that is correlated with the lagged public information. The number of cases, out of 28 possible, where the right-tail $p$-values are less than 5 percent are 3,16 , and 6 , respectively, in the three panels. Except for Panel B, small $p$-values are found more than would be expected under the null hypothesis that the state variables may be excluded from the model. The multiplecomparisons $t$-statistics for the three panels are $1.39,12.66$, and 3.98 , respectively. 28 We thus find particularly strong evidence of time-varying betas for the market-timing funds in response to the public information represented by the financial market state variables.

Ferson and Schadt as well as Becker, Myers, and Schill found that conditional timing models made funds look better than unconditional models. Table 10 provides mixed evidence on this score. In Panel B, which conditions on the term-structure state variables, the point estimates of the timing coefficients appear to confirm their result for our sample. Remarkably, in all 28 cases examined, the conditional timing coefficient is larger than the unconditional coefficient. But in Panels $\mathrm{C}$ and $\mathrm{D}$, we do not find the same result, and the

28 The calculations are as follows: Let $x$ be the number of cases where the $p$-value is less than 0.05 . The multiple-comparisons $t$-statistic across the 28 cases in each panel is $(x / 28-0.05) /$ $(0.05 \times 0.95 / 28)^{1 / 2}$. 
differences actually go the other way in all but four or five cases we examined in constructing the table. The most important instruments that were used in the studies of Ferson and Schadt and Becker, Myers, and Schill are related to interest rates, which could reconcile our results with those of the earlier studies.

The $t$-statistics attached to the timing coefficients allow us to address the question of whether the timing funds have significant market-timing ability. For the unconditional timing models, 4 of the 28 fund groupings produce $t$ statistics larger than 2.0 (shown in bold). On a multiple-comparisons basis, that result implies a $t$-statistic of 2.25 , more than would be expected if there is no ability. Only 5 of the 28 unconditional coefficients are negative, which is consistent with the results of Becker, Myers, and Schill that negative unconditional timing coefficients are less likely to occur when the sample concentrates on likely market timers. Moving to the conditional timing models, we find 8,3 , and 5 examples in the three panels, respectively, where the $t$-statistics are larger than 2.0 in absolute value, and all of these are positive. The multiplecomparisons $t$-statistics for finding this many large $t$-statistics out of 28 are $5.72,1.39$, and 3.12 , respectively. So, evidence exists that some of the markettiming funds may have positive conditional timing ability.

Comparing the timing coefficients across the fund groups with high, medium, and low values of the various characteristics provides further insights into which types of timing funds are more likely to be successful. There are several striking results. The strongest results relate to age and fund size as measured by the total net assets (TNA). Older funds tend to be better timers than medium-aged or young funds. Funds with high TNA at the end of the previous year have larger timing coefficients than smaller funds. Funds with the lowest expense ratios have the largest timing coefficients. Mediumexpense-ratio funds do not time as well as low-expense-ratio funds, and highexpense-ratio funds have the smallest timing coefficients. Interestingly, there is some evidence, albeit weaker, that high-load funds may have better markettiming ability. This finding is consistent with the use of load fees as a screening device to penalize investors who trade frequently, which can make it more difficult for the fund to effectively implement its own active trading strategy. Finally, when the previous year's capital gains distribution is small, it predicts better timing performance over the next year.

We checked these findings by ungrouping the lagged state variables, using them one at a time, and confirm that the best conditional timers had the longest track records, the largest TNA, the lowest expense ratios, and the smallest capital gains. We also ran the analysis of Table 10 substituting the style-related benchmarks for the market index. In this case, we picked a style benchmark at random for each fund-characteristic group. The main findings are also robust to this experiment. 
In Table 11, we summarize the results for the market-timing model of Equation 10 using the discrete dummy versions of the lagged state variables. In this model, we allow timing ability to vary across the states, and as described earlier, we avoid the assumptions that conditional betas are linear functions and that the timing coefficients have any particular functional form. We estimate the average conditional timing coefficient given high, low, and normal values of the state variable; the table summarizes results for the high and low states using the state variables one at a time. We report the timing coefficients in the high and low states, $t$-statistics for the hypothesis that a coefficient differs from zero, and a $t$-statistic that examines the hypothesis that the timing coefficients are equal in the high and low states for a given group of funds. Each row of the table summarizes a particular characteristic-based fund portfolio. To conserve space, only cases where an absolute $t$-statistic is larger than 2.0 are reported.

Much of the evidence of Table 11 remains consistent with neutral conditional timing performance. The fraction of absolute $t$-statistics larger than 2.0 is not significant (given the number of cases examined) when we condition on the level of interest rates, interest rate or stock market volatility, credit spread, or macroeconomy state variables. In some instances, however, we find significant evidence of conditional timing in certain states.

The most striking example of time-varying timing ability is related to the slope of the term structure. In 23 cases out of the 56 examined, the absolute $t$-statistic for the timing coefficient is larger than 2.0 (shown in bold). This result corresponds to a multiple-comparisons $t$-statistic of more than 40.0. Furthermore, all the significant cases occur conditional on a high termstructure slope, and all these coefficients are positive. Thus, we have striking evidence that market-timing funds can deliver significant conditional timing performance when the term-structure slope is steep. In contrast, when the slope is shallow, none of the conditional timing coefficients are significant and about one-quarter of the point estimates are negative. The $t$-statistics testing the hypothesis that the two conditional timing coefficients are equal strongly rejects the hypothesis, with 19 out of $28 t$-statistics examined larger than 2.0 (again shown in bold). The timing funds seem unable to deliver reliable market-timing services when the slope of the term structure is flat. The results conditioning on term-structure concavity are similar, with significant timing performance when the term structure is highly concave. This finding probably reflects, in large part, the high correlation between these two states: When the term structure is steep, the yield curve tends to present more concavity. 
Table 11. Conditional Market-Timing Models with Time-Varying Ability

\begin{tabular}{|c|c|c|c|c|c|}
\hline Funds & $\gamma_{h i}$ & $t\left(\gamma_{h i}\right)$ & $\gamma_{l o}$ & $t\left(\gamma_{l o}\right)$ & $t\left(H_{0}: \gamma_{h i}=\gamma_{l o}\right)$ \\
\hline \multicolumn{6}{|l|}{ A. Short-term rates } \\
\hline Low flow & -0.1676 & -0.4355 & 0.4686 & 2.237 & -1.528 \\
\hline High capital gains & -0.2143 & -0.6171 & 0.4650 & 2.041 & -1.710 \\
\hline \multicolumn{6}{|l|}{ B. Term-structure slope } \\
\hline All & 1.182 & 3.832 & 0.0329 & 0.1143 & 2.729 \\
\hline High flow & 1.695 & 3.233 & 0.3195 & 0.8638 & 2.186 \\
\hline Med flow & 1.582 & 4.167 & 0.2148 & 0.7416 & 2.854 \\
\hline Low flow & 0.7967 & 1.959 & -0.3117 & -0.8497 & 2.056 \\
\hline High age & 1.340 & 3.815 & 0.3004 & 1.164 & 2.449 \\
\hline Med age & 1.487 & 3.832 & -0.2754 & -0.6574 & 3.086 \\
\hline High total net assets & 1.785 & 5.425 & 0.3204 & 1.301 & 3.604 \\
\hline Med total net assets & 1.207 & 3.116 & -0.0329 & -0.093 & 2.383 \\
\hline Low total net assets & 0.7717 & 3.068 & 0.0917 & 0.242 & 1.534 \\
\hline High income & 1.522 & 3.929 & 0.1868 & 0.6728 & 2.858 \\
\hline Med income & 1.201 & 3.713 & 0.1305 & 0.4120 & 2.413 \\
\hline High capital gains & 0.9923 & 2.062 & 0.05035 & 0.1589 & 1.640 \\
\hline Low capital gains & 2.109 & 4.062 & 0.2036 & 0.6895 & 3.216 \\
\hline High turnover & 1.281 & 3.570 & -0.1162 & -0.3872 & 2.963 \\
\hline Med turnover & 0.8490 & 2.622 & 0.3057 & 0.9710 & 1.216 \\
\hline Low turnover & 1.861 & 4.012 & 0.2168 & 0.6450 & 2.910 \\
\hline High load & 1.259 & 2.730 & 0.3735 & 1.053 & 1.532 \\
\hline Med load & 1.467 & 3.724 & 0.04086 & 0.1193 & 2.765 \\
\hline Low load & 0.7728 & 2.761 & -0.1253 & -0.4308 & 2.238 \\
\hline High expense & 0.8288 & 2.667 & 0.2276 & 0.6061 & 1.250 \\
\hline Med expense & 1.356 & 3.540 & 0.01819 & 0.04606 & 2.457 \\
\hline Low expense & 1.341 & 4.125 & 0.03097 & 0.1319 & 3.278 \\
\hline Med lagret & 1.633 & 5.009 & 0.1360 & 0.4291 & 3.403 \\
\hline Low lagret & 2.384 & 2.894 & 0.02229 & 0.04121 & 2.369 \\
\hline \multicolumn{6}{|c|}{ C. Term-structure concavity } \\
\hline All & 0.6625 & 1.823 & -0.2599 & -1.214 & 2.230 \\
\hline High flow & 1.038 & 1.840 & -0.3444 & -1.221 & 2.225 \\
\hline Med flow & 0.9374 & 2.248 & -0.3735 & -1.538 & 2.766 \\
\hline Low flow & 0.4214 & 1.352 & -0.3056 & -1.175 & 1.836 \\
\hline High age & 0.8543 & 2.450 & -0.2219 & -1.123 & 2.733 \\
\hline High total net assets & 1.103 & 2.590 & -0.1790 & -1.030 & 2.839 \\
\hline Med total net assets & 0.6338 & 1.625 & -0.4484 & -2.004 & 2.452 \\
\hline Low total net assets & 0.2272 & 0.608 & -0.3343 & -1.327 & 1.268 \\
\hline High income & 0.9737 & 1.866 & -0.3633 & -1.641 & 2.381 \\
\hline Med income & 0.6060 & 1.982 & -0.2736 & -1.427 & 2.505 \\
\hline Low capital gains & 1.400 & 2.119 & -0.6939 & -2.880 & 3.009 \\
\hline
\end{tabular}


Table 11. Conditional Market-Timing Models with Time-Varying Ability (continued)

\begin{tabular}{|c|c|c|c|c|c|}
\hline Funds & $\gamma_{h i}$ & $t\left(\gamma_{h i}\right)$ & $\gamma_{l o}$ & $t\left(\gamma_{l o}\right)$ & $t\left(H_{0}: \gamma_{h i}=\gamma_{l o}\right)$ \\
\hline Low turnover & 1.088 & 2.471 & -0.2425 & -1.021 & 2.684 \\
\hline Med load & 0.7075 & 1.212 & -0.5114 & -2.195 & 1.961 \\
\hline Low load & 0.5145 & 1.869 & -0.3875 & -1.664 & 2.603 \\
\hline Med expense & 0.7377 & 1.739 & -0.5246 & -1.950 & 2.552 \\
\hline Low expense & 0.7699 & 2.076 & -0.106 & -0.8321 & 2.276 \\
\hline Med lagret & 1.019 & 2.008 & -0.3456 & -1.772 & 2.536 \\
\hline Low lagret & 1.553 & 4.269 & -0.9025 & -2.383 & 4.984 \\
\hline \multicolumn{6}{|l|}{ D. Interest rate volatility } \\
\hline Low flow & -0.4944 & -1.623 & 0.7279 & 2.571 & -3.062 \\
\hline Med age & -0.8208 & -1.902 & 0.3038 & 0.820 & -2.054 \\
\hline Low income & -0.8510 & -2.165 & 0.4999 & 1.147 & -2.397 \\
\hline High capital gains & -0.4584 & -1.590 & 0.5799 & 1.688 & -2.388 \\
\hline High turnover & -0.4260 & -1.478 & 0.6181 & 1.735 & -2.350 \\
\hline Low load & -0.6713 & -2.081 & 0.4837 & 1.519 & -2.628 \\
\hline High expense & -0.6715 & -1.358 & 0.6229 & 1.562 & -2.102 \\
\hline Low lagret & -1.205 & -1.713 & 0.9673 & 1.711 & -2.498 \\
\hline \multicolumn{6}{|l|}{ E. Credit spread } \\
\hline Low turnover & 0.9018 & 2.185 & 0.8291 & 1.398 & 0.1036 \\
\hline \multicolumn{6}{|l|}{ F. Dividend yield } \\
\hline High flow & 0.5224 & 1.105 & 0.2866 & 2.070 & 0.4894 \\
\hline Med flow & 0.2591 & 1.550 & 0.2807 & 2.911 & -0.1176 \\
\hline High age & 0.3351 & 1.490 & 0.2939 & 3.238 & 0.1749 \\
\hline High total net assets & 0.4190 & 2.001 & 0.3041 & 3.002 & 0.5038 \\
\hline High income & 0.4916 & 1.885 & 0.3017 & 2.421 & 0.6745 \\
\hline Low capital gains & 0.1839 & 0.9878 & 0.6764 & 2.967 & -1.732 \\
\hline Low turnover & 0.4682 & 1.014 & 0.5137 & 3.263 & -0.096 \\
\hline Med load & 0.3231 & 1.191 & 0.2308 & 2.176 & 0.3245 \\
\hline Low expense & 0.3446 & 1.756 & 0.1738 & 2.138 & 0.8171 \\
\hline \multicolumn{6}{|c|}{ G. Short-term corporate illiquidity } \\
\hline High total net assets & 0.2845 & 2.850 & 0.9434 & 2.080 & -1.425 \\
\hline Med income & -0.1544 & -1.753 & 0.8574 & 2.116 & -2.447 \\
\hline High capital gains & -0.2442 & -2.333 & 0.8889 & 2.422 & -2.996 \\
\hline Med capital gains & -0.4287 & -3.406 & 0.2807 & 0.441 & -1.094 \\
\hline Low capital gains & 0.6123 & 3.157 & 0.5893 & 1.233 & 0.045 \\
\hline High expense & -0.2380 & -2.364 & 0.5407 & 1.603 & -2.225 \\
\hline Low lagret & -0.05288 & -0.2501 & 1.242 & 2.325 & -2.241 \\
\hline
\end{tabular}


Table 11. Conditional Market-Timing Models with Time-Varying Ability (continued)

\begin{tabular}{lccccc}
\hline Funds & $\gamma_{h i}$ & $t\left(\gamma_{h i}\right)$ & $\gamma_{l o}$ & $t\left(\gamma_{l o}\right)$ & $t\left(H_{0}: \gamma_{h i}=\gamma_{l_{o}}\right)$ \\
\hline H. Stock market liquidity & & & & & \\
All & 1.791 & $\mathbf{2 . 1 1 2}$ & 0.2677 & 1.176 & 1.748 \\
High flow & 1.992 & $\mathbf{3 . 3 3 6}$ & -0.0043 & -0.015 & $\mathbf{3 . 0 5 2}$ \\
High age & 1.198 & $\mathbf{2 . 3 0 3}$ & 0.2636 & 1.101 & 1.652 \\
High total net assets & 1.864 & $\mathbf{2 . 3 1 7}$ & 0.1351 & 0.6481 & $\mathbf{2 . 0 9 6}$ \\
Med total net assets & 1.369 & $\mathbf{2 . 0 4 7}$ & 0.2105 & 0.5538 & 1.554 \\
High income & 1.458 & $\mathbf{2 . 2 9 7}$ & 0.1586 & 0.4708 & 1.851 \\
Low capital gains & 2.858 & $\mathbf{3 . 5 5 8}$ & 0.0456 & 0.1443 & $\mathbf{3 . 3 1 5}$ \\
Med turnover & 1.551 & $\mathbf{2 . 1 3 3}$ & 0.2228 & 0.7958 & 1.733 \\
Low turnover & 1.757 & $\mathbf{2 . 1 8 5}$ & 0.1960 & 0.5698 & 1.819 \\
Med load & 2.148 & $\mathbf{2 . 6 4 0}$ & 0.2211 & 0.6047 & $\mathbf{2 . 2 0 7}$ \\
Med expense & 1.584 & $\mathbf{2 . 3 5 5}$ & 0.1868 & 0.5280 & 1.886 \\
Med lagret & 1.581 & $\mathbf{2 . 4 3 6}$ & 0.4784 & 1.020 & 1.427 \\
Low lagret & 1.425 & 1.143 & 0.0821 & 0.2556 & 1.053 \\
& & & & & \\
I. Inflation & & & & & \\
High total net assets & 0.5861 & $\mathbf{2 . 2 7 0}$ & -0.0052 & -0.0111 & 1.113 \\
J. Industrial output growth & & & & & \\
Low flow & 0.5323 & 1.112 & -0.6697 & $\mathbf{- 2 . 7 1 8}$ & $\mathbf{2 . 3 3 5}$ \\
High turnover & 0.4275 & 0.6989 & -0.6105 & $\mathbf{- 2 . 1 1 7}$ & 1.578 \\
\hline Notes: Mothly retur & & & &
\end{tabular}

Notes: Monthly returns for groups of market-timing funds in excess of the 90-day T-bill return are regressed on a broad equity market excess return, its square, its products with lagged state variables, and the products of the state variables with the squared excess return. The state variables are the dummy variables for high and low economic states. The fund sample period is January 1973 through December 2000 (336 total observations); $\gamma_{h i}$ is the estimated timing coefficient given a high state, and $t\left(\gamma_{h i}\right)$ is its heteroscedasticity consistent $t$-statistic; $\gamma_{l_{o}}$ is the conditional timing coefficient given a low state, and $t\left(\gamma_{l o}\right)$ is its $t$-statistic. The right-hand column presents $t$-statistic testing the hypothesis that the timing coefficients are equal in the high and low states.

We find evidence of time-varying conditional timing ability associated with three other state variables relating to the state of the financial markets: dividend yield, short-term corporate illiquidity, and stock market liquidity. In the case of dividend yield, positive timing ability is found conditional on high yield states. We find 10 cases with absolute $t$-statistics larger than 2.0 in these states, which out of the 56 cases examined implies a multiple-comparisons $t$-statistic of 14.3. For stock market liquidity, we find 12 absolute $t$-statistics larger than 2.0, which implies a multiple-comparisons $t$-statistic of 18.3. All these coefficients are associated with high-liquidity states, and all are positive. In low-liquidity states, we find no $t$-statistics larger than 2.0 on the timing coefficients, and 6 of the 28 coefficients examined are less than zero. It makes 
sense that successful market timing should be more likely when the stock market is highly liquid because market-timing trades may be made at lower cost in highly liquid markets. Finally, we find some time variation in timing ability associated with the states of short-term corporate illiquidity. In 9 of 56 absolute $t$-statistics we examined, the results are larger than 2.0 (multiplecomparisons $t$-statistic equals 12.3). Among those coefficients with $t$-statistics larger than 2.0, we find mostly negative coefficients when illiquidity is high and positive coefficients when the markets are more liquid. Thus, the effects of liquidity in the stock and corporate debt markets seem to operate in a similar fashion.

Finally, the results of Table 11 confirm our earlier findings about which types of funds are likely to be the most effective market timers. The model with time-varying timing ability almost always assigns the largest conditional timing coefficients to the funds with the longest track records, the largest total net assets, the lowest expense ratios, or the highest load charges.

\section{Implications for Practicing Financial Analysts}

Conditional performance evaluation (CPE) is potentially important for several areas of investment management (as well as academic research). For institutions that hire money managers, such as mutual fund companies, pension plan sponsors, university endowments, foundations, and trusts, knowing how well a manager has performed is important. Because $\mathrm{CPE}$ uses more information than traditional methods (bringing in additional variables to measure the state of the economy), it has the potential to provide more accurate performance measures. This monograph illustrates versions of conditional performance models that can be easily estimated as multiple regressions. Through the choice of the lagged variables in the regressions, one can set the hurdle for superior ability at any desired level of lagged information. That is, managers have to perform better than a mechanical strategy using the chosen lagged variables to record superior performance. Our results provide practical guidance on the regressions to run and the variables to use.

$\mathrm{CPE}$ can provide estimates of performance that depend on the economic state, whereas the traditional alpha ignores information about the state of the economy. If managers' performance is variable depending on the economic state, fund sponsors and investors may wish to allocate resources across funds in light of this information. Investors also need to understand how funds implement their investment policies dynamically over time. How, for example, does a fund's equity, bond, or style exposure change in a time of high interest rates or market volatility? $\mathrm{CPE}$ is designed to provide a rich description of funds' portfolio dynamics in relation to the state of the economy. For pension 
consultants and the other intermediaries that work with fund managers and their ultimate investors, CPE opens up a wealth of new descriptive and analytical tools. One of the goals of this monograph is to motivate the use of $\mathrm{CPE}$ in future financial practice.

The empirical findings in this monograph carry implications for practicing financial analysts relative to three main issues. The first has to do with understanding the expected returns and risks of classes of financial assets and how these vary with the state of the economy over market and economic cycles. An understanding of these broad patterns is an important input for the problem of asset allocation. The second issue has to do with patterns in the expected returns and risks of mutual funds with different investment styles and fund characteristics and how these behave over market and economic cycles. An understanding of these patterns is important for investors who may choose to implement a portion of their portfolio strategy using mutual funds. The third issue relates to the risk-adjusted, or abnormal, performance of mutual funds. The evidence here may affect the desirability of mutual funds relative to other investment vehicles, as well as the characteristics of specific funds to be included in a portfolio.

Conditional Behavior of Asset Class Returns. Financial analysts need to be aware of time variation in expected returns and risks for different asset classes, such as we document in this study. We group our measures of the state of the economy according to (1) the term structure or government yield curve, (2) the state of general financial markets, and (3) the macroeconomy. We show that states of the term structure are powerful predictors not just for fixed-income but also for equity returns. High levels of short-term interest rates predict relatively high and volatile short-term bond returns and low stock returns, with a gradual transition as one moves from safer and shorter maturities to riskier and longer-term asset classes. The level and the slope of the term structure seem to be the most informative predictors of return, with the concavity of the yield curve being less important. High interest rate volatility states are highly correlated with high interest rate levels.

We find that among the variables that measure the state of financial markets, high credit spreads predict high subsequent returns on stocks, and high dividend yields predict high returns on both stocks and bonds. The latter effect has weakened in more recent data and should probably be viewed with suspicion in the near future. The weakening of the predictive power of dividend yields has been associated with a trend toward lower yields since the early 1990s. Perhaps, as recent tax law changes encourage higher dividend payouts in the future, the predictive ability of aggregate dividend yields could return. The most economically, if not statistically, significant predictor among 
the financial market instruments we study may be the commercial paperTreasury spread, measuring short-term corporate illiquidity. When the spread is high, all the long-term bonds and stock indexes earn high returns over the next month. Moreover, these high-spread states do not seem to be associated with higher return volatility on these securities.

Among the variables measuring the macroeconomy, high inflation is bad news for stocks and longer-term bonds. High inflation levels predict low and also relatively volatile returns on long-term bonds and stocks, and short-term cash positions offer relatively high expected returns when inflation is high. When output growth is abnormally low, it predicts high returns, especially for the riskier assets, and the volatility of these investments is also high at such times.

The evidence that the risks and expected returns to different asset classes vary with the states of the economy seems compelling. But how can a financial analyst use this information in practice? Consider an investment advisor for a high-net-worth client. Some value may be added by simply explaining these expected return patterns to the client, relative to the current state of the economy at the time. (We have found a graphical representation of the figures in Table 2 to be especially compelling.) A client may wish to alter the asset allocation, taking on more exposure to currently high expected return asset classes and less exposure to asset classes whose currently expected performance is low. This adjustment must be considered, of course, in the context of the total portfolio risk and investment objectives, as well as the client's aversion to particular kinds of risks. In general, clients whose aversion to a specific risk is below that of the average investor may be advised to more aggressively tune the asset allocation to take advantage of higher conditional returns associated with state variables representing that risk at certain times. And an investor who is more risk averse than average about bad economic times may wish to take less risk when volatility is high or expected economic performance is poor than at other times during an economic cycle.

Conditional Behavior of Mutual Fund Returns. In addition to the patterns for broad asset classes, this monograph documents predictable patterns in the returns of some mutual fund types. Some of the patterns mirror those found for the passive asset class benchmarks. For example, the term-structure state variables seem to be the most powerful predictors of future fund returns. Low short-term interest rates predict high equity fund returns, and high interest rates predict low returns. The differences can be dramatic. The expected returns given low interest rates are more than 2 percent per month greater than given high interest rates for the maximum capital gains funds and almost that large for the growth funds. A steep term-structure slope also 
predicts high subsequent returns for most equity fund types. The differences are often economically large, at 3.2 percent per month for the maximum capital gains funds and just less than 2 percent per month for the growth funds. High interest rate volatility is bad news for most fund groups, but the differences here are not significant, except perhaps for timing funds.

We find significant time variation in funds' market and style betas. But little of this variation is associated with the discrete dummy variables measuring shifts in the economic states. It seems likely that much of the time variation in beta is related to higher-frequency investment decisions by funds, perhaps associated with redemptions and new money flows. One of the broad implications for investors and their advisors relates to strategic asset allocation, as discussed earlier. Our results suggest that such strategies should be implemented by changing the allocation across fund-style categories because funds themselves are unlikely to come with such strategic allocations built in.

Risk-Adjusted Fund Performance. According to the theoretical model of Berk and Green (forthcoming 2004), we should see fund flows in response to informative signals of manager ability, and these flows should occur until expected future performance is neutral in equilibrium after costs. Where the flows in response to performance signals are insufficient to neutralize future performance, we may find predictable abnormal future performance.

Overall, we find that although unconditional measures of fund performance are slightly negative, the theoretically superior conditional measures tend to be centered near zero. This finding is broadly consistent with equilibrium in the fund management industry, where managers have enough skill to cover their costs and fees on the funds they manage. Investors are left roughly indifferent between a passive position in the asset class and an actively managed fund in the same asset class. Thus, actively managed funds may be viewed as a viable alternative to index funds, exchange-traded funds, and other passive strategies.

Although the overall distribution of conditional performance, based on funds' returns net of trading costs and fees, is centered near zero, the final question is whether funds with particular characteristics may offer higher or lower risk-adjusted returns than a randomly chosen fund. Our analysis of the cross-sectional distribution of fund alphas suggests that this may be the case. We find that the bottom 20-25 percent of income funds turned in highly significant negative conditional alphas, and this poor performance is not concentrated in particular economic regimes. Unfortunately, our cross-sectional analysis of the income funds turns up no simple relationship between performance and fund characteristics. Thus, we can offer no mechanical rules for avoiding the poorly performing subset of income funds in these market states. 
We also find that extremely good and bad conditional performance is concentrated in particular economic states. Concentrations of abnormally high and low conditional alpha $t$-statistics are associated with dividend yield states for several fund styles. High dividend yield states reveal large fractions of good performers among the growth, small-company growth, sector, and growth and income funds, but none of these appear in low dividend yield states. Growth and income funds are able to generate a large number of positive performers when inflation is high but not when inflation is low.

Finally, our cross-sectional analysis of alphas provides some interesting results in which individual-level fund characteristics are associated with good conditional performance. We find that old growth funds have larger alphas than young funds. Growth funds tend to follow momentum trading strategies, which feeds through to their alphas. Growth funds with relatively high capital gains and total returns over the past year are expected to have higher alphas over the next year. Such a pattern is not to be found, however, among income funds.

We find that funds with higher load charges are expected to have higher alphas than those with lower load charges. This result extends earlier findings of Ippolito to conditional measures. The coefficients for growth funds are on the order of 20-25 bps for a one standard deviation increase in load charges. For income funds, the effect is smaller (10-13 bps) and is not statistically significant. These results must be evaluated in relation to the load fees themselves. Unlike the expense ratios and trading costs, our fund return data are not measured net of load charges, which represent a separate expense to the investor. Thus, the investor needs to balance the higher load charge against the expected performance. Clearly, an investor with a short investment horizon would not want to pay the load fee. But an investor with a very long horizon may be advised to consider load funds.

Market-Timing Ability. A traditional piece of wisdom among many financial analysts is that attempting to time the market is a fool's game. The temptation is great, because if one could correctly call the peaks and troughs and trade accordingly, the returns would be huge. But the chances of successfully calling market highs and lows are thought to be slim, and in the attempt, one is just as likely to buy too high and sell too low, thus missing out on market returns that a passive investment strategy would capture. In addition, market timing requires costly trades that hurt performance. Much of the "bad press" on the market-timing ability of mutual funds, however, is based on unconditional measures of timing ability that are shown to be biased in studies such as Ferson and Schadt as well as Becker, Myers, and Schill. When conditional timing measures are used, the funds that specialize in this activity do not look 
as bad. We measure timing ability that is neutral to slightly positive. The timing ability comes at a cost, however, in average return. The market-timing funds in our sample earn lower average returns than any other fund group, except the income funds. We do not think the evidence of timing ability is strong enough to justify a ringing endorsement of market timing funds, but neither does our evidence rule out some exposure to this style of fund in a balanced portfolio.

Our analysis of conditional-market-timing ability provides potentially useful insights into which funds are more likely to be successful timers. We find that the best overall market timers are the largest funds (measured by total net assets) and the funds with the lowest expense ratios. We also find that older funds with a longer track record tend to be better timers. When we allow for time variation in conditional timing ability, we find some striking evidence that market-timing funds are able to time better in some economic states than in others. The best states for successful market timing are when the slope of the term structure is steep, short-term corporate debt markets are relatively liquid, and stock markets are relatively liquid. It makes sense that successful market timing should be more likely when the markets are highly liquid because market-timing trades may be made at lower cost in highly liquid markets. Conversely, market-timing funds seem unable to deliver reliable market-timing services when the slope of the term structure is flat or when the markets are in an illiquid state.

\section{Summary and Conclusions}

As with all studies based on historical data, describing past relationships is easier than inferring whether the future will look similar to history. In this study, we expand the database of mutual funds to include many new funds in recent years. This approach is both an advantage and a disadvantage. The advantages of a larger sample size are obvious, but new entrants may have different characteristics from more seasoned funds. In this case, the underlying relationships in the data could shift during the sample. As Figures 1 and 2 illustrate, the characteristics of the population of mutual funds have shifted during the period of our analysis. This finding motivates our use of age as a characteristic in sorting the funds, and we find some differences between the old and young funds in our sample. The unit of analysis in our sample is the fund and not the fund manager, which raises another caveat. The investment style of a fund may change over time with changing managers such that data from a given fund may not represent a consistent style or philosophy across economic and market cycles, which is one motivation for allowing timevarying betas as well as alphas, as we do in this study, that may vary across 
market and economic cycles. Even so, our analysis presumes enough stationarity in the behavior of funds so that the process generating a fund's return is similar across repeated experiences of, for example, a high or low interest rate or inflationary regime. Thus, it is not obvious that one can safely extrapolate our results into the future.

Subject to these caveats, the results of our study are relevant to fund managers, management companies, financial advisors, and their ultimate clients-the individual investors. The results should also be of interest to researchers studying mutual funds and their investment performance. Fund managers are interested in how they stack up relative to their peers, and our analysis of relative performance addresses this issue directly. Management companies, among other things, care about how different fund styles are expected to perform in different economic states. Our characterization of conditional performance using discrete states should be informative on this issue. Financial advisors who wish to advise clients on asset allocation, fund style, and fund selection should find our results directly relevant. Finally, academics should be interested both in the extent to which the "stylized facts" from earlier studies hold up in a broad and updated sample as well as in the further pursuit of some of the issues raised by the new results of our analysis. 


\section{Appendix A. Additional Tables}

Table A1 reports summary statistics for the dummy variable indicators for the various states, and Table $\mathrm{A} 2$ reports the correlations of the high- and low-state dummy variables. Table A3 presents the style-specific benchmark weights that we apply to the asset class indexes to generate fund-style-specific benchmark index returns. Tables A4-A9 repeat the analyses of Tables 4-9, substituting the style-specific benchmark indexes for the broad market index of the CAPM.

Table A1. Summary Statistics of Discrete Dummy Variable Instruments for Economic States, January 1973 through December 2000 ( $N=336$ )

\begin{tabular}{|c|c|c|c|c|c|}
\hline Series & Mean & Min & Max & Std. Dev. & $\rho_{1}^{\mathrm{a}}$ \\
\hline \multicolumn{6}{|l|}{ A. High-state dummies } \\
\hline Short-term interest rate & 0.1964 & 0.000 & 1.000 & 0.3979 & 0.8333 \\
\hline Term-structure slope & 0.1310 & 0.000 & 1.000 & 0.3379 & 0.3981 \\
\hline Term-structure concavity & 0.1071 & 0.000 & 1.000 & 0.3098 & 0.5641 \\
\hline Interest rate volatility & 0.2024 & 0.000 & 1.000 & 0.4024 & 0.6305 \\
\hline Stock market volatility & 0.1964 & 0.000 & 1.000 & 0.3979 & 0.5090 \\
\hline Credit spread & 0.1905 & 0.000 & 1.000 & 0.3933 & 0.8293 \\
\hline Dividend yield & 0.1637 & 0.000 & 1.000 & 0.3705 & 0.7385 \\
\hline Short-term corporate illiquidity & 0.1071 & 0.000 & 1.000 & 0.3098 & 0.3463 \\
\hline Stock market liquidity & 0.1369 & 0.000 & 1.000 & 0.3443 & 0.0928 \\
\hline Inflation & 0.1518 & 0.000 & 1.000 & 0.3593 & 0.3522 \\
\hline Industrial output growth & 0.1190 & 0.000 & 1.000 & 0.3243 & 0.0064 \\
\hline \multicolumn{6}{|l|}{ B. Low-state dummies } \\
\hline Short-term interest rate & 0.2351 & 0.000 & 1.000 & 0.4247 & 0.8501 \\
\hline Term-structure slope & 0.2738 & 0.000 & 1.000 & 0.4466 & 0.7186 \\
\hline Term-structure concavity & 0.2530 & 0.000 & 1.000 & 0.4354 & 0.5778 \\
\hline Interest rate volatility & 0.2232 & 0.000 & 1.000 & 0.4170 & 0.6769 \\
\hline Stock market volatility & 0.0952 & 0.000 & 1.000 & 0.2940 & 0.2777 \\
\hline Credit spread & 0.2827 & 0.000 & 1.000 & 0.4510 & 0.7493 \\
\hline Dividend yield & 0.4107 & 0.000 & 1.000 & 0.4927 & 0.8185 \\
\hline Short-term corporate illiquidity & 0.0744 & 0.000 & 1.000 & 0.2628 & 0.1355 \\
\hline Stock market liquidity & 0.1190 & 0.000 & 1.000 & 0.3243 & 0.1482 \\
\hline Inflation & 0.1607 & 0.000 & 1.000 & 0.3678 & 0.3154 \\
\hline Industrial output growth & 0.1458 & 0.000 & 1.000 & 0.3535 & 0.3340 \\
\hline
\end{tabular}

${ }^{\mathrm{a}} \rho_{1}$ is the first-order sample autocorrelation of the series. 


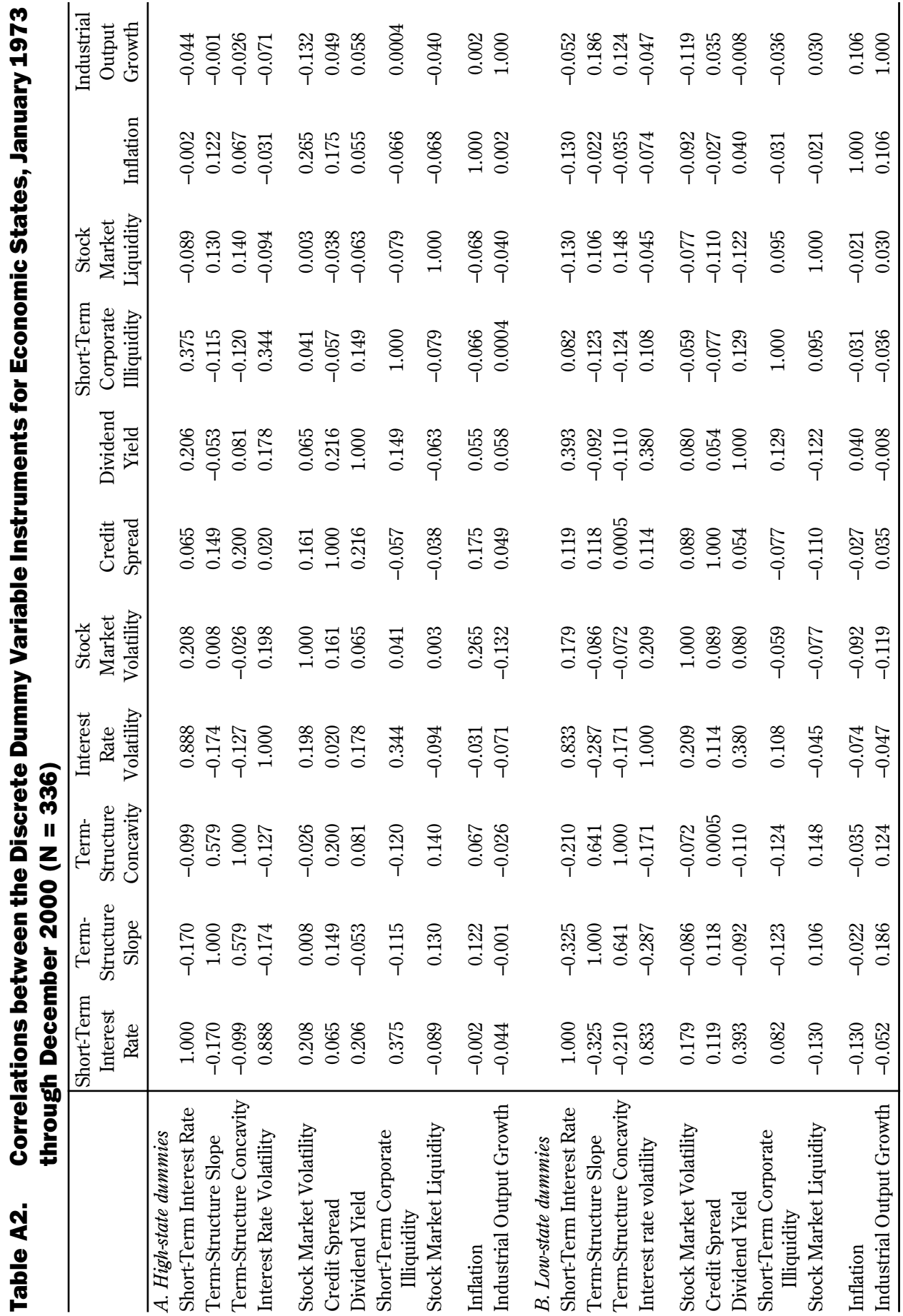


Table A3. Sharpe Style Benchmarks, January 1973-December 2000 (336 observations)

\begin{tabular}{|c|c|c|c|c|c|c|c|c|}
\hline Asset Class & Growth & $\begin{array}{c}\text { Maximum } \\
\text { Capital } \\
\text { Gains }\end{array}$ & $\begin{array}{l}\text { Other } \\
\text { Aggressive } \\
\text { Growth }\end{array}$ & Income & $\begin{array}{l}\text { Growth } \\
\text { and } \\
\text { Income }\end{array}$ & Sector & $\begin{array}{l}\text { Small- } \\
\text { Company } \\
\text { Growth }\end{array}$ & Timing \\
\hline \multicolumn{9}{|c|}{ A. Weights for each fund group applied to asset class returns } \\
\hline 90-day T-bill & 0.250 & 0.510 & 0.000 & 0.000 & 0.160 & 0.000 & 0.000 & 0.000 \\
\hline One-year bond & 0.000 & 0.000 & 0.320 & 0.240 & 0.000 & 0.000 & 0.210 & 0.600 \\
\hline $\begin{array}{l}\text { Government } \\
\text { bond }\end{array}$ & 0.002 & 0.094 & 0.000 & 0.018 & 0.034 & 0.110 & 0.068 & 0.000 \\
\hline $\begin{array}{l}\text { BAA corporate } \\
\text { bond }\end{array}$ & 0.008 & 0.000 & 0.017 & 0.110 & 0.027 & 0.000 & 0.000 & 0.220 \\
\hline $\begin{array}{l}\text { Broad equity } \\
\text { index }\end{array}$ & 0.480 & 0.040 & 0.000 & 0.480 & 0.670 & 0.000 & 0.000 & 0.037 \\
\hline Value stocks & 0.000 & 0.130 & 0.000 & 0.047 & 0.001 & 0.110 & 0.000 & 0.140 \\
\hline Growth stocks & 0.140 & 0.150 & 0.420 & 0.000 & 0.000 & 0.780 & 0.720 & 0.000 \\
\hline Small-cap stocks & 0.120 & 0.077 & 0.250 & 0.100 & 0.110 & 0.000 & 0.000 & 0.000 \\
\hline \multicolumn{9}{|c|}{ B. Summary statistics for style benchmark returns } \\
\hline Fund Group & Mean & Min & Max & Std. Dev. & $\rho_{1}^{\mathrm{a}}$ & & & \\
\hline Growth & 0.9900 & -17.87 & 12.76 & 3.642 & 0.06856 & & & \\
\hline $\begin{array}{l}\text { Maximum capital } \\
\text { gains }\end{array}$ & 0.8599 & -9.128 & 9.129 & 2.109 & 0.1098 & & & \\
\hline $\begin{array}{l}\text { Other aggressive } \\
\text { growth }\end{array}$ & 0.9852 & -18.24 & 14.77 & 3.869 & 0.1263 & & & \\
\hline Income & 0.9855 & -13.95 & 12.12 & 3.132 & 0.06749 & & & \\
\hline $\begin{array}{l}\text { Growth and } \\
\text { income }\end{array}$ & 1.028 & -17.80 & 12.89 & 3.728 & 0.04800 & & & \\
\hline Sector & 1.053 & -23.13 & 16.70 & 5.061 & 0.1011 & & & \\
\hline $\begin{array}{l}\text { Small-company } \\
\text { growth }\end{array}$ & 0.9458 & -18.91 & 13.30 & 4.275 & 0.09984 & & & \\
\hline Timing & 0.8099 & -4.444 & 7.488 & 1.423 & 0.1684 & & & \\
\hline
\end{tabular}

Note: The return units are percent per month.

${ }^{\mathrm{a}} \rho_{1}$ is the first-order sample autocorrelation of the series. 


\section{Table A4. Unconditional and Conditional CAPM Regressions Using Style-} Based Benchmarks

\begin{tabular}{|c|c|c|c|c|c|c|c|}
\hline Funds & Alpha & $t$ (Alpha) & Beta & $t$ (Beta) & $R^{2}$ & & \\
\hline \multicolumn{8}{|c|}{ A. Unconditional CAPM regressions } \\
\hline Growth & -0.05873 & -0.9109 & 1.247 & 65.41 & 0.9394 & & \\
\hline Maximum capital gains & -0.1694 & -1.351 & 2.458 & 31.56 & 0.8882 & & \\
\hline Other aggressive growth & 0.07004 & 0.7882 & 1.460 & 61.58 & 0.9666 & & \\
\hline Income & -0.04146 & -0.5188 & 0.561 & 12.51 & 0.6123 & & \\
\hline Growth and income & -0.01874 & -0.3080 & 0.968 & 60.19 & 0.9165 & & \\
\hline Sector & 0.1805 & 1.610 & 0.761 & 27.10 & 0.8892 & & \\
\hline Small-company growth & 0.09665 & 0.7126 & 1.287 & 40.80 & 0.9220 & & \\
\hline \multirow[t]{2}{*}{ Timers } & -0.1201 & -1.599 & 1.841 & 21.66 & 0.7900 & & \\
\hline & Instrument & Alpha & $t$ (Alpha) & Bet0 & $t($ Bet0) & $R^{21}$ & $p$-Value \\
\hline \multicolumn{8}{|c|}{ B. Conditional CAPM regressions using individual instruments } \\
\hline Growth & Interest rates & -0.0987 & -1.235 & 0.5906 & 12.30 & 0.6499 & 0.000 \\
\hline Maximum capital gains & Industrial output & -0.1388 & -1.082 & 2.513 & 52.24 & 0.8939 & 0.000 \\
\hline \multirow[t]{7}{*}{ Income } & Interest rates & -0.0722 & -0.8688 & 0.3847 & 11.37 & 0.6191 & 0.000 \\
\hline & Term slope & 0.0192 & 0.2161 & 0.3631 & 11.25 & 0.5843 & 0.090 \\
\hline & Convexity & -0.0185 & -0.2253 & 0.5524 & 12.52 & 0.6186 & 0.068 \\
\hline & Rate volatility & -0.1062 & -1.354 & 0.5879 & 12.66 & 0.6528 & 0.000 \\
\hline & Credit spread & 0.0098 & 0.1340 & 0.5880 & 13.58 & 0.6782 & 0.000 \\
\hline & Dividend yield & -0.0198 & -0.2729 & 0.5983 & 11.93 & 0.6843 & 0.000 \\
\hline & Inflation & -0.0783 & -0.9565 & 0.5811 & 12.05 & 0.6227 & 0.012 \\
\hline \multirow[t]{3}{*}{ Sector } & Convexity & 0.1913 & 1.728 & 0.7540 & 29.16 & 0.8908 & 0.094 \\
\hline & Stock liquidity & 0.0515 & 0.4350 & 0.8541 & 27.20 & 0.8689 & 0.070 \\
\hline & Inflation & 0.1573 & 1.406 & 0.7332 & 23.11 & 0.8908 & 0.085 \\
\hline \multirow[t]{4}{*}{ Small-company growth } & Stock volatility & 0.0891 & 0.6755 & 1.322 & 44.96 & 0.9247 & 0.003 \\
\hline & Stock liquidity & -0.0131 & -0.05461 & 1.114 & 20.57 & 0.7289 & 0.060 \\
\hline & Dividend yield & 0.0809 & 0.6117 & 1.389 & 41.93 & 0.9246 & 0.004 \\
\hline & Industrial output & 0.0868 & 0.6530 & 1.287 & 44.93 & 0.9243 & 0.007 \\
\hline \multirow[t]{4}{*}{ Other aggressive growth } & Rate volatility & 0.0748 & 0.8389 & 1.407 & 23.19 & 0.9671 & 0.087 \\
\hline & Stock volatility & 0.0615 & 0.7118 & 1.483 & 61.83 & 0.9675 & 0.012 \\
\hline & Inflation & 0.0539 & 0.6375 & 1.413 & 26.82 & 0.9672 & 0.045 \\
\hline & Industrial output & 0.0796 & 0.8964 & 1.468 & 60.94 & 0.9681 & 0.001 \\
\hline \multirow[t]{6}{*}{ Timers } & Interest rates & -0.1734 & -2.387 & 1.976 & 23.74 & 0.8102 & 0.000 \\
\hline & Term slope & -0.1690 & -2.149 & 1.891 & 24.92 & 0.7962 & 0.008 \\
\hline & Rate volatility & -0.1894 & -2.585 & 1.964 & 22.67 & 0.8089 & 0.000 \\
\hline & Credit spread & -0.0979 & -1.349 & 1.931 & 22.53 & 0.8013 & 0.000 \\
\hline & Dividend yield & -0.1141 & -1.612 & 2.008 & 24.97 & 0.8098 & 0.000 \\
\hline & Inflation & -0.1725 & -2.242 & 1.927 & 25.59 & 0.7987 & 0.001 \\
\hline
\end{tabular}


Table A4. Unconditional and Conditional CAPM Regressions Using StyleBased Benchmarks (continued)

\begin{tabular}{llcccccc}
\hline \multicolumn{1}{c}{ Instrument } & Alpha & $t$ (Alpha) & Bet0 & $t$ (Bet0) & $R^{2} 1$ & $p$-Value \\
\hline C. Conditional CAPM regressions using grouped instruments & & & & \\
Maximum capital gains & Term structure & -0.1707 & -1.345 & 2.375 & 7.039 & 0.8930 & 0.017 \\
Income & Term structure & -0.0349 & -0.4662 & 1.274 & 10.20 & 0.6946 & 0.000 \\
Small-company growth & Term structure & 0.2039 & 1.748 & 0.7815 & 4.669 & 0.8926 & 0.075 \\
Timers & Term structure & -0.1711 & -2.314 & 2.671 & 10.95 & 0.8111 & 0.001 \\
Growth and income & Financial markets & 0.1110 & 1.173 & 1.887 & 10.56 & 0.9688 & 0.002 \\
Income & Financial markets & -0.0111 & -0.1544 & 1.378 & 10.51 & 0.7114 & 0.000 \\
Other aggressive growth & Financial markets & 0.0965 & 0.6932 & 1.320 & 8.616 & 0.9260 & 0.011 \\
Timers & Financial markets & -0.1269 & -1.803 & 2.713 & 8.817 & 0.8195 & 0.000 \\
Maximum capital gains & Macroeconomy & -0.1313 & -1.011 & 2.444 & 29.45 & 0.8940 & 0.001 \\
Growth and income & Macroeconomy & 0.0657 & 0.7664 & 1.532 & 33.52 & 0.9686 & 0.000 \\
Income & Macroeconomy & -0.0783 & -0.9428 & 0.6591 & 8.840 & 0.6227 & 0.031 \\
Small-company growth & Macroeconomy & 0.1524 & 1.376 & 0.8149 & 20.86 & 0.8919 & 0.042 \\
Other aggressive growth & Macroeconomy & 0.0820 & 0.6274 & 1.325 & 22.09 & 0.9244 & 0.019 \\
Timers & Macroeconomy & -0.1673 & -2.148 & 2.105 & 17.37 & 0.7998 & 0.002 \\
\hline Nime Conditional and
\end{tabular}

Notes: Conditional and unconditional alphas relative to Sharpe style benchmarks, based on versions of Equation 1. The sample periods for the returns are January 1973 through December 2000 (336 observations), or a shorter period when indicated by fund availability in Table 3 . Alphas are the abnormal returns, monthly percent; $t$ (alpha) is a heteroscedasticity consistent $t$-statistic. Beta is the CAPM beta and $t$ (beta) is its $t$-statistic. $R^{2}$ is the coefficient of determination of the regression. In Panels $\mathrm{B}$ and $\mathrm{C}$, the regression is given by Equation 1 of the text, which is run for one instrument at a time. Results for instruments that produce exclusion $F$-test $p$-values less than 0.10 are shown. Bet 0 is the average conditional beta, $t$ (bet 0$)$ is its $t$-statistic, $R^{2} 1$ is the regression coefficient of determination, and $p$-value is the right-tail $p$-value of the $F$ statistic for excluding the lagged instrument multiplied by the style index excess return. In Panel $\mathrm{C}$, the instruments are grouped as follows: Term-structure instruments include the interest rate level, slope, convexity, and volatility. The financial markets variables include stock market volatility, credit spread, dividend yield, short-term corporate illiquidity, and stock market liquidity. The macroeconomy variables are inflation and industrial output growth. 


\section{Table A5. Fund Alphas Relative to Style Indexes, Conditional on Discrete State Variables for Equally Weighted Portfolio of Mutual Funds by Group}

\begin{tabular}{|c|c|c|c|c|c|c|c|c|c|}
\hline & No. Obs. & Growth & $\begin{array}{c}\text { Maximum } \\
\text { Capital } \\
\text { Gains }\end{array}$ & $\begin{array}{l}\text { Other } \\
\text { Aggressive } \\
\text { Growth }\end{array}$ & Income & $\begin{array}{l}\text { Growth } \\
\text { and } \\
\text { Income }\end{array}$ & Sector & $\begin{array}{l}\text { Small- } \\
\text { Company } \\
\text { Growth }\end{array}$ & Timers \\
\hline \multicolumn{10}{|c|}{ A. State of the term-structure variables } \\
\hline \multicolumn{10}{|c|}{ Short-term rates } \\
\hline High & 66.00 & 0.0316 & 0.1265 & 1.291 & -0.1963 & -0.019 & 0.9552 & 1.629 & -0.1693 \\
\hline Low & 79.00 & 0.0259 & -0.1856 & 0.079 & 0.0158 & 0.0085 & 0.3407 & 0.4703 & -0.1548 \\
\hline$t$-Statistic & & 0.0255 & 0.8017 & 2.685 & -0.8115 & -0.1301 & 1.014 & 1.623 & -0.0609 \\
\hline \multicolumn{10}{|c|}{ Term-structure concavity } \\
\hline High & 36.00 & 0.0266 & -0.4712 & -0.0783 & 0.0441 & 0.0241 & 0.2887 & 0.3070 & -0.5405 \\
\hline Low & 85.00 & -0.0176 & -0.0240 & 0.4062 & -0.1012 & -0.0052 & 0.2256 & 0.5310 & 0.0435 \\
\hline$t$-Statistic & & 0.2377 & -1.171 & -1.856 & 0.6259 & 0.1801 & 0.1607 & -0.4806 & -2.300 \\
\hline
\end{tabular}

B. State of the financial markets variables

Dividend yield

$\begin{array}{lcccccccrr}\text { High } & 55.00 & -0.3610 & -0.3860 & 0.000 & -0.2303 & -0.3021 & 0.4398 & -0.8476 & -0.4270 \\ \text { Low } & 138.0 & -0.0513 & -0.4014 & 0.000 & 0.0596 & 0.0010 & 0.1437 & 0.1159 & -0.1992 \\ t \text {-Statistic } & & -1.005 & 0.03411 & 0.000 & -1.473 & -1.247 & \mathbf{2 . 2 5 2} & \mathbf{- 6 . 2 7 2} & -0.9968\end{array}$

C. State of the macroeconomy variables Inflation

\begin{tabular}{lrrrrrrrrr} 
High & 51.00 & 0.2072 & 0.2298 & 0.8148 & 0.0397 & 0.2652 & 0.4485 & 0.7085 & -0.0674 \\
Low & 54.00 & -0.1781 & -0.6743 & -0.2206 & -0.1674 & -0.0841 & 0.1860 & 0.0116 & -0.2849 \\
$t$-Statistic & & $\mathbf{2 . 8 8 9}$ & $\mathbf{2 . 8 7 5}$ & $\mathbf{3 . 6 5 1}$ & 0.7203 & $\mathbf{2 . 2 5 1}$ & 0.6510 & 1.304 & 0.6714 \\
\hline
\end{tabular}

Notes: Monthly fund group returns in excess of the 90-day T-bill are regressed on the excess return of a Sharpe style index for the fund group and its product with dummy variables for the state of the economy, as in Equation 2 in the text. The dummy variables are the same as in Table 2. No. obs. is the number of observations for the growth fund sample period, which is January of 1973 through December of 2000 (336 total observations). Other fund groups may have fewer observations, as indicated in Table 3. Cases with fewer than 12 nonmissing observations are excluded and shown as 0.000 ; $t$-statistic is the heteroscedasticityconsistent $t$-statistic for the difference between the high and low state conditional alphas (those greater than 2.0 shown in bold). Only states with an absolute $t$-statistic greater than 2.0 are shown. The units for alpha are percent per month. 


\section{Table A6. Betas on Style Indexes, Conditional on Discrete State Variables for Equally Weighted Portfolio of Mutual Funds, by Group}

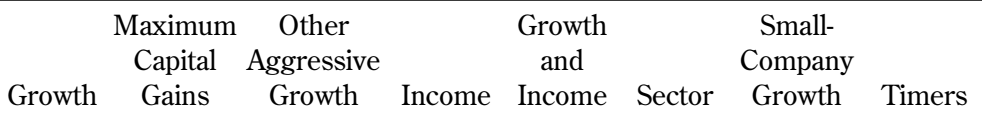

\section{A. State of the term-structure variables}

Short-term rates

$\begin{array}{lrlrrrrrr}\text { High } & 1.213 & 2.493 & 1.474 & 0.4843 & 0.9227 & 0.7012 & 1.189 & 1.597 \\ \text { Low } & 1.233 & 2.488 & 1.478 & 0.4971 & 0.9871 & 0.7980 & 1.408 & 2.043 \\ t \text {-Statistic } & -0.477 & 0.0428 & -0.048 & -0.1255 & -1.417 & -0.8836 & -2.279 & -2.157\end{array}$

Term-structure slope

$\begin{array}{lrllccccc}\text { High } & 1.172 & 2.544 & 1.466 & 0.3210 & 0.8688 & 0.6343 & 1.309 & 1.711 \\ \text { Low } & 1.261 & 2.511 & 1.409 & 0.6396 & 0.9871 & 0.7607 & 1.191 & 1.732 \\ t \text {-Statistic } & -1.258 & 0.1691 & 0.7976 & -3.742 & -1.644 & -1.445 & 1.103 & -0.0955\end{array}$

Term-structure concavity

$\begin{array}{lrlllllll}\text { High } & 1.185 & 2.460 & 1.477 & 0.4373 & 0.9470 & 0.7574 & 1.480 & 1.760 \\ \text { Low } & 1.254 & 2.494 & 1.468 & 0.6442 & 0.9859 & 0.8344 & 1.267 & 1.756 \\ t \text {-Statistic } & -1.662 & -0.2409 & 0.1869 & -2.132 & -0.9609 & -0.6073 & 2.043 & 0.0150\end{array}$

Interest rate volatility

$\begin{array}{lrccrcrrr}\text { High } & 1.215 & 2.541 & 1.451 & 0.4985 & 0.9347 & 0.6648 & 1.179 & 1.615 \\ \text { Low } & 1.275 & 2.558 & 1.497 & 0.5883 & 1.000 & 0.8105 & 1.314 & 2.172 \\ t \text {-Statistic } & -1.641 & -0.1413 & -0.5566 & -0.8193 & -1.449 & -1.701 & -1.551 & -2.472\end{array}$

B. State of the financial markets variables

Credit spread

$\begin{array}{lrrrrrrrr}\text { High } & 1.188 & 2.230 & 1.367 & 0.4901 & 0.9285 & 0.6337 & 1.115 & 1.598 \\ \text { Low } & 1.277 & 2.628 & 1.532 & 0.7274 & 0.9808 & 0.7480 & 1.343 & 1.825 \\ t \text {-Statistic } & -1.033 & -1.503 & -1.853 & -2.745 & -0.8316 & -1.365 & -1.342 & -1.614\end{array}$

Dividend yield

\begin{tabular}{lcccccccr} 
High & 1.234 & 2.412 & 0.000 & 0.4954 & 0.955 & 0.7179 & 1.512 & 1.680 \\
Low & 1.276 & 2.531 & 0.000 & 0.6761 & 1.001 & 0.7655 & 1.277 & 2.221 \\
$t$-Statistic & -0.5972 & -0.4809 & 0.000 & -1.358 & -0.9273 & -1.341 & 5.345 & -2.458 \\
\hline
\end{tabular}

Notes: Monthly fund group returns in excess of the 90-day T-bill are regressed on a fund group specific style index excess return and the products with dummy variables for the state of the economy. The dummy variables are the same as in Table 2. The growth fund sample period is January of 1973 through December of 2000 (336 total observations). Other fund groups may have fewer observations, as indicated in Table 3. Cases with fewer than 12 nonmissing observations are excluded and shown as $0.000 ; t$-statistic is the heteroscedasticity consistent $t$-statistic for the difference between the high and low state conditional betas (those greater than 2.0 shown in bold). Only states with an absolute $t$-statistic greater than 2.0 are shown. 
Table A7. Cross-Sectional Distribution of t-Statistics for Alphas using Style Benchmarks

\begin{tabular}{|c|c|c|c|c|c|c|c|c|c|}
\hline Item & Null & All & Growth & $\begin{array}{c}\text { Maximum } \\
\text { Capital } \\
\text { Gains }\end{array}$ & $\begin{array}{c}\text { Other } \\
\text { Aggressive } \\
\text { Growth }\end{array}$ & Income & $\begin{array}{l}\text { Growth } \\
\text { and } \\
\text { Income }\end{array}$ & Sector & $\begin{array}{l}\text { Small- } \\
\text { Company } \\
\text { Growth }\end{array}$ \\
\hline \multicolumn{10}{|c|}{ A. Unconditional alphas } \\
\hline$t>2.36$ & 0.005 & 0.12 & 0.03 & 0.05 & 0.15 & 0.03 & 0.02 & 0.06 & 0.10 \\
\hline $2.36>t>1.96$ & 0.02 & 0.04 & 0.03 & 0.03 & 0.06 & 0.02 & 0.02 & 0.07 & 0.04 \\
\hline $1.96>t>1.65$ & 0.025 & 0.04 & 0.03 & 0.04 & 0.07 & 0.03 & 0.02 & 0.05 & 0.05 \\
\hline $1.65>t>0$ & 0.45 & 0.40 & 0.44 & 0.25 & 0.45 & 0.32 & 0.43 & 0.53 & 0.49 \\
\hline $0>t>-1.65$ & 0.45 & 0.29 & 0.35 & 0.41 & 0.20 & 0.33 & 0.42 & 0.24 & 0.26 \\
\hline$-1.65>t>-1.96$ & 0.025 & 0.02 & 0.03 & 0.05 & 0.02 & 0.02 & 0.02 & 0.01 & 0.01 \\
\hline$-1.96>t>-2.36$ & 0.02 & 0.02 & 0.02 & 0.07 & 0.02 & 0.03 & 0.03 & 0.01 & 0.02 \\
\hline$t<-2.36$ & 0.005 & 0.07 & 0.06 & 0.09 & 0.03 & 0.22 & 0.05 & 0.04 & 0.03 \\
\hline \multicolumn{10}{|c|}{ B. Alphas conditioned on term structure } \\
\hline$t>2.36$ & 0.005 & 0.13 & 0.05 & 0.06 & 0.14 & 0.03 & 0.02 & 0.09 & 0.09 \\
\hline $2.36>t>1.96$ & 0.02 & 0.03 & 0.03 & 0.03 & 0.07 & 0.01 & 0.01 & 0.05 & 0.03 \\
\hline $1.96>t>1.65$ & 0.025 & 0.04 & 0.03 & 0.02 & 0.07 & 0.02 & 0.02 & 0.05 & 0.04 \\
\hline $1.65>t>0$ & 0.45 & 0.39 & 0.44 & 0.25 & 0.44 & 0.29 & 0.38 & 0.53 & 0.50 \\
\hline $0>t>-1.65$ & 0.45 & 0.30 & 0.34 & 0.42 & 0.23 & 0.36 & 0.45 & 0.21 & 0.28 \\
\hline$-1.65>t>-1.96$ & 0.025 & 0.02 & 0.02 & 0.05 & 0.01 & 0.03 & 0.04 & 0.01 & 0.02 \\
\hline$-1.96>t>-2.36$ & 0.02 & 0.02 & 0.03 & 0.03 & 0.02 & 0.03 & 0.03 & 0.02 & 0.02 \\
\hline$t<-2.36$ & 0.005 & 0.06 & 0.06 & 0.14 & 0.02 & 0.24 & 0.05 & 0.02 & 0.01 \\
\hline \multicolumn{10}{|c|}{ C. Alphas conditioned on financial markets } \\
\hline$t>2.36$ & 0.005 & 0.12 & 0.04 & 0.05 & 0.08 & 0.04 & 0.02 & 0.06 & 0.04 \\
\hline $2.36>t>1.96$ & 0.02 & 0.03 & 0.02 & 0.03 & 0.05 & 0.01 & 0.02 & 0.05 & 0.02 \\
\hline $1.96>t>1.65$ & 0.025 & 0.03 & 0.03 & 0.04 & 0.05 & 0.01 & 0.02 & 0.04 & 0.05 \\
\hline $1.65>t>0$ & 0.45 & 0.30 & 0.32 & 0.29 & 0.39 & 0.19 & 0.31 & 0.45 & 0.38 \\
\hline $0>t>-1.65$ & 0.45 & 0.35 & 0.41 & 0.41 & 0.33 & 0.42 & 0.41 & 0.30 & 0.39 \\
\hline$-1.65>t>-1.96$ & 0.025 & 0.04 & 0.04 & 0.05 & 0.04 & 0.06 & 0.05 & 0.03 & 0.04 \\
\hline$-1.96>t>-2.36$ & 0.02 & 0.04 & 0.04 & 0.05 & 0.03 & 0.04 & 0.06 & 0.03 & 0.04 \\
\hline$t<-2.36$ & 0.005 & 0.09 & 0.09 & 0.08 & 0.04 & 0.23 & 0.11 & 0.05 & 0.04 \\
\hline \multicolumn{10}{|c|}{ D. Alphas conditioned on real economy } \\
\hline$t>2.36$ & 0.005 & 0.12 & 0.03 & 0.09 & 0.14 & 0.03 & 0.02 & 0.07 & 0.10 \\
\hline $2.36>t>1.96$ & 0.02 & 0.03 & 0.02 & 0.03 & 0.06 & 0.02 & 0.01 & 0.04 & 0.05 \\
\hline $1.96>t>1.65$ & 0.025 & 0.04 & 0.03 & 0.02 & 0.08 & 0.03 & 0.02 & 0.06 & 0.05 \\
\hline $1.65>t>0$ & 0.45 & 0.40 & 0.45 & 0.30 & 0.43 & 0.30 & 0.44 & 0.51 & 0.45 \\
\hline $0>t>-1.65$ & 0.45 & 0.30 & 0.35 & 0.40 & 0.22 & 0.35 & 0.41 & 0.25 & 0.30 \\
\hline$-1.65>t>-1.96$ & 0.025 & 0.02 & 0.03 & 0.06 & 0.02 & 0.03 & 0.03 & 0.01 & 0.02 \\
\hline$-1.96>t>-2.36$ & 0.02 & 0.02 & 0.03 & 0.03 & 0.02 & 0.02 & 0.03 & 0.01 & 0.02 \\
\hline$t<-2.36$ & 0.005 & 0.06 & 0.05 & 0.09 & 0.02 & 0.22 & 0.05 & 0.04 & 0.02 \\
\hline
\end{tabular}

Note: This table replicates Table 7 but uses the Sharpe style benchmarks to replace the broad market index. 
Table A8. Distribution of t-statistics for Alphas in High vs. Low Economic States Using Sharpe Style Benchmarks

\begin{tabular}{|c|c|c|c|c|c|c|c|c|c|}
\hline \multicolumn{4}{|c|}{ Interest Rate Volatility } & \multicolumn{5}{|c|}{ Dividend Yield } & \\
\hline Income & Income & SCG & Sector & Growth & Income & SCG & G\&I & Sector & \\
\hline High & Low & Low & Low & High & Low & High & High & High & \\
\hline 0.09 & 0.07 & 0.26 & 0.26 & 0.30 & 0.03 & 0.31 & 0.27 & 0.46 & \\
\hline 0.03 & 0.02 & 0.03 & 0.04 & 0.02 & 0.01 & 0.00 & 0.02 & 0.00 & \\
\hline 0.02 & 0.02 & 0.03 & 0.07 & 0.01 & 0.03 & 0.00 & 0.02 & 0.00 & \\
\hline 0.26 & 0.23 & 0.45 & 0.40 & 0.29 & 0.28 & 0.25 & 0.32 & 0.40 & \\
\hline 0.32 & 0.31 & 0.18 & 0.20 & 0.31 & 0.22 & 0.44 & 0.29 & 0.15 & \\
\hline 0.03 & 0.03 & 0.01 & 0.00 & 0.01 & 0.01 & 0.00 & 0.03 & 0.00 & \\
\hline 0.01 & 0.03 & 0.00 & 0.01 & 0.03 & 0.01 & 0.00 & 0.02 & 0.00 & \\
\hline 0.23 & 0.30 & 0.02 & 0.03 & 0.03 & 0.41 & 0.00 & 0.03 & 0.00 & \\
\hline \multicolumn{2}{|c|}{$\begin{array}{l}\text { Short-Term } \\
\text { Interest Rate }\end{array}$} & Inflation & $\begin{array}{c}\text { Stock Market } \\
\text { Volatility }\end{array}$ & \multicolumn{4}{|c|}{ Term Structure Slope } & & $\begin{array}{l}\text { Stock Market } \\
\text { Liquidity }\end{array}$ \\
\hline Income & Income & G\&I & Income & Income & MCG & SCG & $\overline{\text { Other } \mathrm{AG}}$ & & Sector \\
\hline High & Low & High & Low & High & High & High & High & & Low \\
\hline 0.04 & 0.05 & 0.22 & 0.08 & 0.23 & 0.02 & 0.30 & 0.22 & & 0.14 \\
\hline 0.03 & 0.03 & 0.12 & 0.03 & 0.06 & 0.03 & 0.01 & 0.01 & & 0.05 \\
\hline 0.02 & 0.03 & 0.10 & 0.02 & 0.05 & 0.00 & 0.01 & 0.01 & & 0.03 \\
\hline 0.41 & 0.30 & 0.37 & 0.29 & 0.23 & 0.12 & 0.30 & 0.38 & & 0.29 \\
\hline 0.18 & 0.29 & 0.14 & 0.27 & 0.23 & 0.46 & 0.32 & 0.34 & & 0.24 \\
\hline 0.04 & 0.02 & 0.01 & 0.03 & 0.02 & 0.08 & 0.01 & 0.01 & & 0.03 \\
\hline 0.03 & 0.03 & 0.02 & 0.03 & 0.02 & 0.07 & 0.01 & 0.01 & & 0.03 \\
\hline 0.24 & 0.26 & 0.02 & 0.25 & 0.17 & 0.23 & 0.05 & 0.04 & & 0.19 \\
\hline
\end{tabular}

Notes: $\mathrm{MCG}=$ maximum capital gains; $\mathrm{SCG}=$ small company growth; Other $\mathrm{AG}=$ other aggressive growth; and G\&I = growth and income. Alphas and their $t$-statistics are based on the regression Equation 4 using the conditioning dummy variables one at a time. High (low) means that the value of the state variable is higher (lower) than one standard deviation from its moving average over the past 60 months. The distributions of the $t$-statistics for alpha are presented in the table for those cases where chi-square tests for departures from a normal distribution produce right-tail $p$-values of 10 percent or less. 


\section{References}

Admati, Anat R., Sudipto Bhattacharya, Paul Pfleiderer, and Stephen A. Ross. 1986. “On Timing and Selectivity." Journal of Finance, vol. 41, no. 3 (July):715-730.

Basu S. 1977. "Investment Performance of Common Stocks in Relation to Their Price-Earnings Ratios: A Test of the Efficient Market Hypothesis." Journal of Finance, vol. 32, no. 3 (June):663-682.

Becker, C., W. Ferson, D. Myers, and M. Schill. 1999. "Conditional Market Timing with Benchmark Investors.” Journal of Financial Economics, vol. 52, no. 1 (April):119-148.

Berk, Jonathan, and Richard C. Green. Forthcoming 2004. "Mutual Fund Flows and Performance in Rational Markets." Journal of Political Economy.

Breeden, Douglas T. 1986. "Consumption, Production, and Interest Rates: A Synthesis.” Journal of Financial Economics, vol. 16 (May):3-39.

Brown, Stephen J., and William N. Goetzmann. 1997. "Mutual Fund Styles." Journal of Financial Economics, vol. 43, no. 3 (March):373-399.

Brown, Keith, Van Harlow, and Laura Starks. 1996. "Of Tournaments and Temptations: An Analysis of Managerial Incentives in the Mutual Fund Industry." Journal of Finance, vol. 51, no. 1 (March):85-110.

Brown, Stephen J., William N. Goetzmann, Roger Ibbotson, and Stephen Ross. 1992. "Survivorship Bias in Performance Studies." Review of Financial Studies, vol. 5, no. 4 (Winter):553-580.

—. 1995. "Survival." Journal of Finance, vol. 50, no. 3 (July):853-874.

Campbell, J.Y. 1987. "Stock Returns and the Term Structure." Journal of Financial Economics, vol. 18, no. 2 (June):373-399.

Campbell, John Y., and Robert Shiller. 1991. "Yield Spreads and Interest Rates Movements: A Bird's Eye View." Review of Economic Studies, vol. 58, no. 3 (May):495-514. 
Carhart, Mark M. 1997. “On the Persistence in Mutual Fund Performance.” Journal of Finance, vol. 52, no. 1 (March):57-82.

Chen, Nai-Fu. 1991. "Financial Investment Opportunities and the Macro Economy.” Journal of Finance, vol. 46, no. 2 (June):1467-84.

Chen, Z., and P.J. Knez. 1996. "Portfolio Performance Measurement: Theory and Applications.” Review of Financial Studies, vol. 9, no. 2 (Summer):511-556.

Christopherson, Jon A. 1995. "Equity Style Classifications.” Journal of Portfolio Management, vol. 21, no. 3 (Spring):32-43.

Christopherson, Jon A., Wayne Ferson, and Debra A. Glassman. 1998. "Conditioning Manager Alpha on Economic Information: Another Look at the Persistence of Performance.” Review of Financial Studies, vol. 11, no. 1 (Spring):111-142.

Christopherson, Jon A., W. Ferson, and Andrew L. Turner. 1999. "Performance Evaluation using Conditional Alphas and Betas.” Journal of Portfolio Management, vol. 26, no. 1 (Fall):59-72.

Connor, G., and R.A. Korajczyk. 1986. "Performance Measurement with the Arbitrage Pricing Theory: A New Framework for Analysis." Journal of Financial Economics, vol. 15, no. 3 (March):373-394.

Cumby, Robert, and Jack Glen. 1990. "Evaluating the Performance of International Mutual Funds.” Journal of Finance, vol. 45, no. 2 (June):497-521.

Daniel, Kent, Mark Grinblatt, and Sheridan Titman. 1997. "Measuring Mutual Fund Performance with Characteristics-Based Benchmarks.” Journal of Finance, vol. 53, no. 3 (July):1035-58.

Del Guercio, Diane, and Paula A. Tkac. 2002. "The Determinants of the Flow of Funds of Managed Portfolios: Mutual Funds vs. Pension Funds.” Journal of Financial and Quantitative Analysis, vol. 37, no. 4 (December):523-558.

Dor, Arik Ben, Ravi Jagannathan, and Iwan Meier. 2003. "Understanding Mutual Fund and Hedge Fund Styles using Returns-Based Style Analysis." Journal of Investment Management, vol. 1, no. 1 (First Quarter):94-134.

Edelen, Roger M. 1999. "Investor Flows and the Assessed Performance of Open-End Mutual Funds.” Journal of Financial Economics, vol. 53, no. 3 (September):439-466. 
Elton, Edwin J., Martin J. Gruber, and Christopher R. Blake. 1996. "Survivorship Bias and Mutual Fund Performance.” Review of Financial Studies, vol. 9, no. 4 (Winter):1097-1120.

2001. "A First Look at the Accuracy of the CRSP Mutual Fund Database and a Comparison of the CRSP and Morningstar Databases." Journal of Finance, vol. 56, no 6 (December):2415-30.

Fama, Eugene F. 1970. "Efficient Capital Markets: A Review of Theory and Empirical Work.” Journal of Finance, vol. 25, no. 2 (May):383-417.

—. 1975. "Short-Term Interest Rates as Predictors of Inflation.” American Economic Review, vol. 65, no. 3 (June):269-282.

Fama, E., and K. French. 1989. "Business Conditions and Expected Returns on Stocks and Bonds." Journal of Financial Economics, vol. 25, no. 1 (November):23-49.

1992. "The Cross-Section of Expected Stock Returns." Journal of Finance, vol. 47, no. 2 (June):427-465.

Fama, E., and James D. MacBeth. 1973. "Risk, Return, and Equilibrium: Empirical Tests.” Journal of Political Economy, vol. 81, no. 3 (May/June):607-636.

Fama, Eugene F., and G. William Schwert. 1977. "Asset Returns and Inflation.” Journal of Financial Economics, vol. 5, no. 2 (November):115-146.

Ferson, Wayne E. 1989. "Changes in Expected Security Returns, Risk and the Level of Interest Rates.” Journal of Finance, vol. 44, no. 5 (December): 1191-1217.

Ferson, Wayne E., and Campbell R. Harvey. 1991. "Sources of Predictability in Portfolio Returns.” Financial Analysts Journal, vol. 47, no. 3 (May/June):49-56.

Ferson, Wayne E., and Kenneth Khang. 2002. "Conditional Performance Measurement Using Portfolio Weights: Evidence for Pension Funds.” Journal of Financial Economics, vol. 65, no. 2 (August):249-282.

Ferson, Wayne E., and Robert A. Korajczyk. 1995. "Do Arbitrage Pricing Models Explain the Predictability of Stock Returns?” Journal of Business, vol. 68 (July):309-349. 
Ferson, W., and Rudi Schadt. 1996. "Measuring Fund Strategy and Performance in Changing Economic Conditions.” Journal of Finance, vol. 51, no. 2 (June):425-462.

Ferson, W., and Vincent A. Warther. 1996. "Evaluating Fund Performance in a Dynamic Market.” Financial Analysts Journal, vol. 52, no. 6 (November/ December):20-28.

Ferson, W., Tyler Henry, and Darren Kisgen. 2003. "Evaluating Government Bond Fund Performance with Stochastic Discount Factors.” Working paper, Boston College.

Ferson, Wayne E., Sergei Sarkissian, and Timothy Simin. 2003a. "Is Stock Return Predictability Spurious?” Journal of Investment Management, vol. 1, no. 3:10-19.

- 2003b. "Spurious Regressions in Financial Economics?” Journal of Finance, vol. 58, no. 4 (August):1393-1414.

Freund, John E. 1992. Mathematical Statistics. 5th ed. Englewood Cliffs, NJ: Prentice Hall.

Gatev, Evan, and Phillip Strahan. 2003. "Banks' Advantage in Hedging Liquidity Risk: Theory and Evidence from the Commercial Paper Market." Working paper, Boston College.

Glosten, Lawrence, and Ravi Jagannathan. 1994. “A Contingent Claims Approach to Performance Evaluation.” Journal of Empirical Finance, vol. 1, no. 2 (January):133-166.

Goyal, Amit, and Ivo Welch. 2003. "Predicting the Equity Premium with Dividend Ratios.” Management Science, vol. 49, no. 5 (May):639-654.

Grant, D. 1977. "Portfolio Performance and the 'Cost' of Timing Decisions." Journal of Finance, vol. 32, no. 3 (June):837-846.

Grinblatt, Mark, and Sheridan Titman. 1988. "The Evaluation of Mutual Fund Performance: An Analysis of Monthly Returns.” Working paper, University of California at Los Angeles.

- 1989. "Mutual Fund Performance: An Analysis of Quarterly Portfolio Holdings.” Journal of Business, vol. 62, no. 3 (July):393-416. 
Grinblatt, Mark, Sheridan Titman, and Russ Wermers. 1995. "Momentum Investment Strategies, Portfolio Performance, and Herding: A Study of Mutual Fund Behavior." American Economic Review, vol. 85, no. 5 (December):1088-1105.

Harvey, Campbell R. 1989. "Time-Varying Conditional Covariance in Tests of Asset Pricing Models.” Journal of Financial Economics, vol. 24, no. 2:289-318.

Hansen, Bruce E. 1992. "Consistent Covariance Estimation for Dependent Heterogeneous Process.” Econometrica, vol. 60, no. 4 (July):967-972.

Ippolito, Roger A. 1989. "Efficiency with Costly Information: A Study of Mutual Fund Performance.” Quarterly Journal of Economics, vol. 104, no. 1 (February):1-23.

Jagannathan, R., and R. Korajczyk. 1986. "Assessing the Market Timing Performance of Managed Portfolios.” Journal of Business, vol. 59, no. 2 (April):217-236.

Jagannathan, R., and Zhenyu Wang. 1996. "The Conditional CAPM and the Cross Section of Expected Returns.” Journal of Finance, vol. 51, no. 1 (March):3-53.

Jegadeesh, N., and Sheridan Titman. 1993. "Returns to Buying Winners and Selling Losers: Implications to Stock Market Efficiency.” Journal of Finance, vol. 48, no. 1 (March):65-91.

Jensen, M. 1968. “The Performance of Mutual Funds in the Period 1945-1964.” Journal of Finance, vol. 23, no. 2 (May):389-416.

Keim, Donald B., and Robert F. Stambaugh. 1986. "Predicting Returns in Stock and Bond Markets.” Journal of Financial Economics, vol. 17, no. 2 (December):357-390.

Kosloski, John, Alan Timmermann, Russ Wermers, and Halbert White. 2003. "Can Mutual Fund 'Stars' Really Pick Stocks? New Evidence from a Bootstrap Analysis.” Working paper, University of Maryland.

Lakonishok, Josef, Andrei Shleifer, and Robert Vishny. 1994. "Contrarian Investment, Extrapolation, and Risk.” Journal of Finance, vol. 49, no. 5 (December):1541-78. 
Lehmann, Bruce N., and David M. Modest. 1987. "Mutual Fund Performance Evaluation: A Comparison of Benchmarks and Benchmark Comparisons." Journal of Finance, vol. 42, no. 2 (June):233-266.

Litterman, R., and J. Sheinkman. 1988. "Common Factors Affecting Bond Returns.” New York: Goldman Sachs, Financial Strategies Group.

Merton, Robert C. 1973. "An Intertemporal Capital Asset Pricing Model.” Econometrica, vol. 41, no. 5 (September):867-887.

Merton, Robert C., and Roy D. Henriksson. 1981. “On Market Timing and Investment Performance II: Statistical Procedures for Evaluating Forecasting Skills.” Journal of Business, vol. 54, no. 4 (October):513-534.

Myers, David H. 1999. "The Conditional Performance of Pension Funds.” Working paper, Lehigh University.

Pastor, Lubos, and Robert F. Stambaugh. 2002. "Mutual Fund Performance and Seemingly Unrelated Assets.” Journal of Financial Economics, vol. 63, no. 3 (March):315-349.

- 2003. "Liquidity Risk and Expected Stock Returns.” Journal of Political Economy, vol. 111, no. 3:642-685.

Rakowski, David. 2003. "Fund Flow Volatility and Performance.” Working paper, Georgia State University.

Ross, S.A. 1976. "The Arbitrage Pricing Theory of Capital Asset Pricing." Journal of Economic Theory, vol. 13, no. 2 (December):341-360.

Shanken, Jay. 1990. "Intertemporal Asset Pricing: An Empirical Investigation.” Journal of Econometrics, vol. 45, nos. 1/2:99-120.

Sharpe, W.F. 1964. "Capital Asset Prices: A Theory of Market Equilibrium under Conditions of Risk.” Journal of Finance, vol. 19, no. 3 (September): 425-442.

1988. "Determining a Fund's Effective Asset Mix." Investment Management Review (December):59-69.

1992. "Asset Allocation: Management Style and Performance Measurement.” Journal of Portfolio Management, vol. 18, no. 2 (Winter):7-19. 
Sirri, Erik R., and Peter Tufano. 1998. "Costly Search and Mutual Fund Flows.” Journal of Finance, vol. 53, no. 3 (October):1589-1622.

Spiegel, Matthew, H. Mamaysky, and H. Zhang. 2003. "Estimating the Dynamics of Mutual Fund Alphas and Betas." Yale ICF Working Paper No. 03-03.

Treynor, Jack, and Kay Mazuy. 1966. "Can Mutual Funds Outguess the Market?” Harvard Business Review, vol. 44 (July-August):131-136.

Wermers, Russ. 2000. "Mutual Fund Performance: An Empirical Decomposition into Stock Picking Talent, Style, Transactions Costs and Expenses.” Journal of Finance, vol. 55, no. 4 (August):1655-95.

Zheng, Lu. 1999. "Is Money Smart? A Study of Mutual Fund Investors Fund Selection Ability.” Journal of Finance, vol. 54, no. 3 (June):901-933. 